Portland State University

PDXScholar

\title{
Spectroscopy, NMR, and Electrochemistry Studies of Protonated Aminophenyl/Pyridyl Porphyrins and Their Application in Hydrogen Evolution
}

Chenyi Wang

Portland State University

Follow this and additional works at: https://pdxscholar.library.pdx.edu/open_access_etds

Part of the Chemistry Commons

Let us know how access to this document benefits you.

\section{Recommended Citation}

Wang, Chenyi, "Spectroscopy, NMR, and Electrochemistry Studies of Protonated Aminophenyl/Pyridyl Porphyrins and Their Application in Hydrogen Evolution" (2015). Dissertations and Theses. Paper 2223. https://doi.org/10.15760/etd.2220

This Dissertation is brought to you for free and open access. It has been accepted for inclusion in Dissertations and Theses by an authorized administrator of PDXScholar. Please contact us if we can make this document more accessible: pdxscholar@pdx.edu. 
Spectroscopy, NMR, and Electrochemistry Studies

of Protonated Aminophenyl/Pyridyl Porphyrins

and Their Application in Hydrogen Evolution

by

Chenyi Wang

A dissertation submitted in partial fulfillment of the requirements for the degree of

\author{
Doctor of Philosophy \\ in \\ Chemistry
}

\author{
Dissertation Committee: \\ Carl C. Wamser, Chair \\ Robert Strongin \\ Erik Johansson \\ Jonathan Abramson
}

Portland State University

2015 
(C) 2015 Chenyi Wang 


\begin{abstract}
Spectrophotometric titrations for a full series of 4-aminophenyl/4-pyridyl meso-substituted porphyrins were carried out using methanesulfonic acid in DMSO to study the hyperporphyrin effect across different substitution patterns. The series included zero, one, two (cis and trans), three, and four meso(4-aminophenyl) groups, with the remaining meso substituents being 4-pyridyl groups. The peripheral pyridyl groups consistently protonate before the interior porphyrin pyrrole nitrogens, which protonate before the aminophenyl groups. Aminophenyl substituents increase the basicity of the pyrrole nitrogens and lead to distinctive hyperporphyrin spectra with a broad Soret band and a strong red absorption. The structure proposed to give rise to these spectra is the previously proposed charge-transfer interaction between the aminophenyl and the protonated pyrrole. A novel hyperporphyrin structure involving charge-transfer interactions between two peripheral substituents is also proposed in one case - the triply protonated $(+3)$ porphyrin with three aminophenyl and one pyridyl substituents; two of the aminophenyl groups delocalize the charges on the interior nitrogens while the third aminophenyl group delocalizes with the protonated pyridyl.

The NMR titrations for a full series of 4-aminophenyl/4-pyridyl meso-substituted porphyrins were also performed by methanesulfonic acid in DMSO. Zero, one, two (cis), three, and four meso(4-aminophenyl) groups, with the remaining meso substituents being 4-pyridyl groups are the primary compounds studied here. The
\end{abstract}


inductive effect of the meso-substituents and the $\pi$ system of the macrocycle both determine the hyperporphyrin spectra, in which inductive effect has stronger influence on cis- $\mathbf{A}_{2} \mathbf{P y} \mathbf{y}_{2} \mathbf{P}$ and $\mathbf{A P y} \mathbf{P} \mathbf{P}$. TAPP and $\mathbf{A}_{3} \mathbf{P y P}$ both show slow exchanges from free base to hyperporphyrin, indicating these hyperporphyrin structures are stable. Both 1H-NMR and 2D NOESY spectra further validate the existence of the novel D-type hyperporphyrin from $\mathbf{A}_{3} \mathbf{P y P H}_{3}{ }^{+3}$.

Electrochemical studies of these hyperporphyrins were also performed. The porphyrins involved here are zero, two (cis \& trans), three, and four meso(4-aminophenyl) groups, with the remaining meso substituents being 4-pyridyl groups. The acid titrations were done in DMSO using methanesulfonic acid. Both TAPP and A3PyP can be extensively reduced with up to five distinct reduction waves. The hyperporphyrin from A3PyP, unlike that from TAPP, shows stable structures during the reduction, and $\mathbf{A}_{3} \mathbf{P y P H}_{3}{ }^{+3}$ was proposed to have the ability to reduce protons into hydrogen in a catalytic cycle. 


\section{Acknowledgements}

I want to thank Dr. Carl C. Wamser for taking me as his graduate student and teaching me through my five years of research. I feel very lucky to have had Dr. Wamser as my adviser because his high standard knowledge and his attitude of treating science are worthy to learn and follow through my career. It has been such an honor to work with him for these five years.

I would also like to thank the members in the Wamser research group-Keith James, Alex Rudine, and Nick Day. Their help and friendships have made my graduate career a good experience for me. Also, I want to thank Dr. David Peyton and Dr. Eric Johansson for giving me a lot of advice on the NMR and electrochemistry studies.

Without the support from my family, I wouldn't have gone this far. I want to thank my parents, my parents in law and my wife for their endless love and their belief in me. 


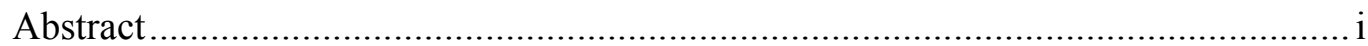

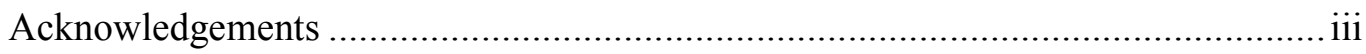

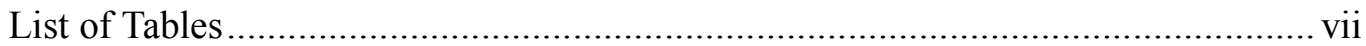

List of Figures ......................................................................................... vii

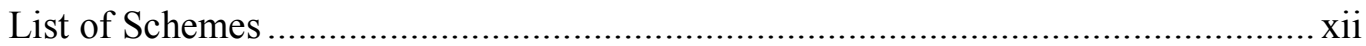

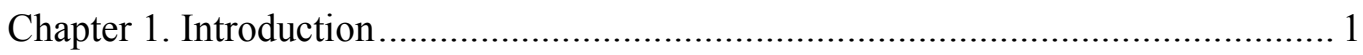

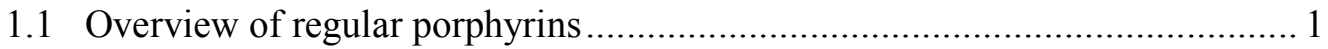

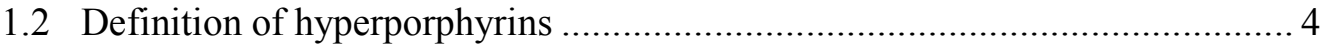

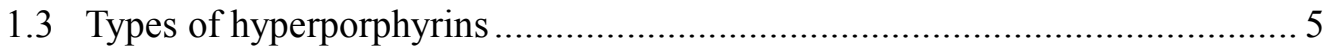

1.4 Hyperporphyrins based on amino substituents ......................................... 6

1.5 Electrochemistry of porphyrins ..................................................... 10

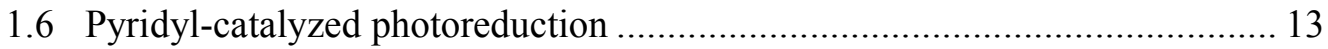

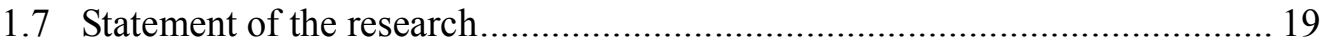

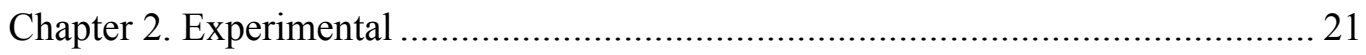

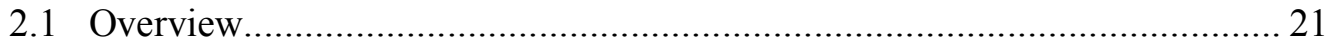


2.3 Spectroscopy studies of protonated aminophenyl/pyridyl porphyrins 26

2.4 NMR studies of protonated aminophenyl/pyridyl porphyrins 26

2.5 Cyclic voltammetry of protonated aminophenyl/pyridyl porphyrins 27

Chapter 3. Spectroscopy Studies of Protonated Aminophenyl/Pyridyl Porphyrins .... 29

3.1 Spectroscopy of protonating regular pyridyl porphyrins 29

3.2 Spectroscopy of protonating aminophenyl/pyridyl porphyrins 34

3.3 Comparison of hyperporphyrin spectra 43

3.4 Relative basicities of different pyridyl porphyrins. 45

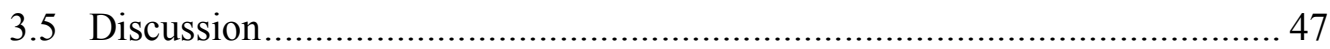

Chapter 4. Proton NMR of Protonated Aminophenyl/Pyridyl Porphyrins 57

4.1 NMR spectra of protonated pyridyl porphyrins. 58

4.2 Comparison of NMR spectra at different states. 70

4.3 2D NMR for $\mathrm{A}_{3} \mathrm{PyP}$ 71

4.4 NMR Evidence for Hyperporphyrin Structure 75

Chapter 5. Electrochemical Study of Protonated

Aminophenyl/Pyridyl Porphyrins. 80 
5.2 Comparison of reduction potentials in different protonation states ............... 98

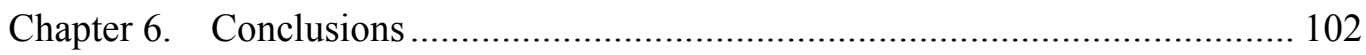

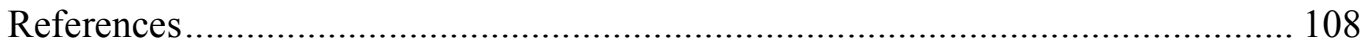




\section{List of Tables}

Table 1. Peak wavelengths and extinction coefficients $\left(\lambda_{\max }(\mathrm{nm}),\left(\mathrm{x}_{10} 0^{3} \mathrm{M}^{-1} \mathrm{~cm}^{-1}\right)\right)$ of the porphyrins and protonated porphyrins,

Table 2. Apparent pKa values (half-equivalence points) for the various protonated forms of the porphyrins. 46

Table 3. Relative positions and intensities of the split Soret band and the far red band in the hyperporphyrin spectra of the various derivatives. 54

Table 4. The proton chemical shifts from all the functional groups of aminophenyl/pyridyl porphyrins in each protonation state. 71

Table 5. The pyridyl and aminophenyl proton chemical shifts compared to standards

(TPyP and TAPP) 79

Table 6 . The reduction potentials of aminophenyl/pyridyl porphyrins in each protonation state. 99 


\section{List of Figures}

Figure 1. The structure of porphyrin macrocycle............................................. 1

Figure 2. Illustration of Gouterman's four-orbital model. ...................................... 2

Figure 3. The structure of a quinonoid type hyperporphyrin from doubly-protonated

TAPP.

Figure 4. The structure of different types of hyperporphyrins 9

Figure 5. Calculated orbitals (HOMO-1, HOMO, LUMO, LUMO+1) for $\operatorname{TPP}\left(\mathrm{NH}_{2}\right)_{4} \mathrm{H}_{2}{ }^{+2}$ 10

Figure 6. Transition-state structure for the formation of $\mathrm{PyCOOH}^{0}$ via $3 \mathrm{H}_{2} \mathrm{O}$ molecules.

Figure 7. The structures of aminophenyl/pyridyl porphyrins. 20

Figure 8. Spectrophotometric titration of $\mathbf{Z n T P y P}(3.37 \mu \mathrm{M})$ with MSA $(0-12 \mu \mathrm{mol})$ in DMSO. 30

Figure 9. Spectrophotometric titration of $\mathbf{T M e P y P}^{+4}(7.5 \mu \mathrm{M})$ with MSA $(0-15 \mathrm{mmol})$ in DMSO.

Figure 10. Spectrophotometric titration of $\operatorname{trans}-\mathbf{P h}_{2} \mathbf{P} \mathbf{y}_{2} \mathbf{P}(3.24 \mu \mathrm{M})$ with MSA in DMSO. 32

Figure 11. Spectrophotometric titration of cis- $\mathbf{P h}_{2} \mathbf{P y} 2 \mathbf{P}(3.24 \mu \mathrm{M})$ with MSA in DMSO.

Figure 12. Spectrophotometric titration of $\mathbf{A P y}_{3} \mathbf{P}(3.24 \mu \mathrm{M})$ with MSA in DMSO. . 35

Figure 13. Spectrophotometric titration of trans- $\mathbf{A}_{2} \mathbf{P y}_{2} \mathbf{P}(9.28 \mu \mathrm{M})$ with MSA in 
Figure 14. Spectrophotometric titration of cis- $\mathbf{A}_{2} \mathbf{P} \mathbf{y}_{2} \mathbf{P}(7.73 \mu \mathrm{M})$ with MSA in DMSO.

Figure 15. Spectrophotometric titration of $\mathbf{A} 3 \mathbf{P y P}(7.57 \mu \mathrm{M})$ with MSA in DMSO. . 41

Figure 16. Spectrophotometric titration of TAPP $(5.93 \mu \mathrm{M})$ with MSA in DMSO... 42

Figure 17. Hyperporphyrin spectra of the various porphyrins studied. 43

Figure 18. Hyperporphyrin resonance forms for trans- $\mathbf{A}_{2} \mathbf{P y}_{2} \mathbf{P H}_{4}{ }^{+4} \ldots \ldots \ldots \ldots \ldots \ldots \ldots . . \ldots 1$

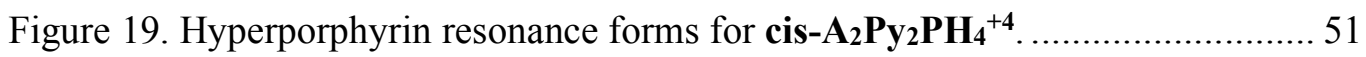

Figure 20. Hyperporphyrin resonance forms for $\mathbf{A}_{3} \mathbf{P y P H}_{3}{ }^{+3} \ldots \ldots \ldots \ldots \ldots \ldots \ldots \ldots \ldots \ldots . . . \ldots \ldots$

Figure 21. Proposed use of a type D hyperporphyrin structure as a hydride donor.... 56

Figure 22. A general structure for aminophenyl/pyridyl porphyrins with notations used

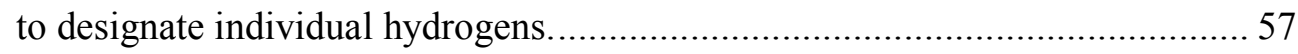

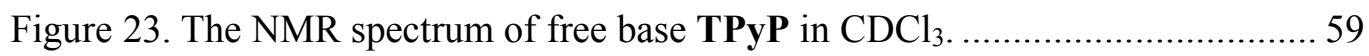

Figure 24. The 1 H-NMR spectra of $\mathbf{T P y P}$ protonation from $\mathbf{T P y P H}_{4}{ }^{+4}$ to $\mathbf{T P y P H}_{6}{ }^{+6}$. 59

Figure 25. The 1 H-NMR spectra of TAPP protonation from TAPP to TAPPH ${ }_{2}^{+2}$. 62 Figure 26. The 1 H-NMR spectra of $\mathbf{A} 3 \mathbf{P y P}$ protonation from $\mathbf{A}_{3} \mathbf{P y P}$ to $\mathbf{A}_{3} \mathbf{P y} \mathbf{P} \mathbf{H}_{3}{ }^{+3}$.

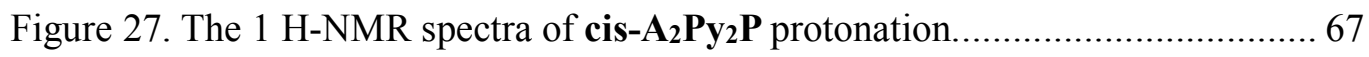

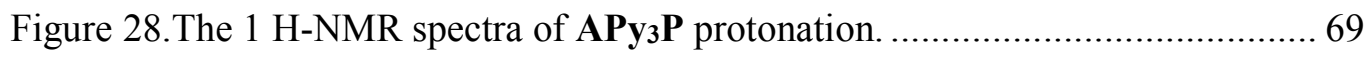

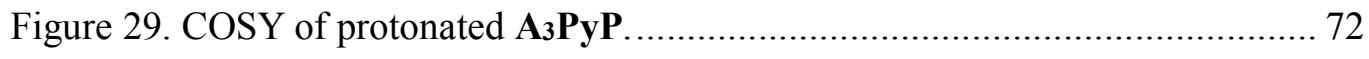

Figure 30. NOESY spectra of protonated A3PyP. ............................................ 74 
Figure 31. The resonance forms of $\mathbf{T A P P H} \mathbf{2}^{+2}$ hyperporphyrin. 77

Figure 32. The resonance forms of $\mathbf{A}_{3} \mathbf{P y} \mathbf{P H} \mathbf{3}^{+3}$ hyperporphyrin. ........................ 78

Figure 33. Cyclic voltammograms of protonating TPP (from TPP to $\mathbf{T P P H}{ }_{2}{ }^{+2}$ )..... 81

Figure 34. UV-vis spectroscopy of TAPP from free base to hyperporphyrin

$\left(\mathrm{TAPPH}_{2}{ }^{+2}\right)$ 82

Figure 35. Cyclic voltammetry of TAPP from free base to hyperporphyrin $\left(\mathbf{T A P P H}{ }^{+2}\right)$.

Figure 36. Cyclic voltammetry scanning different potential ranges in protonated TAPP..

Figure 37. UV-vis spectroscopy of $\mathbf{A} \mathbf{3} \mathbf{P y P}$ from free base to hyperporphyrin

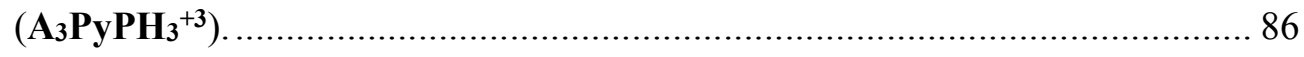

Figure 38. Cyclic voltammetry of $\mathbf{A} 3 \mathbf{P y P}$ from free base to hyperporphyrin $\left(\mathbf{A}_{3} \mathbf{P y} \mathbf{P} \mathbf{H}_{3}{ }^{\mathbf{3}}\right)$

Figure 39. Cyclic voltammetry of scanning different potential ranges in protonated

A3PyP. 89

Figure 40. Reduction of $\mathbf{A}_{3} \mathbf{P y} \mathbf{P H}_{3}{ }^{+3}$ hyperporphyrin at different scan rates from 0 to

$-0.7 \mathrm{~V}$

Figure 41. Correlation of current with scan rate using data from Fig. 40.

92

Figure 42. UV-vis spectroscopy of cis- $\mathbf{A}_{2} \mathbf{P y} 2 \mathbf{P}$ from free base to hyperporphyrin

$\left(\right.$ cis- $\left.\mathrm{A}_{2} \mathrm{Py}_{2} \mathrm{PH}_{4}{ }^{+4}\right)$.

Figure 43. Cyclic voltammetry of cis- $\mathbf{A}_{2} \mathbf{P y} 2 \mathbf{P}$ from free base to hyperporphyrin

$\left(\right.$ cis- $\left.\mathrm{A}_{2} \mathrm{Py}_{2} \mathrm{PH}_{4}{ }^{+4}\right)$. 94 
Figure 44. Cyclic voltammetry scanning different potential ranges in protonated $\operatorname{cis}-\mathbf{A}_{2} \mathbf{P y}{ }_{2} \mathbf{P}$

Figure 45. UV-vis spectroscopy of trans- $\mathbf{A}_{2} \mathbf{P} \mathbf{y}_{2} \mathbf{P}$ from free base to hyperporphyrin $\left(\right.$ trans- $\left.\mathrm{A}_{2} \mathrm{Py}_{2} \mathrm{PH}_{4}{ }^{+4}\right)$ 96

Figure 46. Cyclic voltammetry of trans- $\mathbf{A}_{2} \mathbf{P y} \mathbf{y}_{2} \mathbf{P}$ from free base to hyperporphyrin trans- $\mathrm{A}_{2} \mathrm{Py}_{2} \mathrm{PH}_{4}{ }^{+4}$

Figure 47. Cyclic voltammetry scanning different potential ranges in protonated $\operatorname{trans}-\mathrm{A}_{2} \mathbf{P} \mathbf{y}_{2} \mathbf{P}$. 98

Figure 48. The structure of reduced $\mathbf{D}$ type hyperporphyrin $\left(\mathbf{A}_{3} \mathbf{P y}_{\mathbf{P H}} \mathbf{H}^{+}\right)$. 105

Figure 49. Proposed structure of $\mathbf{A} \mathbf{3} \mathbf{P y} \mathbf{P}$ polymer as catalyst. 106 


\section{List of Schemes}

Scheme 1. Proposed reduction mechanisms of neutral and diprotonated porphyrins in

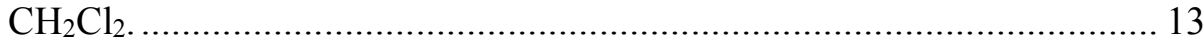

Scheme 2. Possible routes for $\mathrm{CO}_{2}$ reduction catalyzed by pyridine. .................... 15

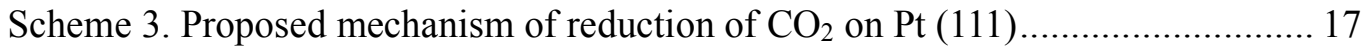

Scheme 4. Possible mechanism of the reduction of $\mathbf{A 3} \mathbf{P y P}$ hyperporphyrin and catalytic

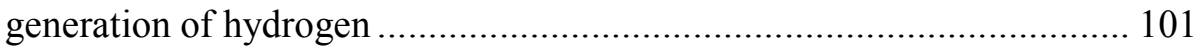




\section{Chapter 1. Introduction}

\subsection{Overview of regular porphyrins}

Porphyrins, some derivatives of which are known as hemes ${ }^{1-2}$ and chlorophylls ${ }^{3-4}$, play important roles in nature. The basic structure of a porphyrin is a macrocycle that consists of four pyrrolic units connected by four methane bridges (Fig. 1). Porphyrins bearing different functional groups on the meso and $\beta$ positions are of synthetic interest for applications in many fields. ${ }^{5}$

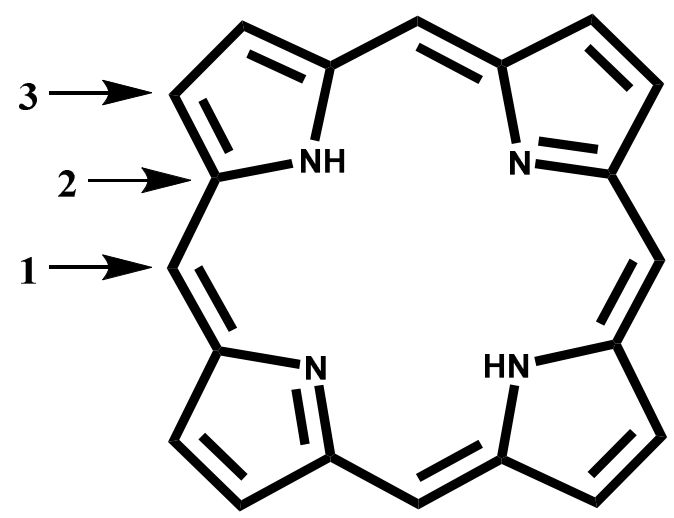

Figure 1. The structure of porphyrin macrocycle (Positions 1, 2, 3 are meso, alpha, beta positions).

The UV-Visible spectra of porphyrins are well-described by Gouterman's four-orbital model (Fig. 2), which states that $\pi-\pi^{*}$ transitions from two nearly degenerate HOMOs $\left[\mathrm{a}_{1 \mathrm{u}}(\pi)\right.$ and $\left.\mathrm{a}_{2 \mathrm{u}}(\pi)\right]$ to LUMOs $\left[\mathrm{e}_{\mathrm{g}}\left(\pi^{*}\right)\right]$ generate porphyrins' one 
large near-UV Soret band and several less intense absorptions in the visible-light region, usually four $\mathrm{Q}$ bands. ${ }^{6}$ Meanwhile, the electrochemistry of porphyrins characterizes the redox potentials of porphyrins which approximately describe the positions of the $\mathrm{a}_{2 \mathrm{u}}(\pi)$ and $\mathrm{e}_{\mathrm{g}}\left(\pi^{*}\right)$ energy levels. ${ }^{7}$

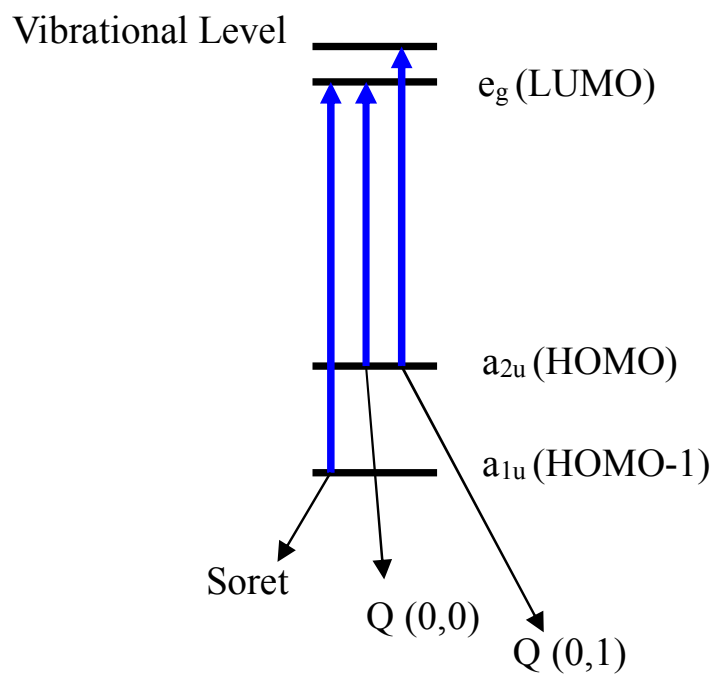

Figure 2. Illustration of Gouterman's four-orbital model.

Upon addition of different amount of acids, porphyrins exhibit quite different UV spectra and redox potentials. The porphyrin macrocycles allow for gain of two protons on the inner nitrogens to form a dication, which lead to an increase in symmetry of the inner porphyrin rings. Gouterman's four-orbital rules explain this phenomena as the inner ring converting from $\mathrm{D}_{2 \mathrm{~h}}$ to $\mathrm{D}_{4 \mathrm{~h}}$ symmetry, resulting in only two absorptions of $\mathrm{Q}(0,0)$ and $\mathrm{Q}(1,0) .{ }^{8-9}$ Meanwhile, peripheral substituents have an influence on the 
acid-titration properties of porphyrins. The free-base porphyrin macrocycles can be described as a planar aromatic system. The peripheral meso substituents, however, usually twist significantly from the plane of the porphyrins, due to steric effects around the periphery, particularly the interaction of meso subsitituents with $\beta$ pyrrole hydrogens. ${ }^{10}$ The protonation of porphyrin forces the four $\mathrm{N}-\mathrm{H}$ bonds of the interior of the ring to tilt either above or below the mean porphyrin plane, thus allowing the peripheral substituents to become more coplanar with the porphyrin plane. Meanwhile, the greater coplanarity of the peripheral substituents leads to an increase in resonance between the substituents and the porphyrin ring, along with the red-shifting of the Soret band. ${ }^{11-12}$ Furthermore, the protonation of porphyrins leads to a change of electron distribution, such that the positions of $\mathrm{a}_{2} \mathrm{u}(\pi)$ and $\mathrm{e}_{\mathrm{g}}\left(\pi^{*}\right)$ and redox potentials are different.

The studies of porphyrin mostly focus on its optoelectronic properties, based on which many applications have been developed, including solar energy conversion via photovoltaics ${ }^{13-15}$ or photocatalysis, ${ }^{16}$ photodynamic therapy, ${ }^{17-19}$ light-emitting diodes, ${ }^{20-22}$ and optical sensors. ${ }^{23-25}$ Higher efficiency based on such applications can be achieved via adjustment of substituents and/or metal complexation. One particular case for such purpose is the design of hyperporphyrins, which could extend the usual absorption spectrum into the red and near-infrared region. 


\subsection{Definition of hyperporphyrins}

The hyperporphyrin effect was first discovered in studying cytochrome 450 26-29 and has been explored for decades. The effect arises in porphyrins that can enable charge transfer within the macrocycle. Charge transfer happens either between some metal centers and porphyrin rings ${ }^{30}$ or between some appropriate substituents on the meso position and the pyrrolic nitrogens. ${ }^{12,31-34}$ In the latter case, sometimes the formation of hyperporphyrin results in the replacement of the porphyrin aromatic structure replaced by a quinonoid structure (Fig. 3). Unlike regular porphyrins which have one large near-UV absorption and several less intense absorptions in the visible-light region, hyperporphyrins show extra absorption bands $\left(\varepsilon>1000 \mathrm{M}^{-1} \mathrm{~cm}^{-1}\right)$ in the region $\lambda>320 \mathrm{~nm}^{6}$

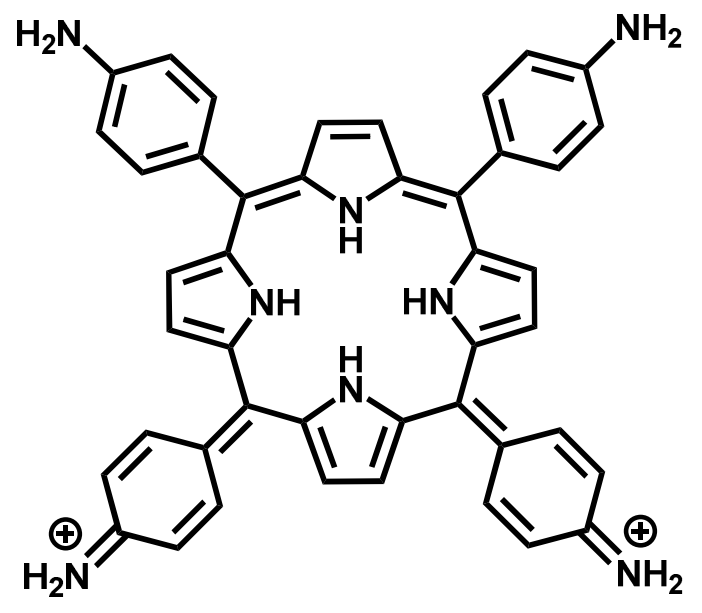

Figure 3. The structure of a quinonoid type hyperporphyrin from doubly-protonated TAPP. 


\subsection{Types of hyperporphyrins}

Until now two types of hyperporphyrins have been extensively studied---metal-based hyperporphyrins and acid/base induced hyperporphyrins. In metal-based hyperporphyrins, two more subclasses can be further categorized (d-type and p-type). In d-type hyperporphyrins, ${ }^{35-36}$ transition metals with partially filled $\mathrm{d}$ orbitals are present and the charge transfer transitions follow the manner of $\mathrm{a}_{1 \mathrm{u}}(\pi)$, $\mathrm{a}_{2 \mathrm{u}}(\pi)$ (porphyrin) $\longrightarrow \mathrm{e}_{\mathrm{g}}\left(\mathrm{d}_{\pi}\right)$ (metal). Metals that can show hyperporphyrin effect include Fe (III), Mn (III), Cr (III), Mo (V), and W(V), which have the common features of empty $e_{g}\left(d_{\pi}\right)$ and low oxidation states. Estimations of the energy of these transitions were achieved by using iterative extended Hückel calculations, and metal porphyrins including Sc (III), Ti (III), V (III), Cr (III), Mn (III), and Fe (III) were systematically calculated and compared. ${ }^{37}$ The metals in p-type metallo-hyperporphyrins come from main group metals and charge transfers $\left(\mathrm{a}_{2 \mathrm{u}}\left(\mathrm{np}_{\mathrm{z}}\right) \quad(\right.$ metal $) \longrightarrow \mathrm{e}_{\mathrm{g}}\left(\pi^{*}\right)$ (porphyrin)) that are different from d-type hyperporphyrins. Main-group metals in lower oxidation states, such as arsenic(III), antimony(III), and bismuth(III) porphyrins, are found to exhibit p-type hyperporphyrins. ${ }^{38-39}$

Other than metal-based hyperporphyrin, porphyrins bearing appropriate substituents and are subject to acidic or basic environments can also produce hyperporphyrin effects. While metal-based hyperporphyrins derive from interactions between metal and porphyrin rings, acid/base induced hyperporphyrins originate from the interaction of functional groups on the meso position with the porphyrin ring. Among them, porphyrins with hydroxyl groups were the first to be studied in both 
acidic and basic environments. De Luca et al. ${ }^{40}$ titrated both methoxy and hydroxy porphyrins with acid in which they noticed while methoxy porphyrins produced monomeric diacid derivatives like TPP, the porphyrins with hydroxy groups showed characteristic hyperporphyrin absorptions. The effect was believed to be caused by aggregation, and modulation of the optical properties by the nature of counteranion was also proposed. Meanwhile, the hyperporphyrin effect from hydroxy porphyrins in basic environment was also investigated. ${ }^{41-43}$ The phenomenon was explained as deprotonation of hydroxy groups, raising the energy level of $\pi$ orbitals of the phenoxide anion more than that of the core ring. Therefore, a different HOMO was created from phenoxide $\pi$ orbitals and a charge-transfer $(\pi$ (phenoxide anion) $\rightarrow$ $\pi^{*}$ (porphyrin)) occurs at lower energy. This theory was further validated by the Resonance Raman and FTIR data showing that there is barely any perturbance on the macrocycles and charges are mainly localized on the substituents.

\subsection{Hyperporphyrins based on amino substituents}

The most well studied acid-induced hyperporphyrins are on the basis of porphyrins with aminophenyl (or dimethylaminophenyl) functional groups. The first research that shed light on this type of hyperporphyrin was conducted by Ojadi, et al. ${ }^{44}$ In their work, trifluoroacetic acid was used to protonate meso-tetraphenylporphyrin derivatives with one, two, or four p-dimethylamino groups. A broad absorption in the visible region was observed during the course of the titration. As the numbers of free 
amino groups increased, stronger and stronger such absorptions were seen, along with the splitting of the Soret band. The NMR study of these compounds ${ }^{45}$ was followed to investigate these particular hyperporphyrins from the structure prospective. The study showed that the addition of trifluoroacetic acid to the porphyrins caused the internal N-H chemically shifted by $3-4$ ppm, from -2.6 to -2.8 ppm to +1.3 to +0.4 ppm. Continually adding acid brought the $\mathrm{N}-\mathrm{H}$ back to free-base porphyrin position. $\mathrm{H}_{\beta}$ from the pyrrole was also found to move upfield initially at the $\mathrm{PH}_{2}$ to $\mathrm{PH}_{4}{ }^{2+}$ stage, and then moved downfield. The aromatic protons kept moving downfield and broadened when the solvent became TFA dominated. These changes were attributed to the loss of the ring current, which could arise from the geometric distortion of the porphyrins. Inspired by the above studies, Wamser group did research on the hyperporphyrin effect of aminophenyl porphyrins. ${ }^{32,34}$ In their work, ${ }^{32}$ a set of amino/carbomethoxyphenyl porphyrins were titrated with methanesulfonic acid. Evidence for a novel monoprotonated porphyrin was observed. The extent of the hyperporphyrin effect was also found to correspond to the number of aminophenyl groups, with cis stronger than trans.

In considering different spectroscopies obtained from the titrations of porphyrins with different numbers of aminophenyl groups, hyperporphyrins have been categorized into three types (Fig. 4). ${ }^{32,44} \mathrm{~A}$ and A' type hyperporphyrins are typically regular porphyrins (both neutral and fully protonated) in which the porphyrin aromatic ring system is not affected by metals or meso substituents. They obey the Gouterman's four orbital rule. A and A' exhibit $\mathrm{D}_{4 \mathrm{~h}}$ and $\mathrm{D}_{2 \mathrm{~h}}$ porphyrin core symmetry 
respectively. While A type hyperporphyrins can be observed in the fully protonated porphyrins, A' type hyperporphyrins are observed in only free base porphyrins. B type hyperporphyrin is observed with porphyrins bearing only one amino group or two amino groups in trans alignment and when the two central nitrogens are protonated. The delocalization of the positive charge on one of the protonated nitrogens to an amino substituent leads to the resonance structure of hyperporphyrin B with one quinoid resonance form. C type hyperporphyrins are observed with two aminos in cis alignment or three amino substituents. Like B type, the two central nitrogens still need to be protonated, but in this case the delocalization can occur with two different amino substituents. B and C type hyperporphyrins can be distinguished via absorption spectroscopy. The characteristic absorption spectra for type B hyperporphyrin include a far red band at 700-730 $\mathrm{nm}$ and a broad flat absorption at 500-525. In type C hyperporphyrins, these bands are stronger and red shifted; the red band occurs at $720-780 \mathrm{~nm}$ and the flat absorption occurs at 520-560 nm. The Soret band also splits in type $\mathrm{C}$ hyperporphyrin. Type $\mathrm{B}$ and type $\mathrm{C}$ hyperporphyrins also have different numbers (1 and 2) of resonance structures, which are used to explain the different intensities of the hyperporphyrin band absorptions. 

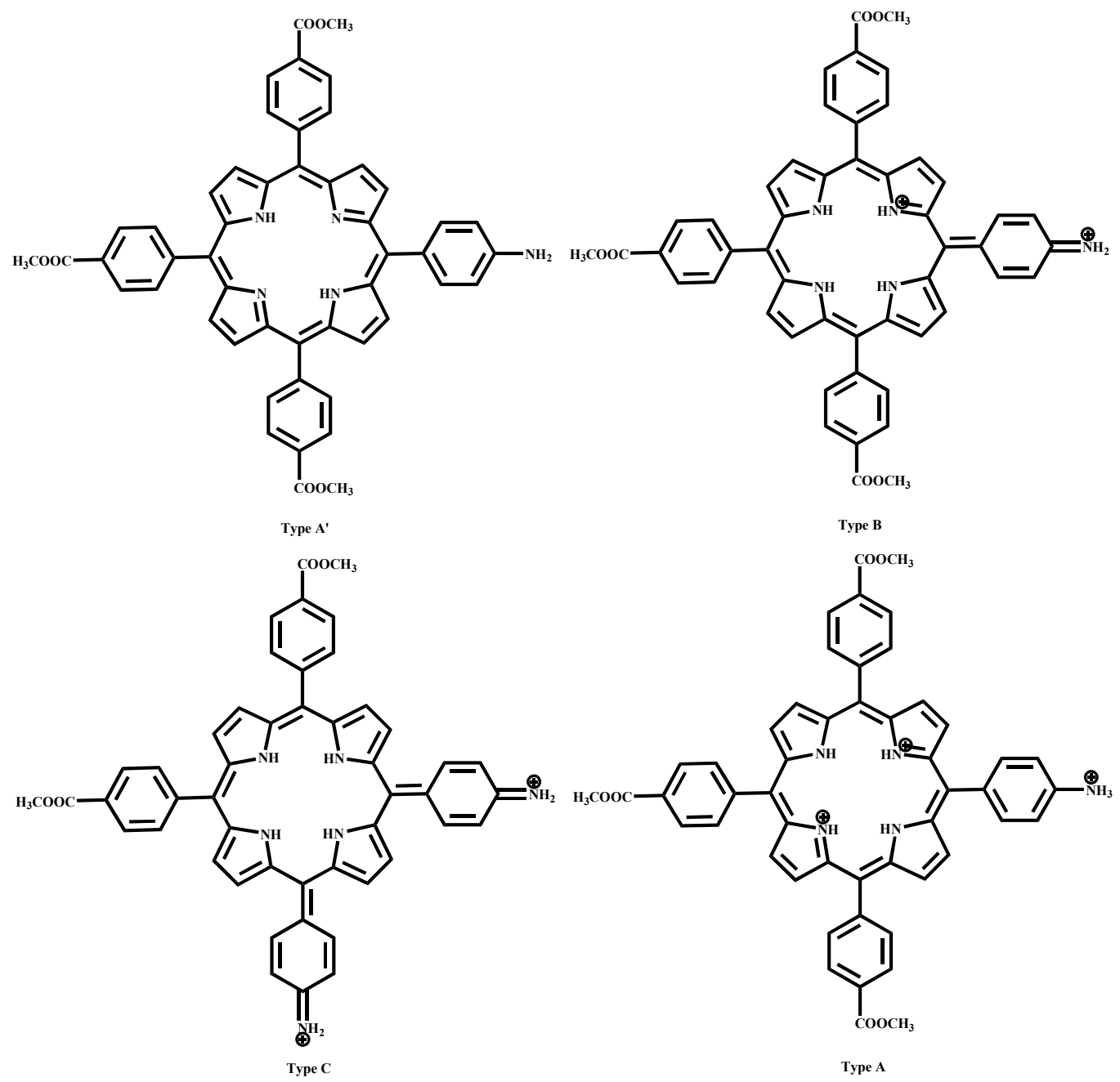

Figure 4. The structure of different types of hyperporphyrins. ${ }^{32}$

Gouterman ${ }^{8}$ calculated the orbitals of different protonation stages of porphyrins and explained how hyperporphyrin forms. By using semiempirical AM1 calculations to determine molecular structure and semiempirical INDO/CI calculations to simulate the spectra, Gouterman concluded that the hyperporphyrin bands are attributed to transitions from $\pi$ orbital on the aminophenyl rings as HOMO or HOMO-1 (Fig. 5) to LUMO of the porphyrin ring. The possibility of changes in the planarity of the ring 
leading to hyperporphyrin was also ruled out.
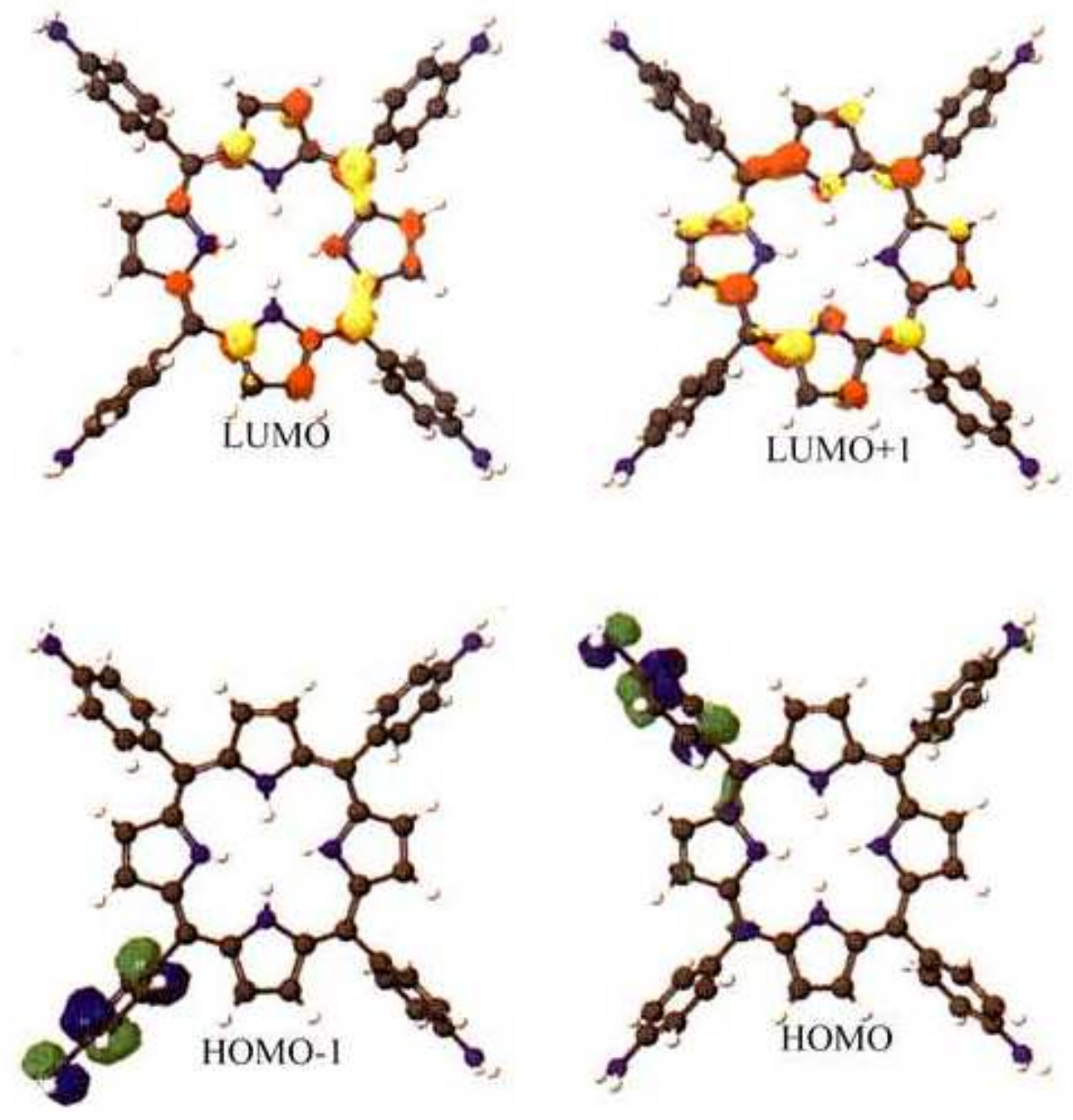

Figure 5. Calculated orbitals (HOMO-1, HOMO, LUMO, LUMO+1) for

$$
\mathrm{TPP}\left(\mathrm{NH}_{2}\right)_{4} \mathrm{H}_{2}{ }^{+2} \cdot{ }^{8}
$$

\subsection{Electrochemistry of porphyrins}

The electrochemical studies of porphyrins mainly focus on potentiometry. ${ }^{46-48}$ The potentials of porphyrins' different redox states can be used to gain the knowledge of 
the correlation of structure-reactivity. Free-base porphyrins were the primary targets of the early studies, ${ }^{49-50}$ and due to insolubility in aqueous solutions, these porphyrins were generally investigated in non-aqueous solvents. The reduction and oxidation of free-base porphyrins both go through two one-electron steps. ${ }^{51}$ While reduction generates a $\pi$-radical anion and then a dianion, oxidation yields a $\pi$-radical cation and then a dication. The study of metalloporphyrins ${ }^{52}$ also indicated the constancy of the potential difference in different reduction steps. This difference $(0.42 \pm 0.05 \mathrm{~V})$ was irrelevant to the metal center, leading to the conclusion that the $\pi$ system of the porphyrin was involved. This postulation was further validated by the Kadish group, 53 in whose work the metalloporphyrin was found to have a constant $1^{\text {st }}$ oxidation and $1^{\text {st }}$ reduction difference of $2.25 \pm 0.15 \mathrm{~V}$, which is in good agreement with the HOMO-LUMO difference of $2.18 \mathrm{eV}$.

Protonation effects on the electrochemistry studies of porphyrins were also investigated. Zakavi et al. ${ }^{7}$ reported that the protonation of $\mathrm{H}_{2} \mathrm{TPP}$ shifts the first and second oxidation potentials more positively. Yet the author became aware of a smaller shift of the second oxidation potential $\left(\Delta \mathrm{E}_{2}\right)$ over the first oxidation potential $\left(\Delta \mathrm{E}_{1}\right)$. In order to explain the positive shift of the potential, both the conformation change of the porphyrin and electron distribution were taken into account. X-ray crystallographic studies revealed that diprotonation of TPP leads to a more coplanar structure of meso-aryl groups with the mean plane of the porphyrin. The consequence of the change is the enhancement of the resonance interactions between the $\pi$ system and the core which destabilize the $\mathrm{a}_{2 \mathrm{u}}$ orbital. In addition, the redistribution of electron 
densities on the pyrrolic nitrogens upon protonation is expected to generate a positive shift. Addition of electron-donating meso-substituents were observed to enhance the positive shift, which can be explained as a higher basicity of the core, originating from electron-donating groups enhancing the electron density. Comparatively, the reduction shifts were found to be 4-6 times greater than oxidation shifts, indicating significantly stabilized $e_{g}$ orbitals. Reduction also caused richer electron densities which affects $\mathrm{a}_{2 \mathrm{u}}$.

Fang et al. ${ }^{54}$ also conducted the electrochemical studies of protonated porphyrins by trifluoroacetic acid titrations of porphyrins. The shift of the reduction potentials were observed to be more positive. Three types of electron-transfer were proposed (Scheme 1). The first mechanism occurs with planar porphyrins without protonation, where a stable $\pi$-anion radical can be formed after one-electron addition. The second mechanism was described as the nonplanar porphyrins being reduced into unprotonated porphyrins, either $[\mathrm{H}(\mathrm{P})]^{-}$or $[(\mathrm{P})]^{2-}$. The third type of the electron-transfer involved fully protonated porphyrins, in which two-electron reduction turned the porphyrins into $\mathrm{H}_{2}(\mathrm{P})$. 


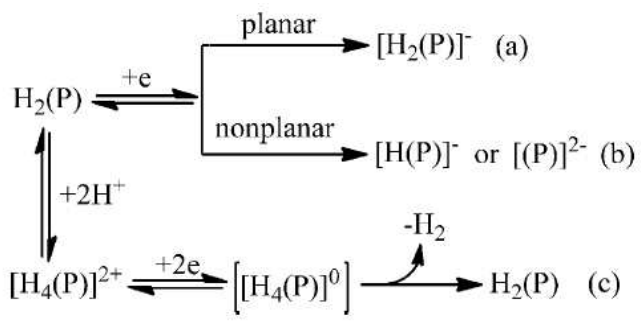

Scheme 1. Proposed reduction mechanisms of neutral and diprotonated porphyrins in

$$
\mathrm{CH}_{2} \mathrm{Cl}_{2 .}{ }^{54}
$$

\subsection{Pyridyl-catalyzed photoreduction}

Nowadays, the energy supply mainly comes from fossil fuels. With the increase of the global population, the annual energy consumption will reach 20 TW by 2030, 55 which makes solely relying on fossil fuels unrealistic. More importantly, the usage of fossil fuels has the downsides of pollution problems and $\mathrm{CO}_{2}$ emissions. Therefore, seeking alternative energy sources is very urgent. One solution for this problem is to utilize sunlight, and it can be achieved by either water splitting to make hydrogen or $\mathrm{CO}_{2}$ photoreduction to make methanol, both of which can be catalyzed by pyridine.

In hydrogen evolution, metals coordinated to pyridine often function as catalysts. One example of such a compound is $\left[\mathrm{Co}(\mathrm{TPY}-\mathrm{OH})\left(\mathrm{OH}_{2}\right)\right]^{2+}(\mathrm{TPY}-\mathrm{OH}=$ 2-bis(2-pyridyl)(hydroxy)methyl-6-pyridylpyridine), ${ }^{56}$ a polypyridyl-based cobalt complex used as water reduction catalyst (WRC). Once receiving one electron from the photosensitizer, $\mathrm{Co}^{\prime l}$ was reduced to $\mathrm{Co}$, which was then protonated to form $\mathrm{Co}^{\prime \prime \prime} \mathrm{H}$. The excess $\mathrm{Co}^{l}$ can reduce $\mathrm{Co}^{\prime \prime \prime} \mathrm{H}$ into $\mathrm{Co}^{\prime \prime} \mathrm{H}$, and hydrogen can be released from Co ${ }^{l l} \mathrm{H}$ with another proton. $\mathrm{Li}$ et al. ${ }^{57}$ also electrochemically grafted pyridine onto a 
silicon surface and applied the material for hydrogen evolution. The overpotential of the evolution was found to be $400 \mathrm{mV}$ less than for H-terminated silicon surface. The possible explanation for this reduced overpotential is the reduction of the immobilized pyridinium to pyridyl radical, where the reduced radicals can generate hydrogen.

$\mathrm{CO}_{2}$ photoreduction using pyridinium as the catalyst was first reported by Bocarsly group. ${ }^{58-61}$ In their work, $\mathrm{p}-\mathrm{GaP}$ was adopted as the photosensitizer in aqueous solution of $\mathrm{pH}$ 5.2. The results showed that this system has achieved nearly $100 \%$ Faradaic efficiency and more than $300 \mathrm{mV}$ underpotential in reducing $\mathrm{CO}_{2}$ to $\mathrm{MeOH}$. To elucidate the mechanism of the catalysis of pyridinium, several assumptions were proposed and examined by experimental and theoretical methods in another paper (scheme 2). ${ }^{62}$ In this paper, the charge transfer of pyridinium was first investigated by experimental and simulated cyclic voltammetry, with the reduction potential of pyridinium to pyridinyl determined as $-0.58 \mathrm{~V}$. Two possible routes for initial $\mathrm{CO}_{2}$ reduction were also proposed - outer-sphere mechanism (Eq. 1.1) and inner-sphere mechanism (Eq. $1.2 \&$ 1.3). To examine which route is more favorable, different N-C bond types were predicted and calculated using Gaussian 03, along with plotting the correlation between the rate constant of electron transfer from the pyridinyl to $\mathrm{CO}_{2}$ and the standard free energy of outer-sphere mechanism. All the results tended to show that the inner-sphere reaction is energy favorable. Yet another route of pyridinium reacting with $\mathrm{CO}_{2}$ which produced a carbamic zwitterion was brought up and verified to be present in a small quantity using a series of experimental and theoretical studies, as described in Eq. 1.4 and 1.5. Formic acid is then produced by 
Eq. 1.6, which was supported by calculations of energies and orbital symmetries of the $\pi^{*}$ HOMOs of pyridinium radical- $\mathrm{CO}_{2}$ adduct and pyridinium radical.

$$
\text { (n) }
$$

Scheme 2. Possible routes for $\mathrm{CO}_{2}$ reduction catalyzed by pyridine. ${ }^{62}$ 
In the reduction of formic acid to formaldehyde, it was noticed that at $\mathrm{pH} 5.3$, formic acid mostly exists as formate anion, which was found to be inert in electrochemical reduction. However, in $\mathrm{pH} 4.75$, both formic acid and pyridine resulted in the production of methanol, while only formic acid present under the same $\mathrm{pH}$ led to no product. Thus, an acidic $\mathrm{pH}$ gradient near the electrode surface was proposed. Eq. 1.7 and 1.8 was validated by the experimental and simulated cyclic voltammagram. Furthermore, formyl radical was reported to poison Pt electrode, but there was no Pt poisoning upon the addition of pyridine. This also indicates the interaction of formyl radical with pyridinyl. Gaussian calculations clarified the $\pi$ fashion overlapping between the HOMO of the pyridine-formyl radical and the HOMO of the pyridinyl to facilitate charge transfer implying that Eq. 1.6 is valid.

In the reduction of formaldehyde to methanol, the comparison of experimental and simulated cyclic voltammagram validated Eq. 1.9. Gaussian calculations revealing that carbon of formaldehyde had a hybridization change from $\mathrm{sp}^{2}$ to $\mathrm{sp}^{3}$ also fortified the theory. Gaussian caculations also showed that Eq. 1.10 is valid.

The overall mechanisms were investigated by several research groups using theoretical calculations. Keith et $\mathrm{al}^{63}$ argued that instead of being $-0.58 \mathrm{~V}$ reported by Bocarsly et al., their calculated reduction potential of pyridinium to pyridinyl was $-1.47 \mathrm{~V}$ vs SCE, which was further validated by $\operatorname{Lim}^{64}$ and Tossell ${ }^{65}$. Therefore, Ertem et al. ${ }^{66}$ suggested hydride should come from the cathode electrode surface. The authors proposed the mechanism in Scheme 3 and calculated the overall free-energy change by PBE level of theory in the Quantum ESPRESSO software package. The 
result showed the three steps give a total free energy of $\mathrm{E}^{0}=-0.72 \mathrm{~V}$ versus $\mathrm{SCE}$, in good agreement with the reduction potential in Bocarsly cell.

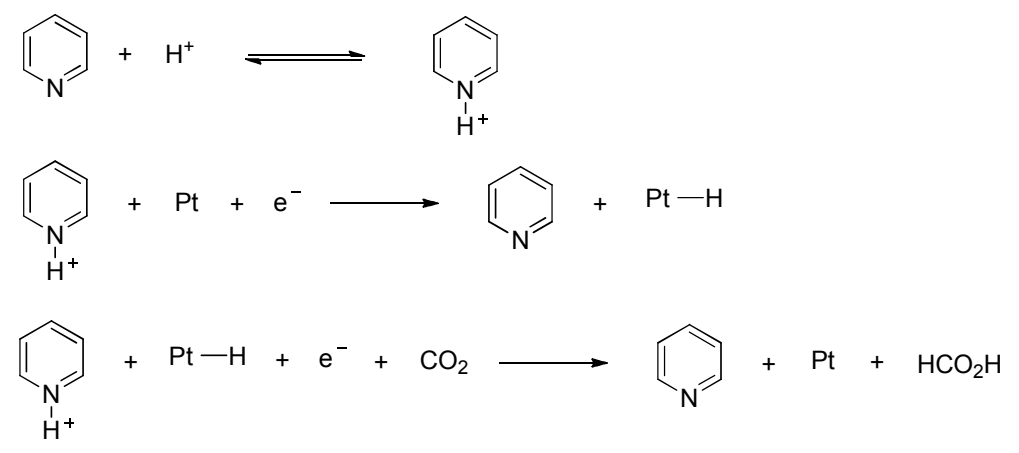

Scheme 3. Proposed Mechanism of Reduction of $\mathrm{CO}_{2}$ on Pt (111). ${ }^{66}$

Lim et al. ${ }^{64}$ interpreted the mechanism by employing $\mathrm{H}_{2} \mathrm{O}$ as proton relay. The authors first rationalized the low reduction potential of pyridinium to pyridinyl by mentioning that platinum is a low overpotential electrode. As to the rate-limiting step - the formation of $\mathrm{PyCOOH}^{0}$, Bocarsly group reported the step with an effective activation barrier of $16.5 \pm 2.4 \mathrm{kcal} / \mathrm{mol}$. However, in this paper the calculations predicted the barrier as $45.7 \mathrm{kcal} / \mathrm{mol}$, lying signicantly higher. Therefore, the authors suggested the process was mediated by water. Through calculations, they noticed the activation barrier of the formation of $\mathrm{PyCOOH}^{0}$ decreased to $18.5 \mathrm{kcal} / \mathrm{mol}$ with three water molecules as proton relay (as shown in Fig. 6), very close to the value reported by the literature. The activation barrier of $16.5 \mathrm{kcal} / \mathrm{mol}$ can be reached upon adding three additional solvating water molecules. 


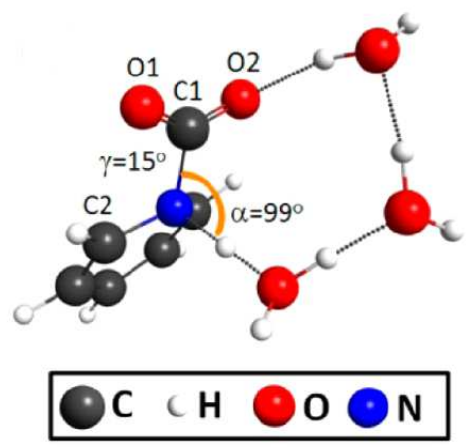

Figure 6. Transition-state structure for the formation of $\mathrm{PyCOOH}^{0}$ via $3 \mathrm{H}_{2} \mathrm{O}$

$$
\text { molecules. }{ }^{64}
$$

Although the mechanism is still under study, the efforts of improving the catalysis system are made by more and more groups. Most recently, a different semiconductor CdTe ${ }^{67}$ was investigated with the catalysis system. The photocurrent generated from irradiating $\mathrm{CdTe}$ increases the cathodic potential high enough to reduce $\mathrm{CO}_{2}$. The overall Faradaic efficiency was reported to increase $30 \%$ compared to without pyridine, with formic acid as the major reduced product. Both hydrogen evolution and $\mathrm{CO}_{2}$ reduction were also integrated into one cell. ${ }^{68}$ On the $\mathrm{CO}_{2}$ side, a pyridine derivative, 2-picoline, was used as catalyst while on the hydrogen evolution side, $\mathrm{CoO}_{\mathrm{X}}$, a recently discovered popular catalyst was used. A voltage under $3 \mathrm{~V}$ was maintained and formate was produced. 


\subsection{Statement of the research}

The primary purpose of this dissertation work is to investigate the hyperporphyrin effect of protonated aminophenyl/pyridyl functionalized porphyrins. Several studies have been conducted on hyperporphyrins arising from acidified aminophenyl porphyrins. However, the influence of coexisting functional groups is rarely studied. This dissertation provides comprehensive studies on one representitive electron-withdrawing functional group (pyridyl) in the hope of helping understanding the influence.

Protonations of aminophenyl/pyridyl porphyrins (Fig. 7) produce hyperporphyrins which are different from the classic ones. Pyridinium from protonation of pyridine here is very electron-withdrawing. An outstanding hyperporphyrin absorption via spectroscopy is noticed from triaminophenyl monopyridyl porphyrin. A new type of hyperporphyrin is proposed based on it.

Hyperporphyrins based on aminophenyl/pyridyl porphyrins are further investigated via NMR spectrometry. Methanesulfonic acid is slowly titrated and each titration is measured by NMR to gain insight on how each proton attacks the porphyrin and how the structures of porphyrins change. A thin-layer cell is used to monitor each titration spectroscopically.

In order to understand how the formation of hyperporphyrins affect the energy level of porphyrins, protonated aminophenyl/pyridyl porphyrins are studied via cyclic voltammetry. Only the reduction side is covered in these studies and a possible hydrogen evolution is proposed here. 


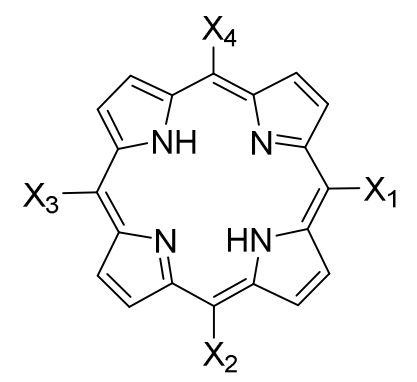

$$
=\mathrm{X}_{1}, \mathrm{X}_{2}, \mathrm{X}_{3}=
$$

Figure 7. The structures of aminophenyl/pyridyl porphyrins. 


\section{Chapter 2. Experimental}

\subsection{Overview}

This chapter is composed of four sections of experiments. The first section describes the syntheses of the various porphyrins studied, many of which are new compounds. The second section describes the UV-vis spectroscopy studies of protonated aminophenyl/pyridyl porphyrins. The third section focuses on the NMR structural characterization of different hyperporphyrins derived from protonated aminophenyl/pyridyl porphyrins. The fourth section investigates the energy levels of these hyperporphyrins based on cyclic voltammetry.

Materials. Solvents and reagents were the highest grade commercially available and used as received. DMSO (spectrophotometric grade) was from Sigma-Aldrich. Methanesulfonic acid (MSA) (99\% extra pure) and 4-pyridinecarboxaldehyde were from Acros Organics. TPyP and TMePyP ${ }^{+4}$ were from Strem Chemicals. Zinc acetate was Baker and Adams reagent grade. Dimethyl sulfoxide- $\mathrm{D}_{6}$ (with $0.03 \%$ TMS) and NMR tubes were purchased from Aldrich and Wilmad LabGlass respectively. Tetrabutylammonium perchlorate was purchased from Fluka. All of the electrodes (glassy carbon, platinum wire, $\mathrm{Ag} / \mathrm{AgCl}$ ) were homemade.

\subsection{Syntheses of porphyrins}

Preparation of ZnTPyP. $\mathrm{Zn}(\mathrm{OAc})_{2}(250 \mathrm{mg}, 1.14 \mathrm{mmol})$ in $\mathrm{MeOH}(2 \mathrm{~mL})$ was 
added to a solution of TPyP $(100 \mathrm{mg}, 162 \mu \mathrm{mol})$ in $50 \mathrm{~mL} \mathrm{CHCl}$. The solution was heated to $75^{\circ} \mathrm{C}$ for $1 \mathrm{~h}$. ZnTPyP was purified by silica gel column chromatography eluted by $\mathrm{CHCl}_{3}$ with $10 \% \mathrm{MeOH}$.

ZnTPyP. $\quad{ }^{1} \mathrm{H}$ NMR (400 MHz; DMSO-D; $\left.\mathrm{Me}_{4} \mathrm{Si} ; \delta_{\mathrm{H}}, \mathrm{ppm}\right) 8.21$ (8H, d, Py-H), 8.82 (8H, s, pyrrole-H), 9.03 (8H, d, Py-H).

Preparation of PhxPyyP. Pyrrole (1.26 g, $18.7 \mathrm{mmol})$, benzaldehyde (1.04 g, 9.8 mmol), and 4-pyridinecarboxaldehyde (1.14 g, $10.6 \mathrm{mmol})$ were dissolved in $100 \mathrm{~mL}$ propionic acid. After the solution was heated to reflux for $1 \mathrm{~h}$, the majority of the propionic acid was removed by vacuum distillation at $150^{\circ} \mathrm{C}$. The remaining solution was neutralized using aqueous $\mathrm{NaOH}$, and the porphyrin was extracted with chloroform. Separation of the porphyrin solution to isolate $\mathbf{P h} \mathbf{h}_{3} \mathbf{P y} \mathbf{P}, \mathbf{P h} \mathbf{h}_{2} \mathbf{P y} 2 \mathbf{P}$ (trans and cis), and $\mathbf{P h P y} \mathbf{P} \mathbf{P}$ was achieved via column chromatography (silica gel 230-400 mesh) eluting with $\mathrm{CHCl}_{3}$ and $\mathrm{MeOH}(2.5 \%-5 \%)$ and $1 \%$ acetic acid. The four components were collected in the second, third, fourth, and fifth red bands, respectively.

5, 10-Di(4-phenyl)-15, 20-di(4-pyridyl)porphyrin (cis-Ph2 $\left.\mathrm{Py}_{2} \mathrm{P}\right), \quad$ UV-vis (DMSO): $\lambda_{\max }, \mathrm{nm}\left(\varepsilon^{*} 10^{3}\right) 417$ (261), 514 (10), 547 (4), 588 (4). ${ }^{1} \mathrm{H}$ NMR (400 MHz; $\left.\mathrm{CDCl}_{3} ; \mathrm{Me}_{4} \mathrm{Si} ; \delta_{\mathrm{H}}, \mathrm{ppm}\right)-2.87(2 \mathrm{H}, \mathrm{s}$, pyrrole-NH), $7.71(6 \mathrm{H}, \mathrm{dd}, \mathrm{Ph}-\mathrm{H}), 8.09(4 \mathrm{H}, \mathrm{d}$, Py-H), 8.15 (4H, dd, Ph-H), 8.69-8.88 (8H, br, pyrrole-H), 8.97 (4H, d, Py-H).

5, 15-Di(4-phenyl)-10, 20-di(4-pyridyl)porphyrin (trans-Ph $\left.2 \mathrm{Py}_{2} \mathrm{P}\right), \quad$ UV-vis (DMSO): $\lambda_{\max }, \mathrm{nm}\left(\varepsilon^{*} 10^{3}\right) 419$ (183), 515 (10), 550 (5), 590 (4), 644 (3). ${ }^{1} \mathrm{H}$ NMR (400 MHz; $\left.\mathrm{CDCl}_{3} ; \mathrm{Me}_{4} \mathrm{Si} ; \delta_{\mathrm{H}}, \mathrm{ppm}\right) \quad-2.91(2 \mathrm{H}, \mathrm{s}$, pyrrole-NH), $7.71(6 \mathrm{H}, \mathrm{dd}, \mathrm{Ph}-\mathrm{H})$, 
8.10 (4H, d, Py-H), 8.13 (4H, dd, Ph-H), 8.68-8.87 (8H, br, pyrrole-H), 8.96 (4H, d, Py-H).

Preparation of CMxPyy. Both 4-carbomethoxybenzaldehyde (1.64 g, $11.1 \mathrm{mmol})$ and 4-pyridinecarboxaldehyde $(3.30 \mathrm{~g}, 30.8 \mathrm{mmol})$ were dissolved in $62.5 \mathrm{~mL}$ propionic acid. The solution was heated to reflux and pyrrole $(2.80 \mathrm{~g}, 41.8 \mathrm{mmol})$ was slowly added. After heating for $1 \mathrm{~h}$ and cooling to room temperature, the workup steps here was adopted from the workup procedures in the synthesis of ZnTPyP. The solution was run through column chromatography (silica gel 230-400 mesh) eluting with $\mathrm{CHCl}_{3}$ and ethyl acetate $(20 \%-100 \%)$ and $1 \%$ triethylamine to yield $\mathbf{C M}_{3} \mathbf{P y P}, \mathbf{C M}_{2} \mathbf{P y} \mathbf{y}_{2} \mathbf{P}$ (trans and cis), and $\mathbf{C M P y _ { 3 }} \mathbf{P}$ (where CM represents the 4-carbomethoxyphenyl substituents).

\section{5, 10, 15-Tri(4-carbomethoxyphenyl)-20-(4-pyridyl)porphyrin (CM3PyP).}

$\mathrm{CM}_{3} \mathrm{PyP}\left(0.3378 \mathrm{~g}, 2 \%\right.$ of the theoretical yield) was eluted with $(4: 1) \mathrm{CH}_{2} \mathrm{Cl}_{2}$ :ethyl acetate $\left(0.1 \% \mathrm{Et}_{3} \mathrm{~N}\right)$ from a silica column. ${ }^{1} \mathrm{H} \mathrm{NMR}\left(400 \mathrm{MHz} ; \mathrm{CDCl}_{3} ; \mathrm{Me}_{4} \mathrm{Si} ; \delta_{\mathrm{H}}\right.$, ppm) $-2.84\left(2 \mathrm{H}, \mathrm{s}\right.$, pyrrole-NH), $4.13\left(9 \mathrm{H}, \mathrm{s},-\mathrm{CO}_{2} \mathrm{CH}_{3}\right), 8.16(2 \mathrm{H}, \mathrm{d}, \mathrm{Py}-\mathrm{H}), 8.29(6 \mathrm{H}$, d, Ph-carbomethoxy), 8.45 (6H, d, Ph-carbomethoxy), 8.78-8.88 (8H, br, pyrrole-H), 9.03 (2H, d, Py-H). MS: m/z $790.26758\left([\mathrm{M}+\mathrm{H}]^{+}\right.$calcd. 790.26601$)$.

\section{5, 10-Di(4-carbomethoxyphenyl)-15, 20-di(4-pyridyl)porphyrin (cis-CM2 $\left.\mathrm{M}_{2} \mathrm{Py}_{2} \mathrm{P}\right)$.}

$\mathrm{CM}_{3} \mathrm{PyP}\left(0.0534 \mathrm{~g}, 0.3 \%\right.$ of the theoretical yield) was eluted with (4:1) $\mathrm{CH}_{2} \mathrm{Cl}_{2}$ :ethyl acetate $\left(0.1 \% \mathrm{Et}_{3} \mathrm{~N}\right)$ from a silica column. ${ }^{1} \mathrm{H} \mathrm{NMR}\left(400 \mathrm{MHz} ; \mathrm{CDCl}_{3} ; \mathrm{Me}_{4} \mathrm{Si} ; \delta_{\mathrm{H}}\right.$, ppm) -2.87 (2H, s, pyrrole-NH), $4.12\left(6 \mathrm{H}, \mathrm{s},-\mathrm{CO}_{2} \mathrm{CH}_{3}\right), 8.17(4 \mathrm{H}, \mathrm{d}, \mathrm{Py}-\mathrm{H}), 8.29(4 \mathrm{H}$, d, Ph-carbomethoxy), 8.46 (4H, d, Ph-carbomethoxy), 8.80-8.89 (8H, d, pyrrole-H), 
$9.06(2 \mathrm{H}, \mathrm{d}, \mathrm{Py}-\mathrm{H}) . \mathrm{MS}: \mathrm{m} / \mathrm{z} 733.25723\left([\mathrm{M}+\mathrm{H}]^{+}\right.$calcd. 790.25578$)$.

5, 15-Di-(4-carbomethoxyphenyl)-10, 20-di(4-pyridyl)porphyrin (trans- $\mathrm{CM}_{2} \mathrm{Py} 2 \mathrm{P}$ ). $\mathrm{CM}_{3} \mathrm{PyP}\left(0.0516 \mathrm{~g}, 0.3 \%\right.$ of the theoretical yield) was eluted with (4:1) $\mathrm{CH}_{2} \mathrm{Cl}_{2}$ :ethyl acetate $\left(0.1 \% \mathrm{Et}_{3} \mathrm{~N}\right)$ from a silica column. ${ }^{1} \mathrm{H} \mathrm{NMR}\left(400 \mathrm{MHz} ; \mathrm{CDCl}_{3} ; \mathrm{Me}_{4} \mathrm{Si} ; \delta_{\mathrm{H}}\right.$, ppm) -2.87 (2H, s, pyrrole-NH), $4.13\left(6 \mathrm{H}, \mathrm{s},-\mathrm{CO}_{2} \mathrm{CH}_{3}\right), 8.16(4 \mathrm{H}, \mathrm{d}, \mathrm{Py}-\mathrm{H}), 8.29(4 \mathrm{H}$, d, Ph-carbomethoxy), 8.46 (4H, d, Ph-carbomethoxy), 8.77-8.93 (8H, m, pyrrole-H), $9.05(4 \mathrm{H}, \mathrm{d}, \mathrm{Py}-\mathrm{H})$.

\section{5-(4-carbomethoxyphenyl)-10, 15, 20-tri(4-pyridyl)porphyrin (CMPy3 P).}

$\mathrm{CM}_{3} \mathrm{PyP}\left(0.0235 \mathrm{~g}, 0.1 \%\right.$ of the theoretical yield) was eluted with (4:1) $\mathrm{CH}_{2} \mathrm{Cl}_{2}$ :ethyl acetate $\left(0.1 \% \mathrm{Et}_{3} \mathrm{~N}\right)$ from a silica column. ${ }^{1} \mathrm{H} \mathrm{NMR}\left(400 \mathrm{MHz} ; \mathrm{CDCl}_{3} ; \mathrm{Me}_{4} \mathrm{Si} ; \delta_{\mathrm{H}}\right.$, ppm) -2.89 (2H, s, pyrrole-NH), $4.12\left(3 \mathrm{H}, \mathrm{s},-\mathrm{CO}_{2} \mathrm{CH}_{3}\right), 8.17(6 \mathrm{H}, \mathrm{d}, \mathrm{Py}-\mathrm{H}), 8.30(2 \mathrm{H}$, d, Ph-carbomethoxy), 8.47 (2H, d, Ph-carbomethoxy), 8.81-8.92 (8H, br, pyrrole-H), 9.06 (6H, d, Py-H). MS: m/z 676.24712 ([M+H $]^{+}$calcd. 676.24555).

Preparation of $\mathbf{A x P y y}$. A Lossen rearrangement was run on each of these individually isolated porphyrins to prepare the corresponding pyridyl aminophenyl porphyrins $\left(\mathbf{A}_{\mathbf{x}} \mathbf{P y} \mathbf{y} \mathbf{P}\right){ }^{69} \quad$ Each individual $\mathbf{C M}_{\mathbf{x}} \mathbf{P} \mathbf{y} \mathbf{y}$ P derivative and 8 equivalents of $\mathrm{NH}_{2} \mathrm{OH} \cdot \mathrm{HCl}$ were warmed to $100{ }^{\circ} \mathrm{C}$ in polyphosphoric acid and the solution was slowly heated to $160{ }^{\circ} \mathrm{C}$ over $3 \mathrm{~h}$. Upon cooling to room temperature, aqueous $\mathrm{NaOH}$ was slowly added to neutralize the solution, and the porphyrin was extracted with chloroform. Column chromatography was then used to remove any residual starting material by eluting with $\mathrm{CHCl}_{3}$ and $\mathrm{MeOH}(5 \%)$.

5, 10, 15-Tri(4-aminophenyl)-20-(4-pyridyl)porphyrin (A3PyP). UV-vis 
(DMSO): $\lambda_{\max }, \mathrm{nm}\left(\varepsilon^{*} 10^{3}\right) 434$ (194), 525 (15), 575 (21), 664 (12). ${ }^{1} \mathrm{H}$ NMR (600 MHz; DMSO-D; $\left.\mathrm{Me}_{4} \mathrm{Si} ; \delta_{\mathrm{H}}, \mathrm{ppm}\right)-2.77\left(2 \mathrm{H}, \mathrm{s}\right.$, pyrrole-NH), $5.59\left(6 \mathrm{H}, \mathrm{s},-\mathrm{NH}_{2}\right), 7.00$ (6H, d, Ph), 7.86 (6H, d, Ph), 8.24 (2H, d, Py-H), 8.75-8.96 (8H, br, pyrrole-H), 9.03 (2H, d, Py-H). MS: m/z $661.28237\left([\mathrm{M}+\mathrm{H}]^{+}\right.$calcd. 661.28227).

5, 10-Di(4-aminophenyl)-15, 20-di(4-pyridyl)porphyrin (cis- $\left.\mathbf{A}_{2} \mathbf{P y}_{2} \mathbf{P}\right) . \quad$ UV-vis (DMSO): $\lambda_{\max }, \mathrm{nm}\left(\varepsilon^{*} 10^{3}\right) 419$ (138), 518 (11), 571 (10), 657 (5). ${ }^{1} \mathrm{H}$ NMR (600 MHz; DMSO-D; $\left.\mathrm{Me}_{4} \mathrm{Si} ; \delta_{\mathrm{H}}, \mathrm{ppm}\right)-2.83\left(2 \mathrm{H}, \mathrm{s}\right.$, pyrrole-NH), $5.62\left(4 \mathrm{H}, \mathrm{s},-\mathrm{NH}_{2}\right), 7.01(4 \mathrm{H}$, dd, Ph), 7.87 (4H, dd, Ph), 8.25 (4H, d, Py-H), 8.77-9.01 (8H, br, pyrrole-H), 9.03 (4H, d, Py-H). MS: m/z $647.26628\left([\mathrm{M}+\mathrm{H}]^{+}\right.$calcd. 647.26662).

5, 15-Di-(4-aminophenyl)-10, 20-di(4-pyridyl)porphyrin (trans-A2 $\left.\mathbf{P y}_{2} \mathbf{P}\right)$. UV-vis (DMSO): $\lambda_{\max }, \mathrm{nm}\left(\varepsilon^{*} 10^{3}\right) 421$ (105), 519 (9), 567 (9), 657 (5). ${ }^{1} \mathrm{H}$ NMR (600 MHz; DMSO-D; $\left.\mathrm{Me}_{4} \mathrm{Si} ; \delta_{\mathrm{H}}, \mathrm{ppm}\right)-2.81\left(2 \mathrm{H}, \mathrm{s}\right.$, pyrrole-NH), $5.61\left(4 \mathrm{H}, \mathrm{s},-\mathrm{NH}_{2}\right), 7.00(4 \mathrm{H}$, dd, Ph), 7.86 (4H, d, Ph), 8.25 (4H, d, Py-H), 8.78-9.01 (8H, br, pyrrole-H), 9.05 (4H, d, Py-H). MS: m/z $647.26730\left([\mathrm{M}+\mathrm{H}]^{+}\right.$calcd. 647.26662).

5-(4-aminophenyl)-10, 15, 20-tri(4-pyridyl)porphyrin (APy3 $\mathbf{P}) . \quad$ UV-vis (DMSO): $\lambda_{\max }, \mathrm{nm}\left(\varepsilon^{*} 10^{3}\right) 418(254), 515$ (11), 554 (3), 589 (4), 650 (1). ${ }^{1} \mathrm{H}$ NMR (600 MHz; DMSO-D; Me $\left.{ }_{4} \mathrm{Si} ; \delta_{\mathrm{H}}, \mathrm{ppm}\right)-2.93\left(2 \mathrm{H}, \mathrm{s}\right.$, pyrrole-NH), $5.65\left(2 \mathrm{H}, \mathrm{s},-\mathrm{NH}_{2}\right), 7.02(2 \mathrm{H}, \mathrm{d}$, $\mathrm{Ph}), 7.87$ (2H, d, Ph), 8.26 (6H, d, Py-H), 8.80-9.03 (8H, br, pyrrole-H), 9.05 (6H, d, Py-H). MS: m/z $633.25106\left([\mathrm{M}+\mathrm{H}]^{+}\right.$calcd. 633.25097). 


\subsection{Spectroscopy studies of protonated aminophenyl/pyridyl porphyrins}

Instruments. UV-visible spectroscopy was performed using a Shimadzu UV-3600 UV-VIS-NIR spectrophotometer with Shimadzu UVProbe software. Typical spectra were run from 300 to $900 \mathrm{~nm}$ using a single visible light source and a single detector. Scanning speed was medium with sample interval of either 0.2 or $1 \mathrm{~nm}$ and a slit width of $3 \mathrm{~nm}$. NMR spectra were taken with a Bruker Avance II $400 \mathrm{MHz}$ spectrometer, and data workup was performed using TopSpin 2.1 software.

Titrations. All porphyrin titrations were performed with MSA in DMSO. Solutions were purged with nitrogen before the titrations of the $\mathbf{A}_{\mathbf{x}} \mathbf{P} \mathbf{y} \mathbf{y} \mathbf{P}$ derivatives were conducted. The titrations began with dilute acid in $2-5 \mu \mathrm{L}$ increments, and concentrated acid in higher increments was used for the later stages. The volume of the initial porphyrin solution was $3.0 \mathrm{~mL}$. Dilution effects on the concentrations of the porphyrins caused by the addition of acid were taken into consideration, and all spectra are reported as extinction coefficients.

\subsection{NMR studies of protonated aminophenyl/pyridyl porphyrins}

Instruments. The UV-vis spectroscopy measurements were taken on samples taken directly from the NMR tests. The spectrometer was the same as the previous section. Because the concentration of the porphyrin solutions were too high to use the standard cuvette $(1 \mathrm{~cm})$, a special thin-layer cell was prepared. Typical procedures to make the cell are as follows: microscope slides were first cut into proper sizes and cleaned. On 
one slide two layers of parafilm were wrapped, another slide was pressed against the wrapped one and fixed with more parafilm wrapped around. The sample solutions can be added by a capillary pipet and the cell is mounted onto a customized holder for measurements (method developed by Keith James). 1D proton and 2D NOESY and COSY NMR data were collected using a Bruker Avance III (600 MHz 1H) spectrometer at $25^{\circ} \mathrm{C}$. Bruker-Topspin 2.1 software was used to process the data. The typical scan range was from -4 to $16 \mathrm{ppm}$.

Titrations. In the NMR tube, the porphyrins were titrated by MSA in deuterated DMSO. The initial volume of the solution was $500 \mu \mathrm{L}$. Diluted and concentrated acids were titrated sequentially in $10-20 \mu \mathrm{L}$ increments. The NMR tube was shaken to mix the solution.

\subsection{Cyclic voltammetry of protonated aminophenyl/pyridyl porphyrins}

Instruments. The UV-vis measurements of the actual solutions studied were performed in a thin-layer cell as described in the previous section. The electrochemistry studies were all performed on Gamry Reference 600 with Gamry Instruments Framework software. Three electrodes system was adopted here, in which glassy-carbon, platinum wire, and $\mathrm{Ag} / \mathrm{AgCl}$ were used as working, counter and reference electrodes. A typical scan rate was $50 \mathrm{mV} / \mathrm{s}$. The scan range was from 0 to $-2 \mathrm{~V}$.

Titrations. In a homemade electrocell, the porphyrins were titrated by MSA in 
DMSO with tetrabutylammonium perchlorate as the electrolyte. Inert gas was purged before each titration, and working electrode was rinsed after each one. Diluted acid was titrated first, following by concentrated acid in $10-20 \mu \mathrm{L}$ increments. The initial volume of the solution was $1 \mathrm{~mL}$. 
Chapter 3. Spectroscopy Studies of Protonated Aminophenyl/Pyridyl Porphyrins

This chapter was originally published on J. Phys. Chem. A, 2014, 118 (20), pp 3605-3615 and the results and discussion sections are reproduced here in their entirety.

\subsection{Spectroscopy of protonating regular pyridyl porphyrins}

The spectroscopy observed from the protonation of tetra(4-pyridylporphyrin) (TPyP) has been reported in the literature. ${ }^{70}$ It was concluded that the pyridyl groups protonated first, based on the very small effects on the spectra observed during the initial aliquots of acid additions, where further additions of acid generated the characteristic protonated porphyrin spectrum. While these conclusions are fully consistent with the observed spectroscopy, because it was particularly important for our study to know the order of protonation of the various substituents, we proceeded to confirm the spectroscopic signatures for protonation of the porphyrin ring as distinguished from protonation of pyridyl groups on porphyrins.

ZnTPyP. Upon protonation of ZnTPyP (Fig. 8), the Soret band red shifts by $6 \mathrm{~nm}$ (426 to $432 \mathrm{~nm}$ ) and broadens. The two Q bands show very little change. In this case, the four peripheral pyridyl groups become protonated, leading to small effects on the basic porphyrin spectrum. 


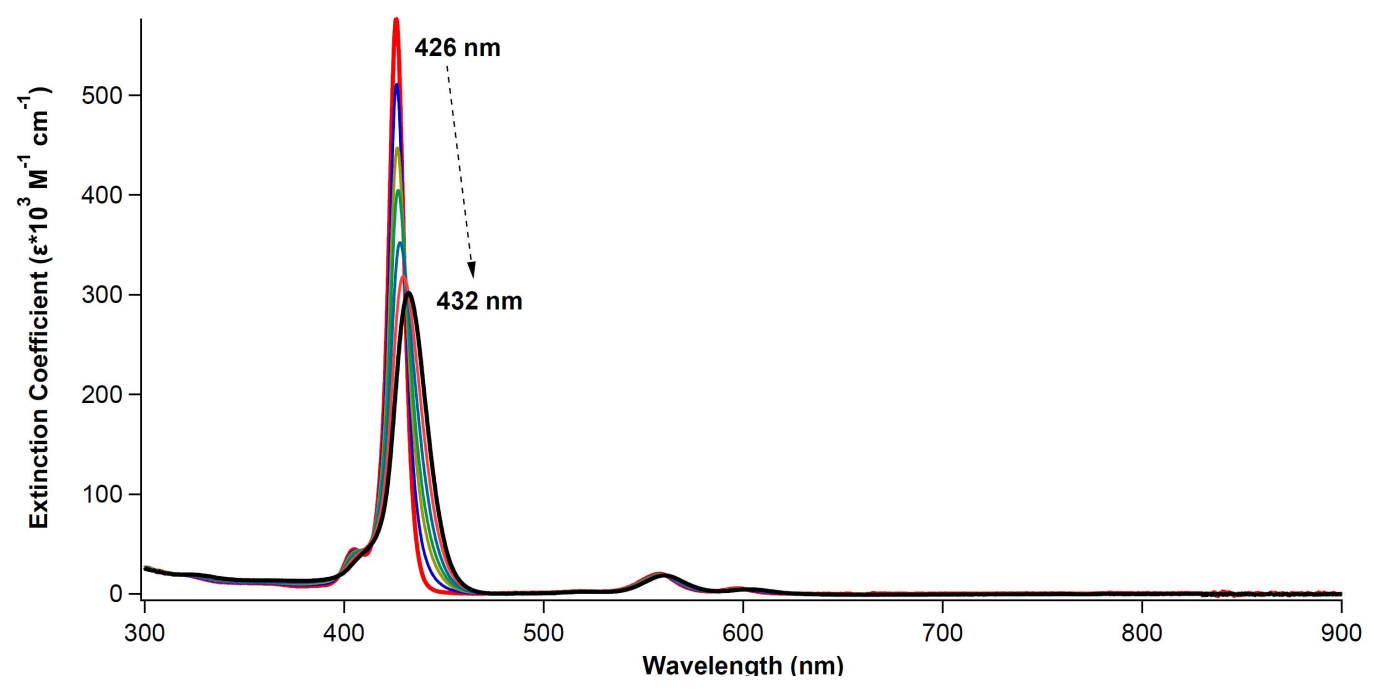

Figure 8. Spectrophotometric titration of ZnTPyP $(3.37 \mu \mathrm{M})$ with MSA (0 - $12 \mu \mathrm{mol})$ in DMSO.

TMePyP ${ }^{+4}$. The spectra observed during acid titration of $\mathbf{T M e P y P} \mathbf{P}^{+4}$ (Figure 9) show a strong Soret band with a large red shift ( $24 \mathrm{~nm}$, from 422 to $446 \mathrm{~nm}$ ) as well as the collapsing of the four Q bands into two at 591 and $642 \mathrm{~nm}$, with the $\mathrm{Q}(0,0)$ band substantially stronger. These changes are typical for protonation of the two internal nitrogens in a free-base porphyrin. It is also notable that these protonations require acid concentrations significantly higher than those needed to protonate the peripheral pyridyl groups above. 


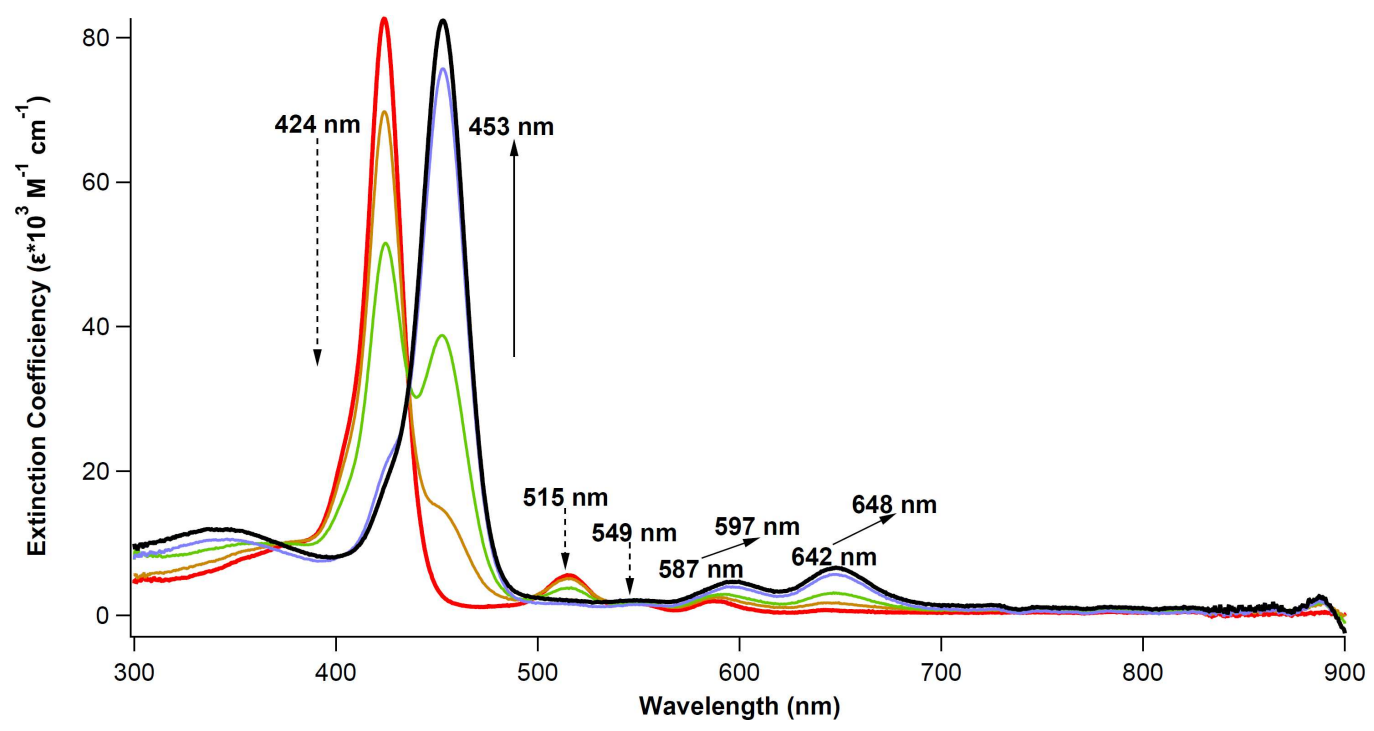

Figure 9. Spectrophotometric titration of $\mathbf{T M e P y P} \mathbf{P}^{+4}(7.5 \mu \mathrm{M})$ with MSA (0 - 15 mmol) in DMSO.

$\mathbf{P h}_{2} \mathbf{P y} 2 \mathbf{P}$ (trans \& cis). The spectrophotometric acid titrations of both the trans and cis isomers of $\mathbf{P h}_{2} \mathbf{P y} \mathbf{y}_{2} \mathbf{P}$ (Figures 10 and 11) show spectral changes similar to those observed for TPyP. The addition of acid first leads to a small red shift $(3-5 \mathrm{~nm})$ of the Soret band as well as the weakening and broadening of the band. With further addition of acid, the Soret band shifts more strongly $(27-29 \mathrm{~nm})$, and the four Q bands disappear in favor of the characteristic strong band at about $650 \mathrm{~nm}$. Thus unsubstituted phenyl substituents are unremarkable in terms of any interactions with protonated pyridyl groups or protonated porphyrins. 

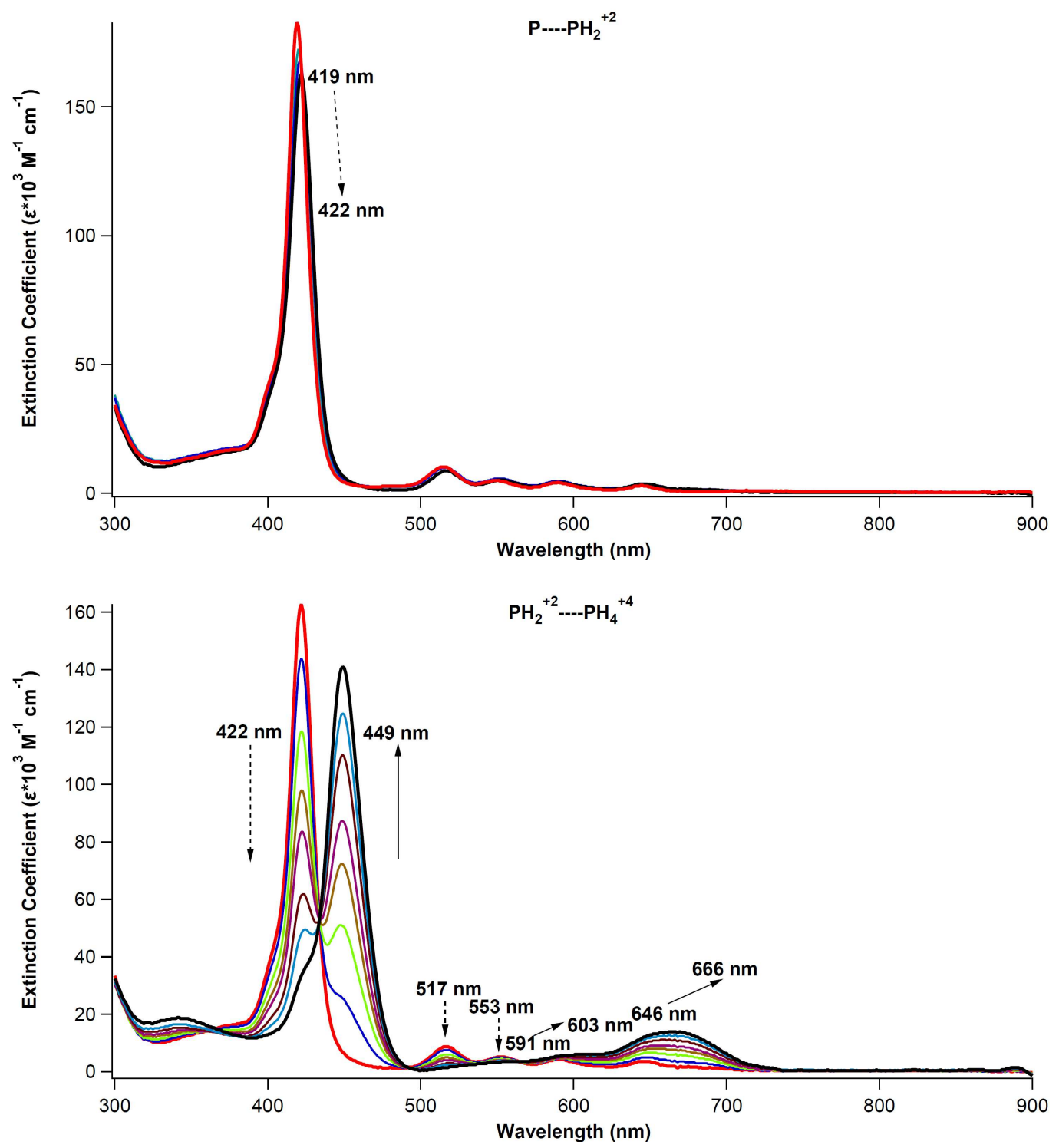

Figure 10. Spectrophotometric titration of $\operatorname{trans}-\mathbf{P h}_{2} \mathbf{P y}_{2} \mathbf{P}(3.24 \mu \mathrm{M})$ with MSA in

\section{DMSO.}

$\mathrm{PH}_{2}{ }^{+2}$ represents protonation of the two peripheral pyridyl groups (0 - $\left.66 \mu \mathrm{mol} \mathrm{MSA}\right)$, while $\mathrm{PH}_{4}{ }^{+4}$ represents protonation of the internal porphyrin nitrogens $(0.066-3.95$ mmol MSA). 

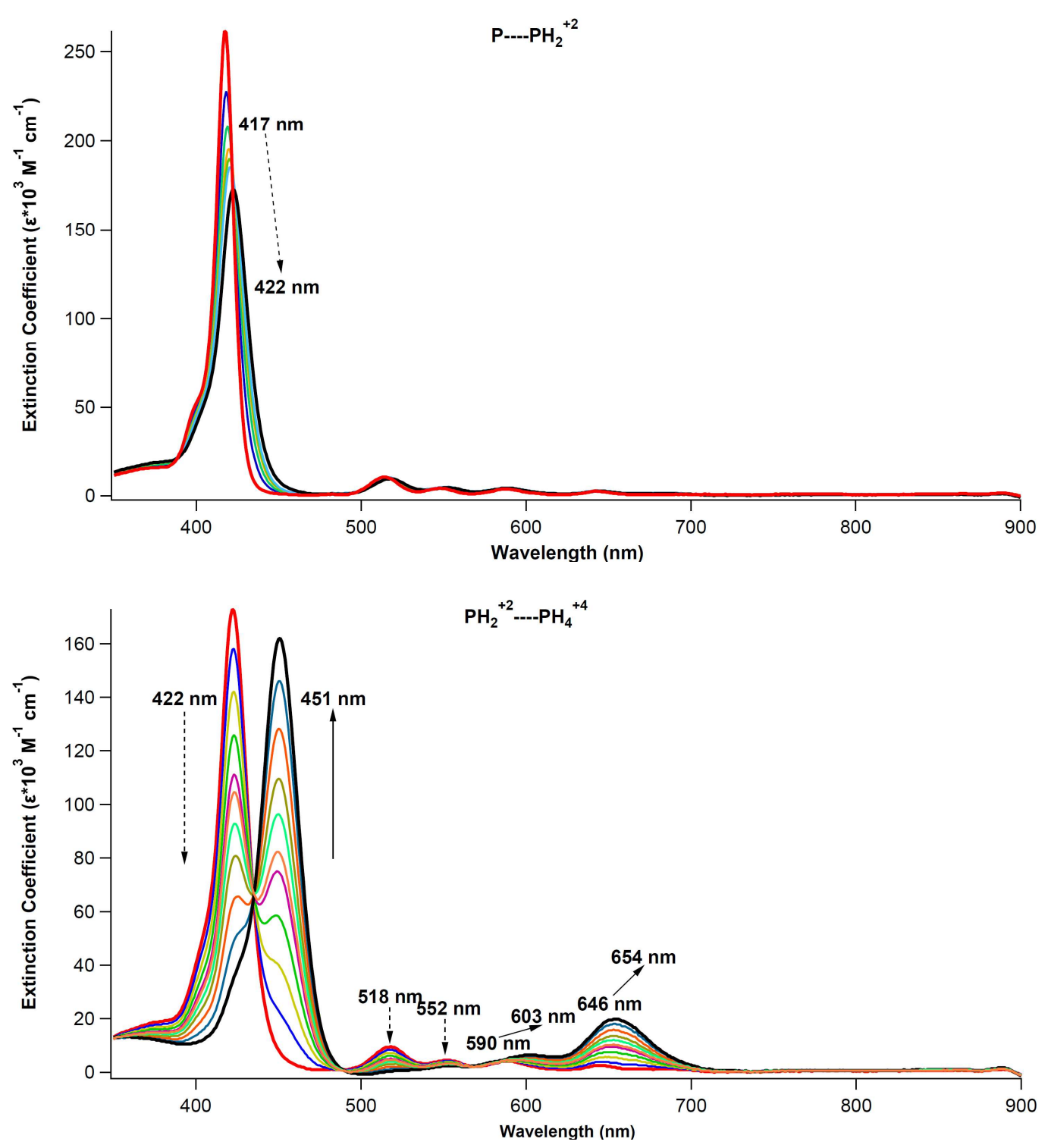

Figure 11. Spectrophotometric titration of $\mathbf{c i s}-\mathbf{P h}_{2} \mathbf{P} \mathbf{y}_{2} \mathbf{P}(3.24 \mu \mathrm{M})$ with MSA in DMSO.

$\mathrm{PH}_{2}{ }^{+2}$ represents protonation of the two peripheral pyridyl groups ( 0 - $70 \mu \mathrm{mol}$ MSA), while $\mathrm{PH}_{4}{ }^{+4}$ represents protonation of the internal porphyrin nitrogens $(0.07-2.3$ mmol MSA). 


\subsection{Spectroscopy of protonating aminophenyl/pyridyl porphyrins}

APy 3 P. The protonation of $\mathbf{A P y}_{3} \mathbf{P}$ can be tracked in three distinct stages as the pyridyl groups, porphyrin, and amino all protonate separately (Fig. 12). Initial aliquots of acid generate a small red shift of the Soret band from 418 to $423 \mathrm{~nm}$, characteristic of protonation of the three pyridyl groups only; Q bands were essentially unaffected during this initial stage of the titration. Additional acid generated a weak, broad absorption between $700-800 \mathrm{~nm}$ indicative of a hyperporphyrin; the Soret band slightly broadened without shifting. In the final stage, acid protonated the amino group, effectively destroying the mild hyperporphyrin effect. The final spectrum shows a red-shifted Soret and a strong $658 \mathrm{~nm}$ band characteristic of a fully protonated porphyrin.

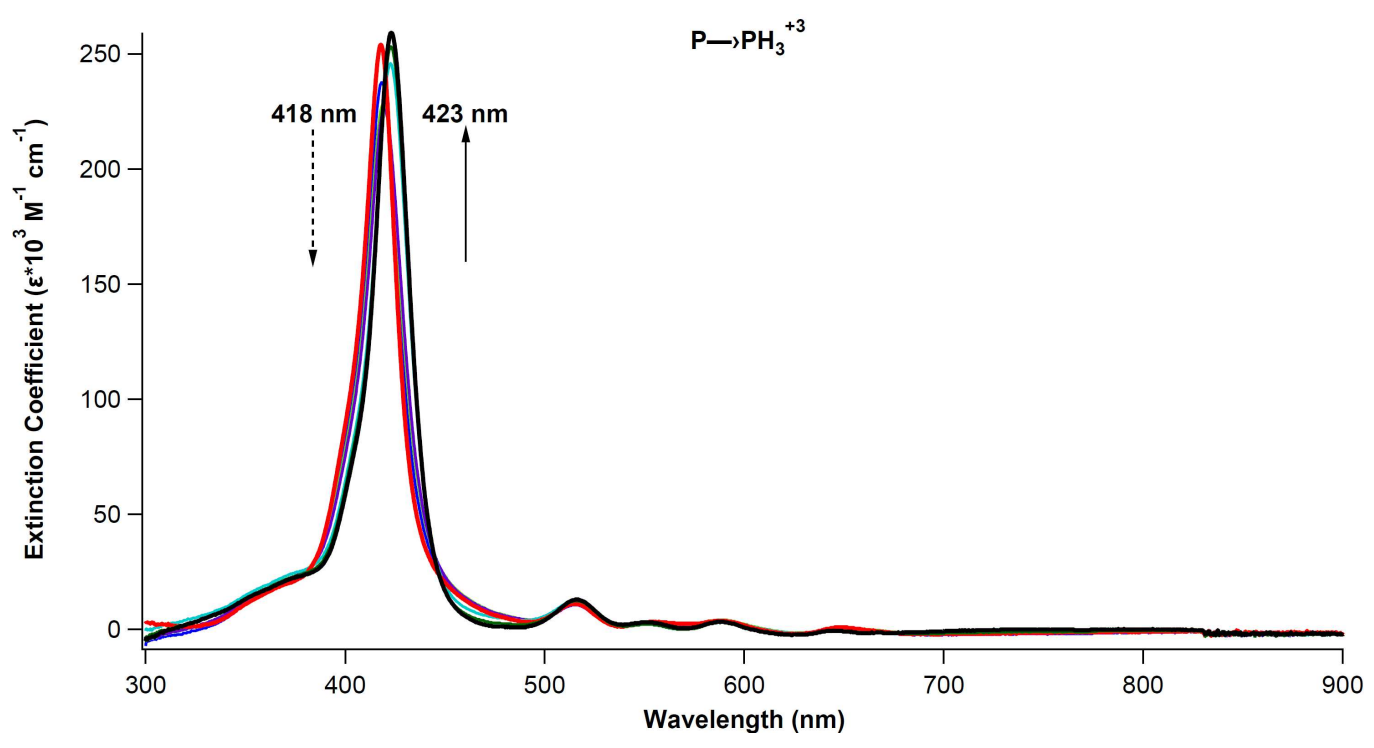




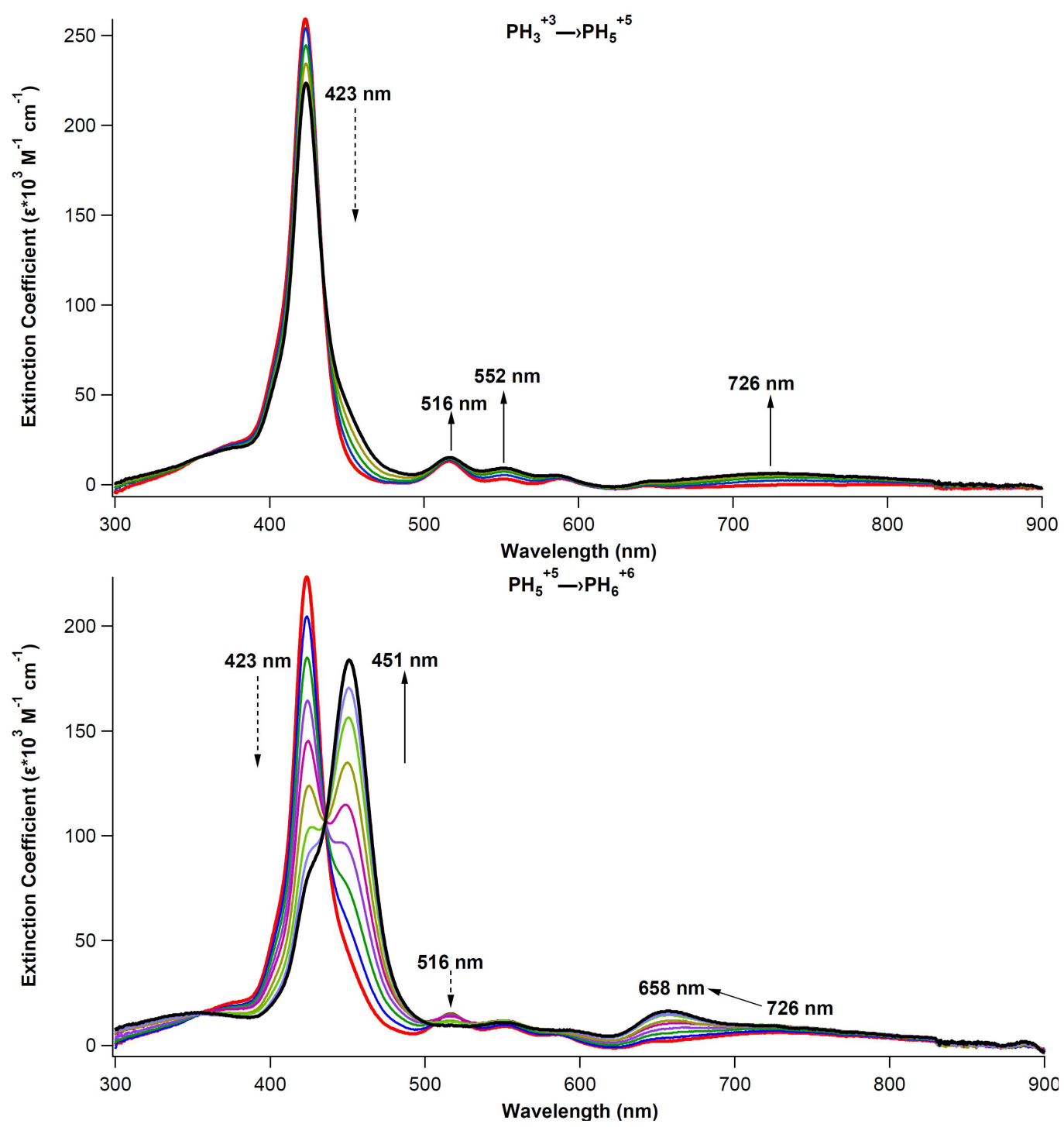

Figure 12. Spectrophotometric titration of $\mathbf{A P y}_{3} \mathbf{P}(3.24 \mu \mathrm{M})$ with MSA in DMSO. $\mathrm{PH}_{3}{ }^{+3}$ represents protonation of the three peripheral pyridyl groups $(0-385 \mu \mathrm{mol}$ MSA), $\mathrm{PH}_{5}{ }^{+5}$ represents protonation of the internal porphyrin nitrogens $(0.385-2.77$ mmol MSA), and $\mathrm{PH}_{6}{ }^{+6}$ represents protonation of the peripheral aminophenyl group (2.77 - 9.7 mmol MSA). 
$\mathbf{A}_{2} P y_{2} P$ (trans \& cis). Only two distinct stages can be discerned in the acid titrations of both the trans and cis isomers of $\mathbf{A}_{2} \mathbf{P} \mathbf{y}_{2} \mathbf{P}$ (Figures 13 and 14). Initially the Soret bands (421 nm in trans and $419 \mathrm{~nm}$ in cis) increase and red shift to $422 \mathrm{~nm}$, while all the Q bands also undergo red shifts by 6 to $20 \mathrm{~nm}$. At wavelengths above $700 \mathrm{~nm}$, broad hyperporphyrin absorbances appear in both spectra, in which the cis isomer shows considerably stronger absorption than the trans isomer. These features indicate that the pyrrole groups have been protonated and are interacting with the aminophenyl groups to generate hyperporphyrin spectra. The small changes associated with protonation of only the pyridyl groups, i.e., a +2 diprotonated state, cannot be distinguished during the titration. This implies that the pyrrole groups of the porphyrin have become more basic with the presence of the two aminophenyl substituents and the pyrroles protonate together with the pyridyl groups. In the second stage of the titrations, new Soret bands (448 nm in trans and $450 \mathrm{~nm}$ in cis) grow in, the Q bands collapse into one major absorption (673 nm in trans and $656 \mathrm{~nm}$ in cis), and the hyperporphyrin peaks disappear, characteristic of a fully protonated porphyrin with all groups noninteracting. 

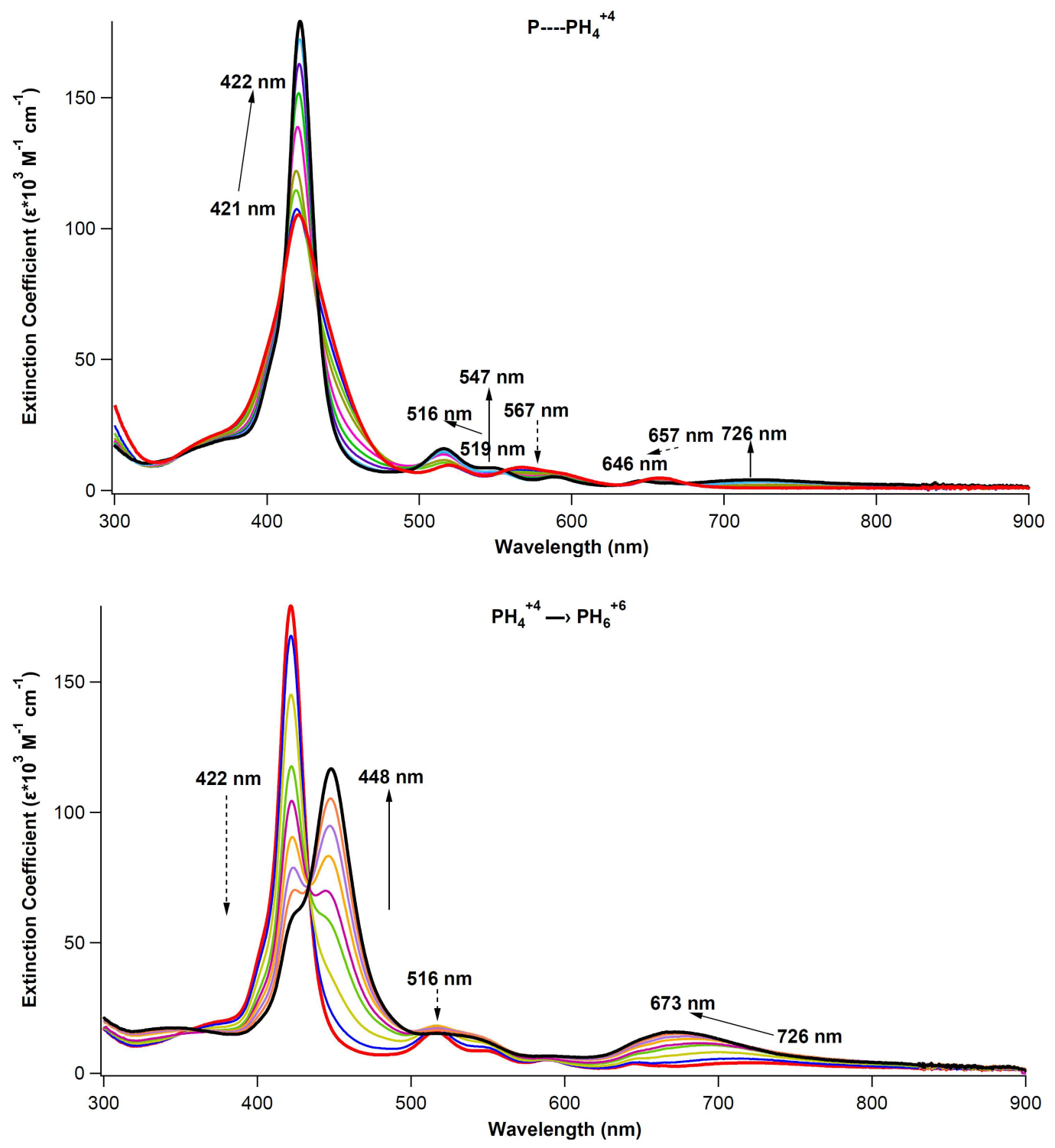

Figure 13. Spectrophotometric titration of trans-A2 $\mathbf{P} \mathbf{y}_{2} \mathbf{P}(9.28 \mu \mathrm{M})$ with MSA in

\section{DMSO.}

$\mathrm{PH}_{4}{ }^{+4}$ represents protonation of the two peripheral pyridyl groups as well as the two internal porphyrin nitrogens ( 0 - $230 \mu \mathrm{mol} \mathrm{MSA})$, and $\mathrm{PH}_{6}{ }^{+6}$ includes protonation of the two peripheral amino groups as well (0.23 - 5.1 mmol MSA). 

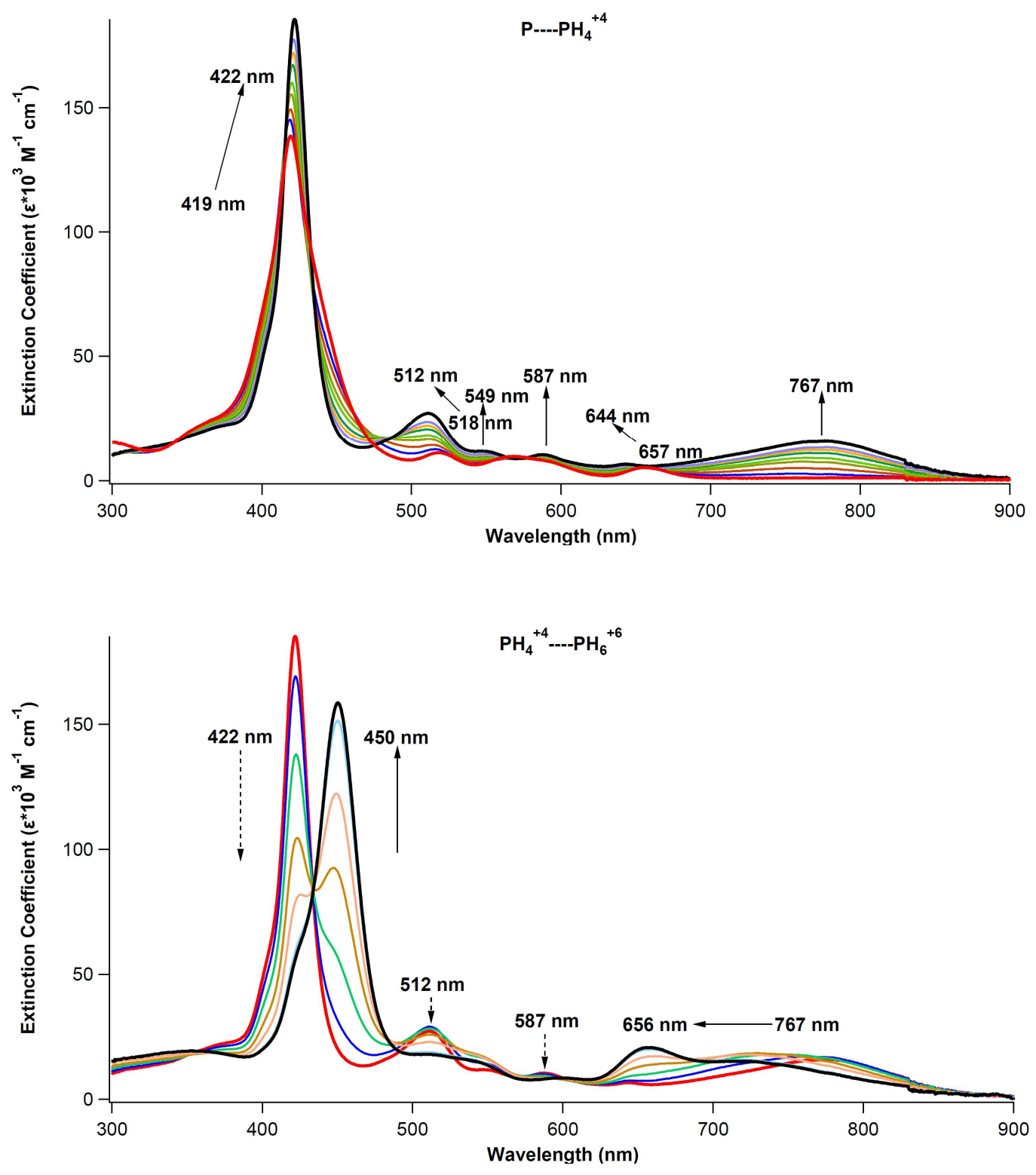

Figure 14. Spectrophotometric titration of $\mathbf{c i s - \mathbf { A } _ { 2 } \mathbf { P y } 2} \mathbf{P}(7.73 \mu \mathrm{M})$ with MSA in DMSO.

$\mathrm{PH}_{4}{ }^{+4}$ represents protonation of the two peripheral pyridyl groups as well as the two internal porphyrin nitrogens ( 0 - $155 \mu \mathrm{mol} \mathrm{MSA})$, and $\mathrm{PH}_{6}{ }^{+6}$ includes protonation of the two peripheral amino groups as well (0.155 - 6.2 mmol MSA).

A3PyP. The spectrophotometric acid titration of A3PyP (Figure 15) shows three 
distinct stages. A simple +1 protonated state, indicating protonation of the pyridyl group only, was not observable. The first protonation stage is characterized by clear isosbestic points marking the development of a split Soret band (402 and $478 \mathrm{~nm}$, intensity ratio 1.84), loss of the four Q bands, and growth of a huge red absorbance peaking at $781 \mathrm{~nm}$, all features indicating very strong hyperporphyrin interactions. This all takes place at a significantly lower acid concentration than any of the previous titrations; thus the molecule has been made significantly more basic by the presence of the multiple amino groups. We assign this spectrum to a +3 state, assuming that the pyridyl substituent is also protonated, a topic discussed later while considering the contributing resonance forms. During the second stage of the acid titration, there are no clear isosbestic points as multiple effects seem to be taking place. The Soret band at $402 \mathrm{~nm}$ grows into a higher absorption at increasing wavelength, while the Soret band at $478 \mathrm{~nm}$ decreases and moves to longer wavelength. The red hyperporphyrin absorbance decreases and shifts to shorter wavelengths. We consider this to be the protonation of one of the three amino groups, possibly at different positions, to form +4 isomers, as well as protonation of two amino groups to form a +5 state. The hyperporphyrin effect is weakened but remains remarkably strong throughout these changes. As the acid titration completes, distinct isosbestic points can be observed, leaving only one Soret band at $477 \mathrm{~nm}$ and one Q band at $658 \mathrm{~nm}$, indicative of the fully protonated porphyrin. We attribute the final stage to protonation of the last remaining amino group. 

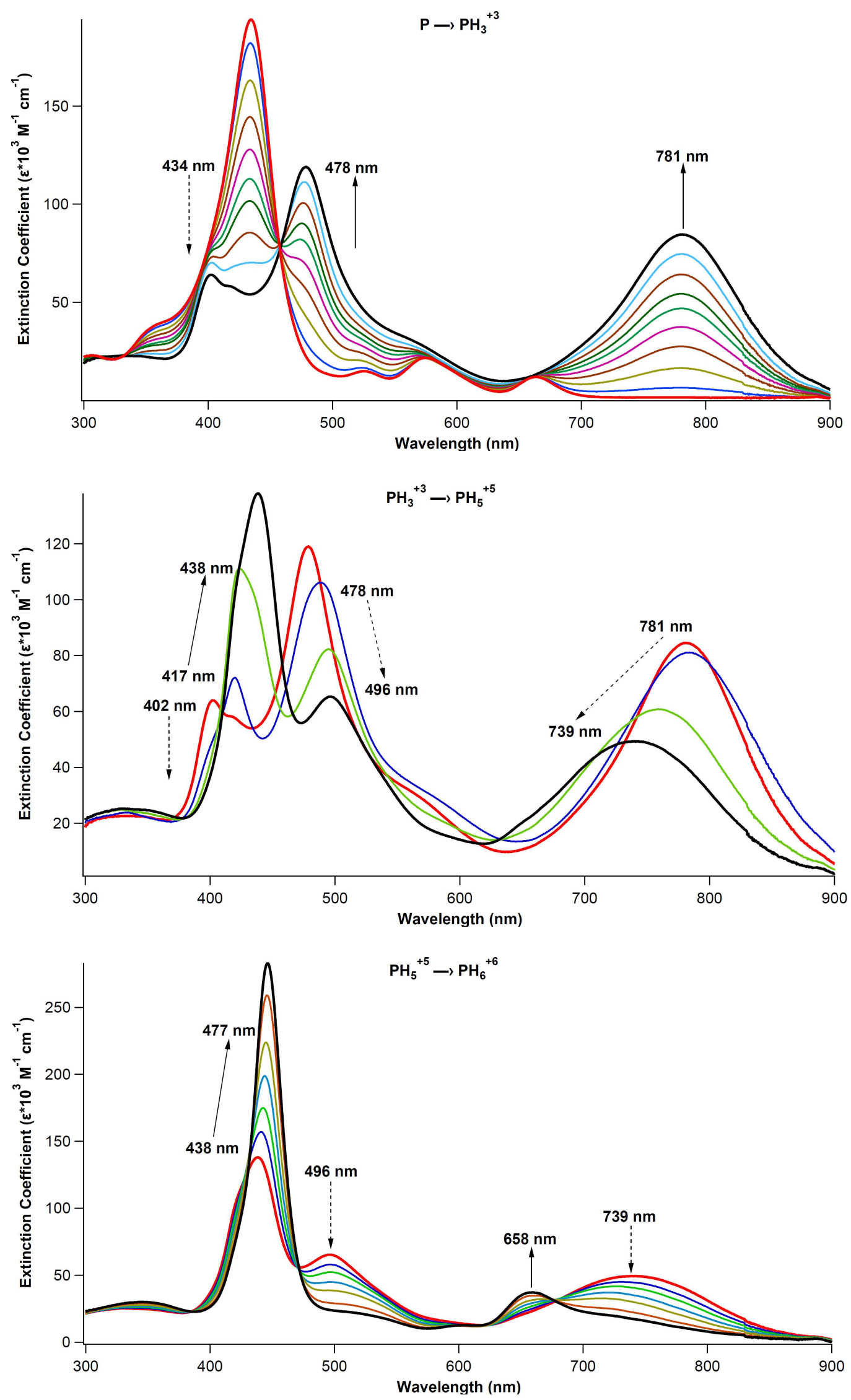
Figure 15. Spectrophotometric titration of $\mathbf{A 3} \mathbf{P y P}(7.57 \mu \mathrm{M})$ with MSA in DMSO. $\mathrm{PH}_{3}{ }^{+3}$ represents protonation of the one peripheral pyridyl group as well as the two internal porphyrin nitrogens $(0-7.7 \mu \mathrm{mol} \mathrm{MSA}), \mathrm{PH}_{5}{ }^{+5}$ represents protonation of two of the three peripheral amino groups $(0.077-1.57 \mathrm{mmol} \mathrm{MSA})$, and $\mathrm{PH}_{6}{ }^{+6}$ represents protonation of all of the three peripheral amino groups (1.57 - $7.7 \mathrm{mmol} \mathrm{MSA})$.

TAPP. The acid titration of TAPP is shown in Figure 16, which is consistent with titrations reported in the literature. ${ }^{34,44}$ TAPP is significantly more basic than all the other porphyrins in this study. Initially, the Soret band splits into a weak absorption at $392 \mathrm{~nm}$ and a strong one at $467 \mathrm{~nm}$, as well as a strong red absorption peaking at $813 \mathrm{~nm}$. Protonation to the +4 state still leaves a remarkably strong hyperporphyrin spectrum. Complete protonation leads to a Soret band at $443 \mathrm{~nm}$ and a Q band at $660 \mathrm{~nm}$.





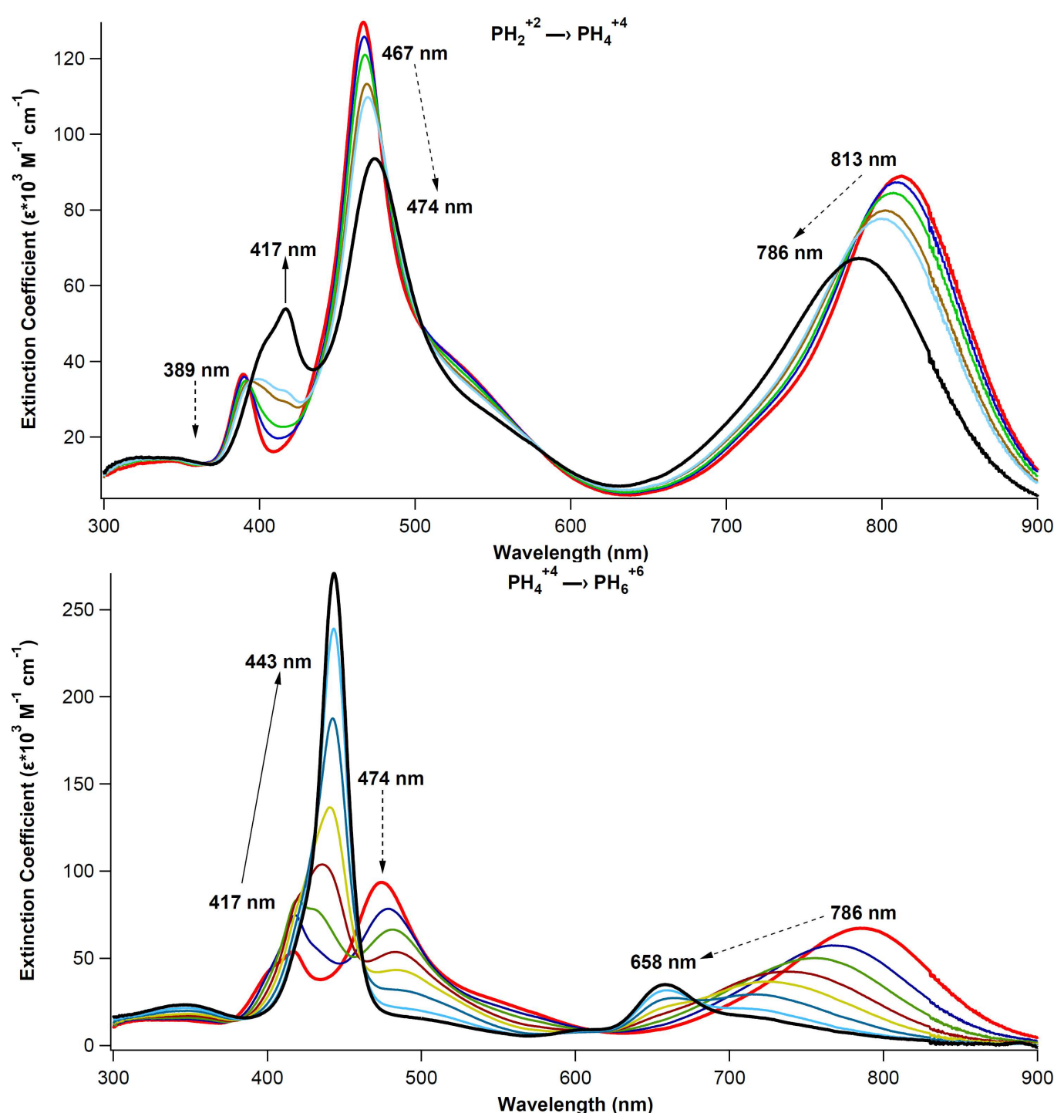

Figure 16. Spectrophotometric titration of TAPP $(5.93 \mu \mathrm{M})$ with MSA in DMSO.

$\mathrm{PH}_{2}{ }^{+2}$ represents protonation of the two internal porphyrin nitrogens $(0-690 \mathrm{nmol}$ MSA), $\quad \mathrm{PH}_{4}^{+4}$ represents protonation of two peripheral amino groups (0.69- 126 $\mu \mathrm{mol}$ MSA), and $\quad \mathrm{PH}_{6}{ }^{+6}$ represents protonation of the last two peripheral amino groups (0.126 - 7.1 mmol MSA). 


\subsection{Comparison of hyperporphyrin spectra}

Figure 17 highlights the spectra of the different hyperporphyrins obtained from the variously substituted aminophenyl / pyridyl porphyrins. With increasing numbers of aminophenyl groups, clear trends are observed in terms of the wavelength and intensity of the red hyperporphyrin band as well as the wavelength and intensity of the split Soret band. Table 1 summarizes these spectral features, which are discussed further in terms of resonance delocalization in the next section.

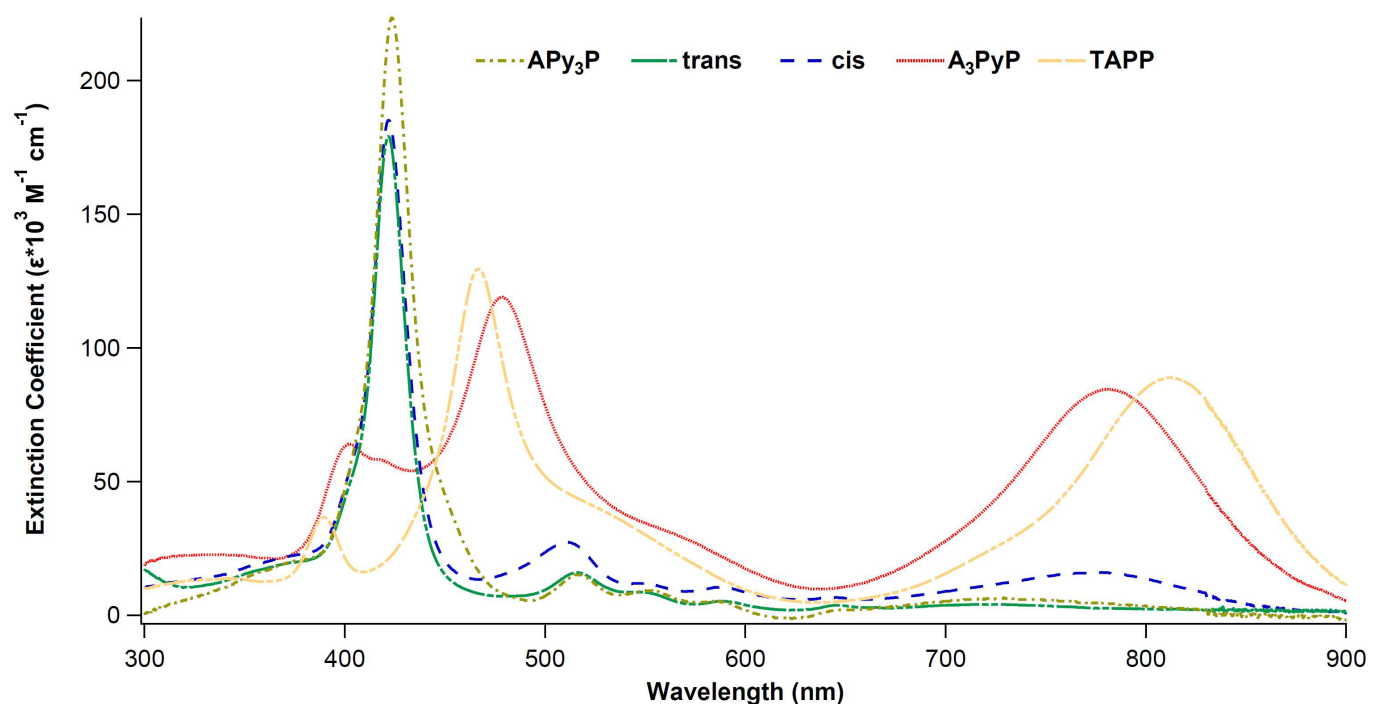

Figure 17. Hyperporphyrin spectra of the various porphyrins studied.

Table 1. Peak wavelengths and extinction coefficients $\left(\lambda_{\max }(\mathrm{nm}),\left(\mathrm{x} 10^{3} \mathrm{M}^{-1} \mathrm{~cm}^{-1}\right)\right)$ of the porphyrins and protonated porphyrins, along with the initial porphyrin concentration (3 $\mathrm{mL}$ volume) and the amount of acid (MSA in DMSO) used to create the maximum concentration of that particular species and give rise to the reported 
spectrum. The far-red hyperporphyrin bands are highlighted in boldface.

\begin{tabular}{|c|c|c|c|c|c|}
\hline & $\begin{array}{c}\mathbf{P} \\
\lambda_{\max }\left(\varepsilon \times 10^{3}\right)\end{array}$ & $\begin{array}{c}\mathbf{P H}_{\mathbf{2}}^{\mathbf{+ 2}} \\
\lambda_{\max }\left(\varepsilon \times 10^{3}\right)\end{array}$ & $\begin{array}{c}\mathbf{P H}_{3}{ }^{+3} \\
\lambda_{\max }\left(\varepsilon \times 10^{3}\right)\end{array}$ & $\begin{array}{c}\mathbf{P H}_{4}+4 * \\
\lambda_{\max }\left(\varepsilon \times 10^{3}\right)\end{array}$ & $\begin{array}{c}\mathbf{P H}_{\mathbf{6}}{ }^{+6} \\
\lambda_{\max }\left(\varepsilon \times 10^{3}\right)\end{array}$ \\
\hline \multirow{6}{*}{$\begin{array}{c}\operatorname{trans} \\
\mathbf{P h}_{2} \mathbf{P y}_{2} \mathbf{P} \\
(3.24 \mu \mathrm{M})\end{array}$} & $0 \mathrm{mmol}$ & $66 \mu \mathrm{mol}$ & & $4.0 \mathrm{mmol}$ & \\
\hline & 419 (183) & $422(163)$ & & & \\
\hline & $515(10)$ & $517(9)$ & & $449(141)$ & \\
\hline & $550(5)$ & $552(5)$ & & $603(6)$ & \\
\hline & $590(4)$ & $590(4)$ & & $666(14)$ & \\
\hline & $644(3)$ & $645(4)$ & & & \\
\hline \multirow{6}{*}{$\begin{array}{c}\text { cis } \\
\mathbf{P h}_{2} \mathbf{P y} \mathbf{y}_{2} \mathbf{P} \\
(3.24 \mu \mathrm{M})\end{array}$} & $0 \mathrm{mmol}$ & $70 \mu \mathrm{mol}$ & & $2.3 \mathrm{mmol}$ & \\
\hline & $417(261)$ & $422(172)$ & & & \\
\hline & $514(10)$ & $518(9)$ & & $451(162)$ & \\
\hline & $547(4)$ & $552(4)$ & & $603(6)$ & \\
\hline & $588(4)$ & $589(4)$ & & $654(20)$ & \\
\hline & $642(3)$ & $645(2)$ & & & \\
\hline \multirow{6}{*}{$\begin{array}{c}\mathbf{A P y}_{\mathbf{3}} \mathbf{P} \\
(4.75 \mu \mathrm{M})\end{array}$} & $0 \mathrm{mmol}$ & & $385 \mu \mathrm{mol}$ & $+\mathbf{5}^{*} 2.8 \mathrm{mmol}$ & $9.7 \mathrm{mmol}$ \\
\hline & $418(254)$ & & $423(259)$ & $423(223)$ & \\
\hline & $515(11)$ & & $516(13)$ & $\begin{array}{c}517(15) \\
552(9)\end{array}$ & \\
\hline & $554(3)$ & & $551(3)$ & $552(9)$ & $451(184)$ \\
\hline & $589(4)$ & & $589(3)$ & $\begin{array}{l}585(5) \\
650(2)\end{array}$ & \\
\hline & $650(1)$ & & $650(1)$ & $\begin{array}{l}650(2) \\
726(6)\end{array}$ & \\
\hline \multirow{7}{*}{$\begin{array}{c}\text { trans } \\
\mathbf{A}_{2} \mathbf{P y}_{2} \mathbf{P} \\
(9.28 \mu \mathrm{M})\end{array}$} & $0 \mathrm{mmol}$ & & & $230 \mu \mathrm{mol}$ & $5.1 \mathrm{mmol}$ \\
\hline & & & & $422(179)$ & \\
\hline & $421(105)$ & & & $516(16)$ & \\
\hline & $519(9)$ & & & $547(9)$ & 448 (117) \\
\hline & $567(9)$ & & & $589(5)$ & $673(16)$ \\
\hline & $657(5)$ & & & $646(4)$ & \\
\hline & & & & $726(4)$ & \\
\hline \multirow{7}{*}{$\begin{array}{c}\text { cis } \\
\mathbf{A}_{2} \mathbf{P y}_{2} \mathbf{P} \\
(7.73 \mu \mathrm{M})\end{array}$} & $0 \mathrm{mmol}$ & & & $155 \mu \mathrm{mol}$ & $6.2 \mathrm{mmol}$ \\
\hline & & & & $422(185)$ & \\
\hline & 419 (138) & & & $512(27)$ & \\
\hline & $518(11)$ & & & $551(12)$ & $450(158)$ \\
\hline & $571(10)$ & & & $589(10)$ & $656(21)$ \\
\hline & $657(5)$ & & & $644(7)$ & \\
\hline & & & & $767(16)$ & \\
\hline \multirow{4}{*}{$\begin{array}{c}\mathbf{A}_{\mathbf{3}} \mathbf{P y} \mathbf{P} \\
(7.57 \mu \mathrm{M})\end{array}$} & $0 \mathrm{mmol}$ & & $7.7 \mu \mathrm{mol}$ & $+\mathbf{5}^{*} 1.6 \mathrm{mmol}$ & $7.7 \mathrm{mmol}$ \\
\hline & 434 (194) & & $403(64)$ & $438(138)$ & \\
\hline & $525(15)$ & & $478(118)$ & $496(65)$ & $\begin{array}{l}44 /(283) \\
658(37)\end{array}$ \\
\hline & $575(21)$ & & $781(84)$ & 740 (49) & \\
\hline
\end{tabular}




\begin{tabular}{|c|c|l|c|c|c|}
\hline & $664(12)$ & & & & \\
\hline & $0 \mathrm{mmol}$ & & $690 \mathrm{nmol}$ & $126 \mu \mathrm{mol}$ & $7.1 \mathrm{mmol}$ \\
\cline { 2 - 4 } TAPP & $438(174)$ & & $390(38)$ & $417(54)$ & 4 \\
$(5.93 \mu \mathrm{M})$ & $530(11)$ & & $467(130)$ & $474(93)$ & $643(271)$ \\
& $580(20)$ & & $\mathbf{8 1 3 ( 8 9 )}$ & $\mathbf{7 8 6}(\mathbf{6 7})$ & $658(35)$ \\
& $669(11)$ & & & \\
\hline
\end{tabular}

* The +5 states for $\mathbf{A P y} \mathbf{P}$ and $\mathbf{A 3}_{3} \mathbf{P y P}$ appear in the +4 column for ease of display.

\subsection{Relative basicities of different pyridyl porphyrins}

Because most of the various protonated forms are distinguishable spectroscopically, it is possible to determine the relative order of basicity of the different nitrogen bases present. Generally, the peripheral pyridyl groups protonate first, followed by the interior porphyrin pyrrole groups, followed by the peripheral amino groups. When there are two or more aminophenyl substituents, the interior porphyrin pyrrole groups become more basic and protonate along with the pyridyl groups (we could not distinguish separate protonation stages for $\mathbf{A} 3 \mathbf{P y} \mathbf{P}$ or cis or trans $\left.\mathbf{A}_{2} \mathbf{P y} \mathbf{y}_{2} \mathbf{P}\right)$. The aminophenyl groups consistently protonate last; in the molecules under study, they are involved in electron donation to the hyperporphyrin and bear partial positive charge.

Quantitative measures of basicities were determined by monitoring the acid titrations at three or more distinct wavelengths to distinguish the relative concentrations of different species at different points in the titrations, using the 
method of Splan ${ }^{12}$ and Rudine. An apparent $\mathrm{pK}_{\mathrm{a}}$ value was obtained from the interpolated point at which the acid concentration was sufficient to generate equal concentrations of both the acid and conjugate base forms. These are considered apparent $\mathrm{pK}_{\mathrm{a}}$ values because of the nonaqueous solvent (DMSO) and the unidentified state of ionization of MSA. Nevertheless, they are useful indicators of the relative basicity of the different derivatives, which are tabulated in Table 2. Because of the unique spectrum obtained for $\mathbf{A}_{3} \mathbf{P y P H}_{3}{ }^{+3}$, we also investigated other triaminosubstituted porphyrins, and these are included in the table as well.

Table 2. Apparent pKa values (half-equivalence points) for the various protonated forms of the porphyrins. Parenthetical indications denote whether the protonation is assigned to pyridyl (Py), porphyrin pyrrole (P), or aminophenyl (A) groups.

\begin{tabular}{|c|c|c|c|c|c|}
\hline Porphyrin (P) & $\mathbf{P H}_{2}{ }^{+2}$ & $\mathbf{P H}_{3}{ }^{+3}$ & $\mathrm{PH}_{4}{ }^{+4}$ & $\mathbf{P H}_{5}^{+5}$ & $\mathbf{P H}_{6}{ }^{+6}$ \\
\hline trans- $\mathrm{Ph}_{2} \mathrm{Py}_{2} \mathrm{P}$ & $2.53(\mathrm{Py})$ & & $0.72(\mathrm{P})$ & & \\
\hline cis- $\mathrm{Ph}_{2} \mathrm{Py}_{2} \mathbf{P}$ & $2.68(\mathrm{Py})$ & & $1.0(\mathrm{P})$ & & \\
\hline $\mathbf{A P y}_{3} \mathbf{P}$ & & $1.82(\mathrm{Py})$ & & $0.37(\mathrm{P})$ & $-0.32(\mathrm{~A})$ \\
\hline $\operatorname{trans}-\mathbf{A}_{2} \mathbf{P y} y_{2} \mathbf{P}$ & & & $2.43(\mathrm{Py}, \mathrm{P})$ & & $0.21(\mathrm{~A})$ \\
\hline cis- $\mathbf{A}_{2} \mathbf{P y}_{2} \mathbf{P}$ & & & $2.38(\mathrm{Py}, \mathrm{P})$ & & $0.16(\mathrm{~A})$ \\
\hline $\mathbf{A}_{3} \mathbf{P y P}$ & & $3.5(\mathrm{Py}, \mathrm{P})$ & & $0.84(\mathrm{~A})$ & $-0.03(\mathrm{~A})$ \\
\hline
\end{tabular}




\begin{tabular}{|c|c|l|l|l|l|}
\hline TAPP & $4.57(\mathrm{P})$ & & $1.86(\mathrm{~A})$ & & $0.37(\mathrm{~A})$ \\
\hline $\mathbf{A} \mathbf{3} \mathbf{C M P P}$ & $3.8^{\mathrm{a}}(\mathrm{P})$ & & & $0.5^{\mathrm{a}}(\mathrm{A})$ & \\
\hline $\mathbf{A} \mathbf{M} \mathbf{M P P}$ & $4.0(\mathrm{P})$ & & & $0.78(\mathrm{~A})$ & \\
\hline $\mathbf{Z n T P y P}$ & & & $3.72(\mathrm{Py})$ & & \\
\hline
\end{tabular}

Data from ref 32.

\subsection{Discussion}

The most common examples of hyperporphyrin effects occur with strong electron-donating groups available to promote charge-transfer interactions with positively charged sites on the interior of a protonated porphyrin. We have previously reported such hyperporphyrin effects of 4-aminophenyl groups, which are strong electron donors by resonance effects, studying a complete series of derivatives with either 4-aminophenyl or 4-carbomethoxyphenyl substituents. ${ }^{32}$ In this study, we have examined a similar series with either 4-aminophenyl or 4-pyridyl as the substituents. Although the pyridyl groups are similarly electron withdrawing, comparable to carbomethoxyphenyl, the additional complexity is that the pyridyl groups are readily protonated, creating an even stronger electron-withdrawing effect. We propose that under certain circumstances the protonated pyridyl groups can also take part in charge-transfer interactions with the aminophenyl groups via resonance effects through the porphyrin ring. 
In the series we studied, a typical porphyrin has multiple possible sites for protonation - the interior of the porphyrin, the pyridyl substituents, and the aminophenyl substituents. The reported acid titration of TPyP led to the conclusion that the peripheral pyridyl groups protonate before the porphyrin interior, ${ }^{70}$ which is consistent with our observations of the spectroscopy of protonated ZnTPyP (which cannot protonate on the interior) (Figure 8) and $\mathbf{T M P y P} \mathbf{P}^{+4}$ (where the methylated pyridinium groups simulate protonated pyridyl groups) (Figure 9).

Acid titration of $\mathbf{A P y}_{3} \mathbf{P}$ showed subtle but distinctive spectra indicating all three protonations: first the three pyridyl groups, then the porphyrin interior, then the amino group (Figure 12). Protonation of the pyridyl groups first was consistently observed until two or more aminophenyl substituents were present; these groups apparently enhance the basicity of the interior porphyrin pyrrole groups, so for the cis and trans isomers of $\mathbf{A}_{2} \mathbf{P y} \mathbf{y}_{2} \mathbf{P}$ as well as for $\mathbf{A} 3 \mathbf{P y P}$, it was not possible to detect separately the protonation of the pyridyl groups and the protonation of the porphyrin pyrroles.

Examining the trends in $\mathrm{pK}_{\mathrm{a}}$ values in Table 2, pyridyl groups are relatively consistent in their basicity, although multiple electron-donating amino groups distinctly improve basicity. Basicity of the porphyrin pyrrole groups, however, is strongly affected by amino groups. As one to four amino groups are added, relative $\mathrm{pK}_{\mathrm{a}}$ values increase: $0.3,2.43$ or $2.38,3.5,4.57$. Part of this trend is likely due to the effects of the electron-withdrawing pyridinium substituents that would decrease basicity; as more amino groups are added, fewer pyridinium groups are necessarily present. This effect can be normalized by comparison with the unsubstituted phenyl 
derivatives; even with two pyridinium substituents, the $\mathrm{pK}_{\mathrm{a}}$ of the porphyrin of trans or cis $\mathbf{P h}_{2} \mathbf{P y} \mathbf{y}_{2} \mathbf{P}$ (0.72 or 1.0) is significantly lower (less basic) than that of $\mathbf{A}_{2} \mathbf{P} \mathbf{y}_{2} \mathbf{P}$ (2.43 or 2.38). Thus the amino groups provide the dominant effect in increasing basicity.

Aminophenyl groups always protonate last. Since the aminophenyl groups provide effective stabilization of the protonated porphyrin via hyperporphyrin resonance, they already bear a partial positive charge and protonation to an ammonium ion would cause a loss of the resonance stabilization. The $\mathrm{pK}_{\mathrm{a}}$ values roughly correlate with the overall charge on the molecule, i.e., forming a +6 state requires more acid than forming $\mathrm{a}+5$ or +4 state.

The importance of the amino groups for the hyperporphyrin spectral effect is also emphasized by comparisons with the acid titrations of the $\mathbf{P h}_{2} \mathbf{P y}_{2} \mathbf{P}$ derivatives (Figures 10 and 11). These porphyrins protonate essentially identically to TPyP, i.e., first the pyridyl groups protonate, then the porphyrin pyrroles protonate. No hyperporphyrin spectral effects are detectable at any stage, indicating that simple phenyl groups are not suitable to generate hyperporphyrin effects.

Significant hyperporphyrin effects are seen with two or more aminophenyl groups (Figures 13-16). Although the initial protonations on the pyridyl groups are relatively localized, the two positive charges generated by protonation of the interior pyrrole groups can be delocalized. A variety of different resonance forms can be generated to illustrate the sites for delocalization of these positive charges. For this, we apply (and extend) the Gouterman framework for porphyrin spectroscopy, 
specifically for anomalous porphyrin spectroscopy such as hyperporphyrins. ${ }^{6,44}$ In this framework, A type spectra are normal porphyrin spectra, in which the four meso substituents do not interact significantly with the porphyrin ring; there are both neutral and diprotonated A type spectra. When meso substituents are capable of strong interaction with the porphyrin $\pi$ system, however, the chromophore can be extended significantly beyond the porphyrin core and anomalous spectra result. In a $\mathbf{B}$ type spectrum, one such substituent interacts, while in a $\mathbf{C}$ type spectrum, two such substituents interact.

Figure 18 illustrates both $\mathbf{A}$ and $\mathbf{B}$ types of resonance forms for trans- $\mathrm{A}_{2} \mathrm{Py}_{2} \mathbf{P H}_{4}{ }^{+4}$. Note that we are correlating the terminology of the anomalous spectral types in the Gouterman formalism with the resonance forms that we propose give rise to the anomalous spectra. The parenthetical numbers in Figures 18-20 indicate the number of unique sites to which the charge may be delocalized using that type of resonance; the total number of resonance forms will be much larger. In the case of trans- $\mathbf{A}_{2} \mathbf{P y}_{2} \mathbf{P H}_{4}{ }^{+4}$, there are two unique aminophenyl groups that could delocalize the charge as in the $\mathbf{B}$ type form. Note that fully protonated porphyrins will necessarily revert back to the A type spectrum, since the strongly interacting amino groups become noninteracting ammonium ions once protonated.

Note that a single amino substituent, as in $\mathbf{A P y} \mathbf{P} \mathbf{P}$, will give rise to a set of resonance forms similar to those of trans (although only one $\mathbf{B}$ possibility), and $\mathbf{A P y}_{3} \mathbf{P H}_{5}{ }^{+5}$ displays a similarly weak hyperporphyrin effect. 


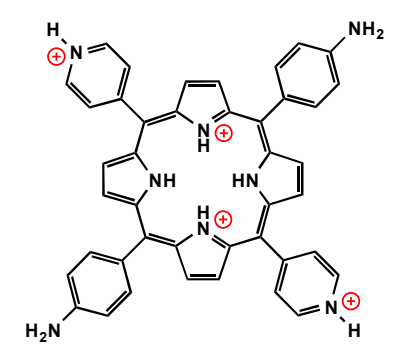

Type A

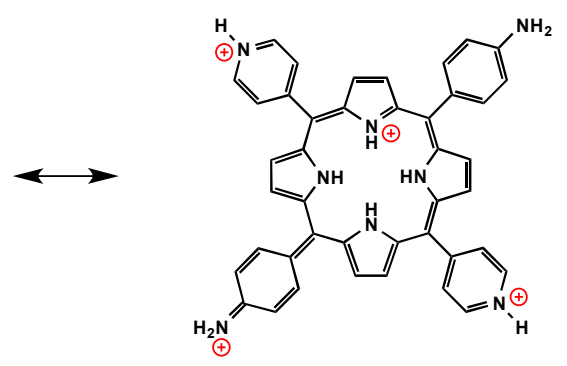

Type B (2)

Figure 18. Hyperporphyrin resonance forms for trans- $\mathbf{A}_{2} \mathbf{P y}_{2} \mathbf{P H}_{4}{ }^{+4}$.

$\mathbf{A}$ and $\mathbf{B}$ types are discussed in the text.

Careful manipulation of the available resonance forms will show that delocalization of both positive charges cannot be accomplished when the donor groups are trans. For donor groups at cis meso positions, however, both charges may be delocalized simultaneously generating the $\mathbf{C}$ type resonance form (Figure 19). Thus cis- $\mathbf{A}_{2} \mathbf{P y}_{2} \mathbf{P H}_{4}{ }^{+4}$ has an additional type of resonance form, unavailable to the trans isomer, and the observation is a much stronger hyperporphyrin effect (compare Figures 13 and 14).

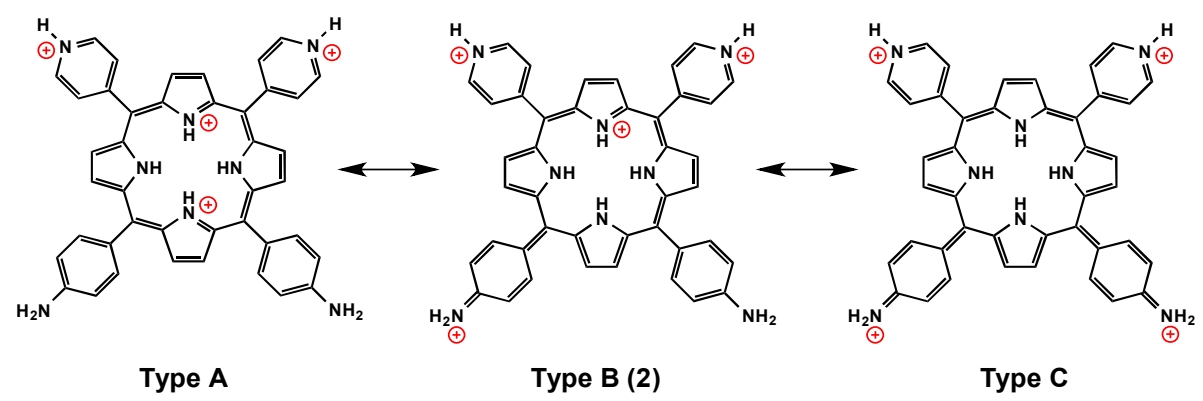

Figure 19. Hyperporphyrin resonance forms for cis- $\mathbf{A}_{2} \mathbf{P y}_{2} \mathbf{P H}_{4}{ }^{+4} . \mathbf{A}, \mathbf{B}$, and $\mathbf{C}$ types 
are discussed in the text.

With three aminophenyl groups available, as in $\mathbf{A 3} \mathbf{P y P}$, a novel situation arises (Figure 20). There are three unique aminophenyl sites for type $\mathbf{B}$ resonance and two different cis orientations that could lead to $\mathbf{C}$ type resonance. However, the type $\mathbf{C}$ form leaves still one more available aminophenyl group. We propose that yet another type of resonance form is possible, which we call type D. In this case, the third aminophenyl group provides electron donation to the protonated pyridinium group, leading to a novel type of resonance form in which all four meso groups are interacting through the porphyrin core. The hyperporphyrin effect in $\mathbf{A}_{3} \mathbf{P y} \mathbf{P H}_{3}{ }^{+\mathbf{3}}$ is remarkably strong, comparable to that observed for $\mathbf{T A P P H} \mathbf{P}^{+2}$, and we propose that this additional type D resonance delocalization contributes to the strengthened hyperporphyrin effect. As with $\mathbf{T A P P H} \mathbf{H}^{+2}$, all four substituents can be involved in resonance with the porphyrin core. 


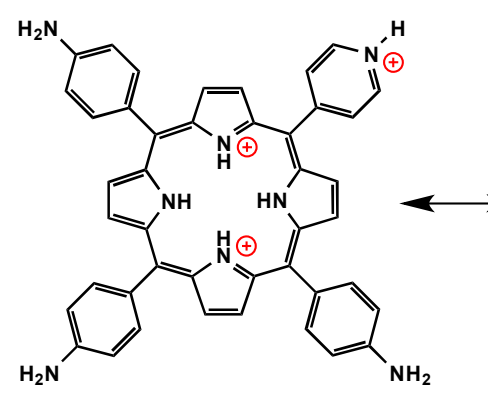

Type A

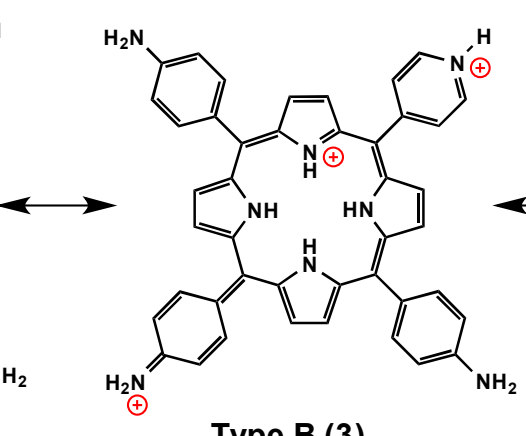

Type B (3)

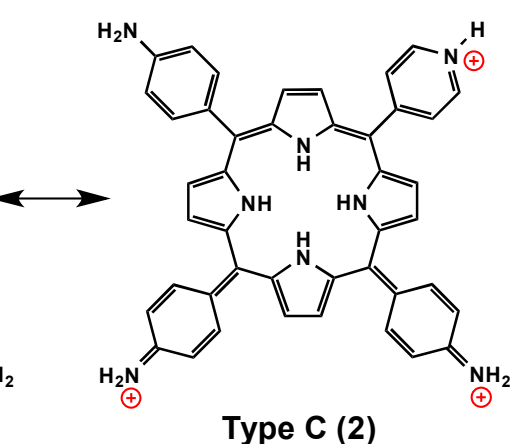

Type C (2)

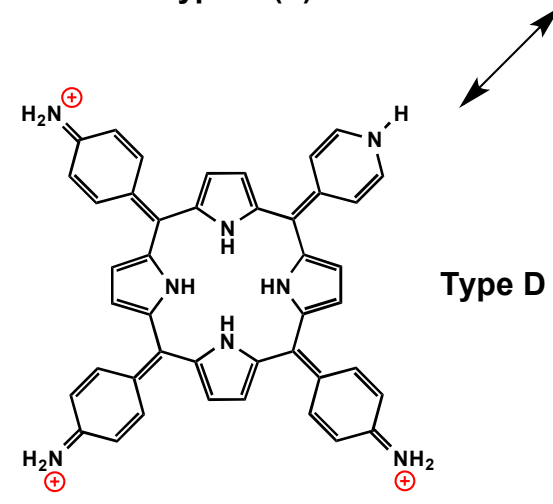

Figure 20. Hyperporphyrin resonance forms for $\mathbf{A}_{3} \mathbf{P y P H}_{3}{ }^{+3}$. A, B, C, and $\mathbf{D}$ types are discussed in the text.

Overall, the spectral trends observed can be correlated by the wavelength position and intensity of the red hyperporphyrin band as well as the wavelength position and intensity of the split Soret band. Increasing numbers of aminophenyl groups lead to a more intense and red-shifted hyperporphyrin band, as well as a more intense split Soret band. We tabulate these as ratios of extinction coefficients in Table 3, and also indicate the number of unique positions for each type of resonance form as an indicator of the extent of resonance delocalization possible.

In order to determine whether the protonation behavior of $\mathbf{A 3}_{\mathbf{3}} \mathbf{P y P}$ was unusual, 
we also examined other cases of tris(p-aminophenyl)porphyrins. We had earlier published results including a carbomethoxy derivative (A3CMP). ${ }^{32}$ However, like a pyridinium group, the carbomethoxy group is electron withdrawing and could engage in a similar push-pull resonance effect. Therefore we synthesized a methyl derivative for this study (A3MP), where the methyl group is electron donating and cannot partake in resonance effects. Results from both are included in Table 3 below.

Where there are more than two amino groups available for resonance, it becomes possible to protonate one or more while still leaving two available for hyperporphyrin effects. Thus in the case of TAPP, it is possible to observe a secondary hyperporphyrin spectrum in which two amino groups remain unprotonated, i.e., $\mathbf{T A P P H}_{4}{ }^{+4}$. In the case of $\mathbf{A}_{3} \mathbf{P y P}$, we could not clearly identify such a spectrum, but it seemed clear that there were other hyperporphyrin states present between the +3 and +5 states (see Figure 15). Data for these are included in the comparisons with the other hyperporphyrins below.

Table 3. Relative positions and intensities of the split Soret band and the far red band in the hyperporphyrin spectra of the various derivatives. Relative positions and intensities of the split Soret band and the far red band in the hyperporphyrin spectra of the various derivatives, correlated with the number of unique resonance forms of each type. 


\begin{tabular}{|c|c|c|c|c|c|}
\hline Hyperporphyrin & Split Soret (ratio) & Far red band $(\varepsilon)^{b}$ & Type B & Type C & Type D \\
\hline $\mathrm{APy}_{3} \mathbf{P H}_{5}{ }^{+5}$ & $423,517(0.067)$ & $726(6)$ & 1 & 0 & 0 \\
\hline $\operatorname{trans}-\mathrm{A}_{2} \mathrm{Py}_{2} \mathrm{PH}_{4}{ }^{+4}$ & $422,516(0.089)$ & $726(4)$ & 2 & 0 & 0 \\
\hline cis- $\mathrm{A}_{2} \mathrm{Py}_{2} \mathrm{PH}_{4}{ }^{+4}$ & $422,512(0.145)$ & $767(16)$ & 2 & 1 & 0 \\
\hline $\mathrm{TAPPH}_{2}{ }^{+2}$ & $390,467(3.42)$ & $813(89)$ & 4 & 4 & 0 \\
\hline TAPPH $_{4}{ }^{+4}$ & $417,474(1.72)$ & $786(67)$ & 2 & 1 & 0 \\
\hline $\mathbf{A}_{3} \mathbf{P y P H}_{3}{ }^{+3}$ & $403,478(1.84)$ & $781(84)$ & 3 & 2 & 1 \\
\hline $\mathbf{A}_{3} \mathrm{PyPH}_{5}{ }^{+5}$ & $438,496(0.47)$ & 740 (49) & 2 & 1 & 0 \\
\hline $\mathbf{A}_{3} \mathbf{M P H}_{2}{ }^{+2}$ & $420,474(1.35)$ & $785(56)$ & 3 & 2 & 0 \\
\hline $\mathbf{A}_{3} \mathrm{CMPH}_{2}{ }^{+2} \mathrm{c}$ & $420,480(1.21)$ & $784(53)$ & 3 & 2 & 0 \\
\hline
\end{tabular}

a Soret peaks $(\mathrm{nm})$ and ratio of extinction coefficients (longer wavelength/shorter wavelength)

b Far red hyperporphyrin band (nm) and extinction coefficient $\left(x 10^{3} \mathrm{M}^{-1} \mathrm{~cm}^{-1}\right)$

c Data from ref 32.

Comparing the hyperporphyrin effects of the three triamino derivatives, we conclude that the pyridinium group has a significant effect on the hyperporphyrin band extinction coefficient $\left(84,000\right.$ vs. 56,000 or $\left.53,000 \mathrm{M}^{-1} \mathrm{~cm}^{-1}\right)$ as well as the wavelength of the high-energy Soret peak (403 nm vs. $420 \mathrm{~nm}$ ). Thus we propose 
that forms of type $\mathbf{D}$ are uniquely significant in the structure of this particular hyperporphyrin. Structures of type $\mathbf{D}$ have been observed before and are generally categorized as oxoporphyrinogens. ${ }^{71}$ Porphyrinogens are saturated at the meso positions, while oxoporphyrinogens show exocyclic $\pi$ bonds at the meso positions. Oxoporphyrinogens are often tautomeric forms, e.g., of p-hydroxyphenylporphyrins. ${ }^{71}$

We have been particularly interested in pyridyl derivatives as part of push-pull photosensitizers, considering that structures of type $\mathbf{D}$ might be able to utilize the reduced pyridine ring as a hydride donor. As such, electron-rich pyridinium could serve as a two-electron reducing agent, somewhat analogous to NADH. Hydride loss would lead to restoration of the pyridine aromatic ring and oxidation of the porphyrin, as indicated in Figure 15. Experiments are underway to determine if this proposed chemistry can be made to occur in either stoichiometric or catalytic fashion, using either electrochemical or photochemical stimulation. We cite the example of $\mathrm{CO}_{2}$ reduction because pyridine has been reported as an effective catalyst for photoreduction of $\mathrm{CO}_{2} \cdot{ }^{60,62}$
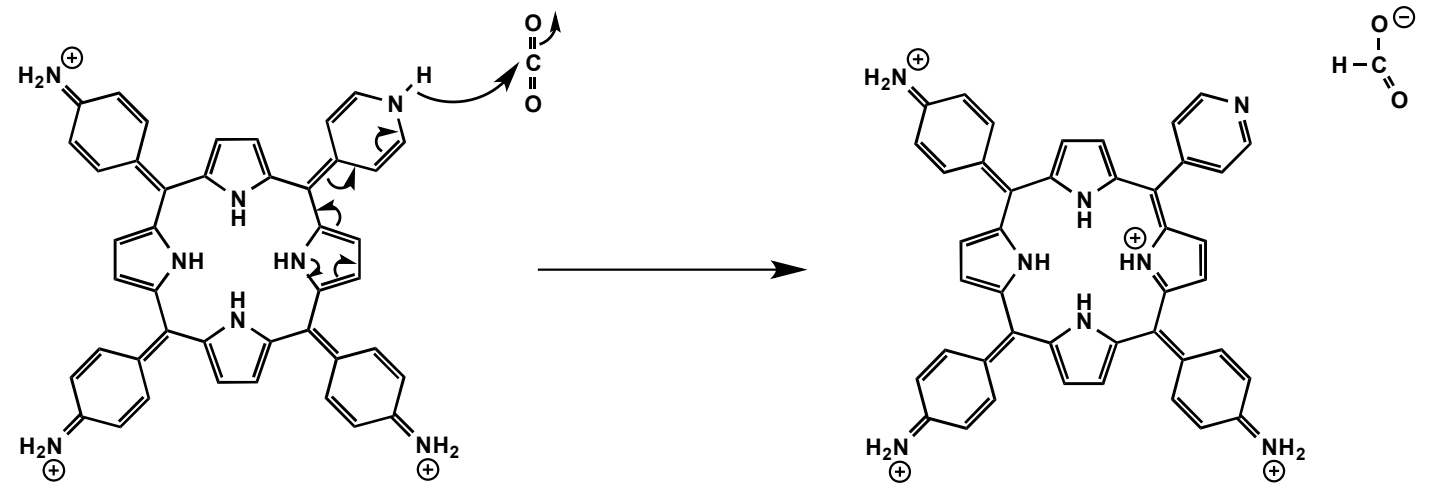

Figure 21. Proposed use of a type D hyperporphyrin structure as a hydride donor. 


\section{Chapter 4. Proton NMR of Protonated Aminophenyl/Pyridyl Porphyrins}

One difficulty of analyzing the NMR spectra of hyperporphyrins induced by protonation is that sometimes the spectra are too complicated because of the multiple possible protonation states. ${ }^{45}$ Spectroscopy using a thin-layer cell was adopted here to address this problem by identifying the protonation state via UV-vis spectroscopy of the same solution used for the NMR spectra. In many of the spectra a very strong broad peak goes off-scale; this is the water peak, which is unavoidable in these experiments.

The basic structures of pyridyl porphyrins studied here are shown in Fig. 22. The protons at different positions are labeled with abbreviations for the corresponding positions: $\mathrm{A}=$ amino $\left(\mathrm{NH}_{2}\right), \mathrm{P}=$ porphyrin $(\mathrm{NH}), \mathrm{Pr}=$ pyrrole $(\beta), \mathrm{Ph}=$ phenyl (o or $\mathrm{m}$ ), Py=pyridyl (2 or 3$)$.

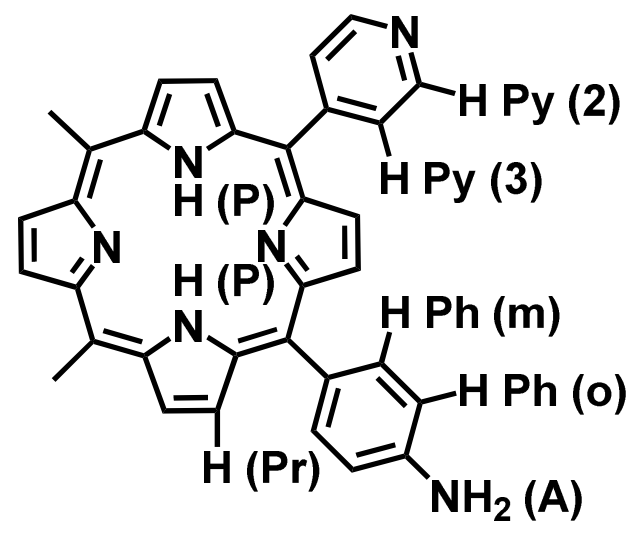

Figure 22. A general structure for aminophenyl/pyridyl porphyrins with notations used to designate individual hydrogens. 


\subsection{NMR spectra of protonated pyridyl porphyrins}

TPyP. Due to the insolubility of the free base in DMSO, a reference spectrum was taken in $\mathrm{CDCl}_{3}$ (Figure 23). The free base TPyP spectrum in chloroform-D showed peaks at $-2.93(2 \mathrm{H}, \mathrm{br}, \mathrm{s}, \mathrm{NH}), 8.15-8.17$ (8H, Py-3, dd), 9.06-9.07 (8H, Py-2, dd), $8.87(8 \mathrm{H}, \mathrm{Pr}, \mathrm{s})$. In order to solublize TPyP, it was purposely acidified beforehand with MSA in DMSO. The initial protonation state was determined to be $\mathbf{T P y P H}{ }_{4}^{+4}$ by the NMR spectra (Fig. 24 (a)), in which the four peripheral pyridyl groups are protonated. The solvent effect on the NMR spectra of TPyP is minimal, considering the two pyrrolic N-Hs (-2.93 ppm in $\mathrm{CHCl}_{3}-\mathrm{D}$ and $-3.08 \mathrm{ppm}$ in DMSO-D); thus the two spectra are considered to be comparable. During the stage from TPyP to $\mathbf{T P y P H}_{4}{ }^{+4}$, the protonation of the peripheral pyridyl groups moves all the pyridyl proton signals and $\beta$ pyrrole proton $\left(\mathrm{H}_{\beta}\right)$ signal downfield, which is understandable considering that the positive charges on the pyridinium groups deshield the protons on pyridyl groups and pyrrole $\beta$ positions. Further protonation happens to the internal nitrogens, $\left(\mathbf{T P y P H}_{\mathbf{6}}{ }^{+\mathbf{6}}\right)$ characterized by broadening and decreasing of the porphyrin $\mathrm{N}-\mathrm{H}$ signals and further downfield shift of the pyridyl proton on 2-position. Structurally, the protonation of the inner nitrogens makes the macrocycle distort from planar to nonplanar. ${ }^{11}$ Consequently the proton exchanges of the inner ring with the solution are easier and faster, which leads to the disappearance of the porphyrin $\mathrm{N}-\mathrm{H}$ signals. 


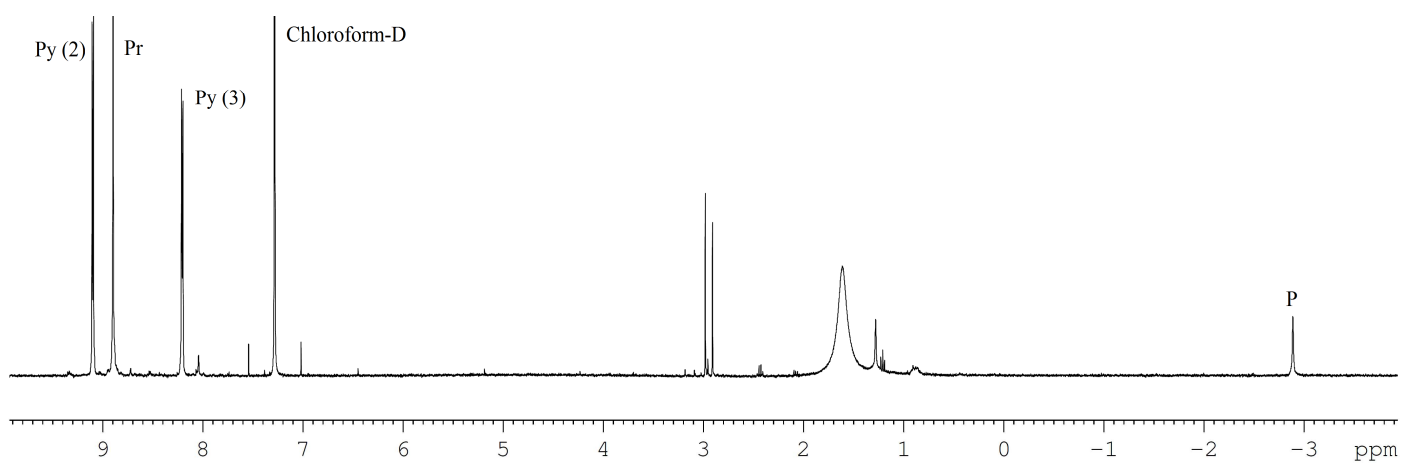

Figure 23. The NMR spectrum of free base TPyP in $\mathrm{CDCl}_{3}$.
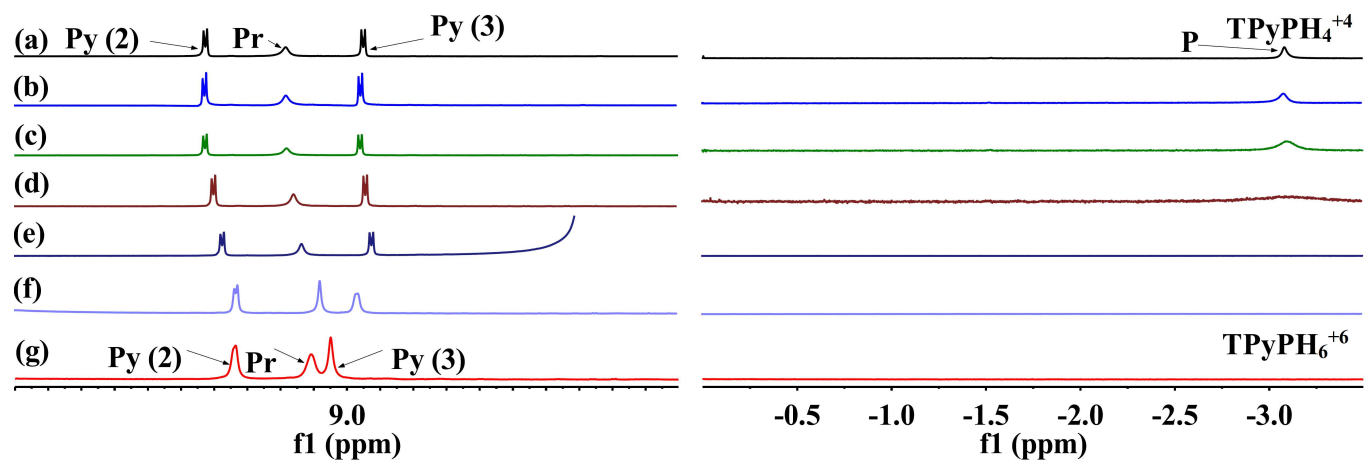

Figure 24. The 1 H-NMR spectra of $\mathbf{T P y P}$ protonation from $\mathbf{T P y P H}{ }^{+4}$ to $\mathbf{T P y P H}_{6}{ }^{+6}$ $(\mathrm{a}-\mathrm{g})$.

TAPP. Acid titrations of TAPP go through two stages (Fig. 25). In the first stage, the UV-vis spectroscopy shows that the Soret band at $440 \mathrm{~nm}$ first splits into two bands at $390 \mathrm{~nm}$ and $466 \mathrm{~nm}$. All the Q bands disappear and a huge absorbance at 808 $\mathrm{nm}$ grows in, all characteristic of protonating the interior porphyrin nitrogens which initiates charge transfer to the aminophenyl groups and thus produces the hyperporphyrin effect (Fig.25 (I)). ${ }^{44}$ In the NMR spectrum of this stage (TAPP $\rightarrow$ 
TAPPH $^{+2}$ ) (Fig. 25 (III)), substantial changes can be observed on the aromatic protons, which move downfield by $0.25-0.49 \mathrm{ppm}$. Meanwhile, the pyrrole $\mathrm{H}_{\beta}$ and the internal $\mathrm{N}-\mathrm{H}$ moves upfield and downfield by $0.59 \mathrm{ppm}$ and $3.5 \mathrm{ppm}$ respectively, indicating loss of the aromaticity of the porphyrin ring. The movement of amino proton signal is also worth noting. Upon acid titration, the original signal at $5.56 \mathrm{ppm}$ is gradually replaced by the new one at $6.41 \mathrm{ppm}$. More importantly, both the spectra of free base and the diprotonated base coexist during this stage, indicating the proton exchange is a slow process.

In the second stage of the titration, protons attack the aminophenyl groups and force the positive charges back onto the pyrrolic N-Hs, resulting in the fully protonated porphyrin $\left(\mathbf{T A P P H}_{\mathbf{6}}{ }^{+6}\right)$. The spectroscopy here is characterized by a growth of Soret band from $390 \mathrm{~nm}$ to $443 \mathrm{~nm}$, disappearance of Soret band at 467 ppm and a $\mathrm{Q}$ absorbance at $659 \mathrm{~nm}$ (Fig. 25 (III)). In the NMR spectra, all the aromatic protons and the pyrrole $\mathrm{H}_{\beta}$ move downfield by $0.41-0.76 \mathrm{ppm}$, along with the disappearance of $-\mathrm{NH}_{2}$. The internal $\mathrm{N}-\mathrm{H}$ signal moves upfield to $-0.7 \mathrm{ppm}$ and broadens (Fig. 25 (IV)). 


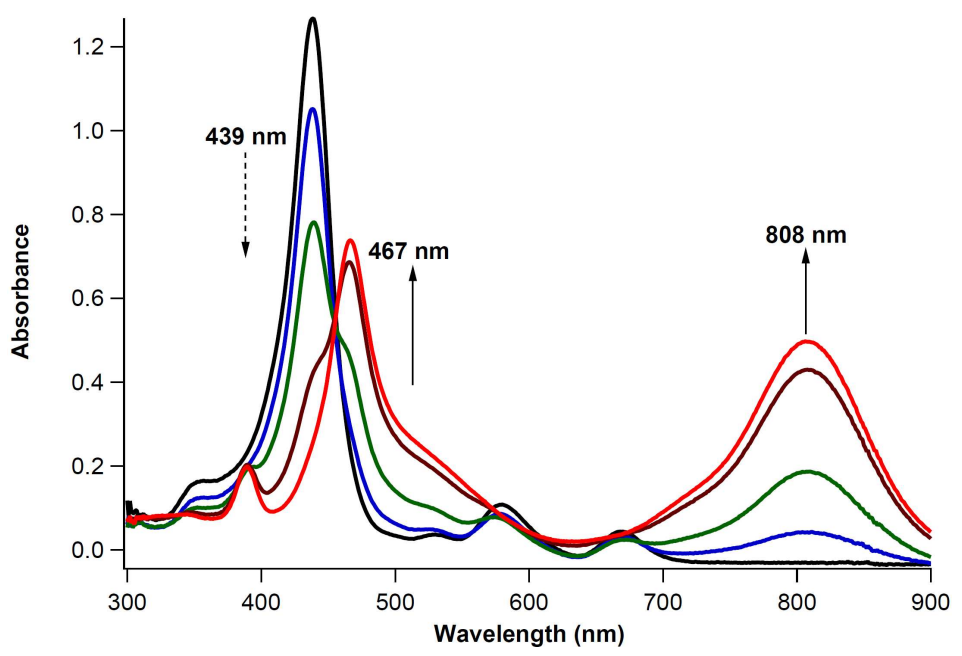

(I)
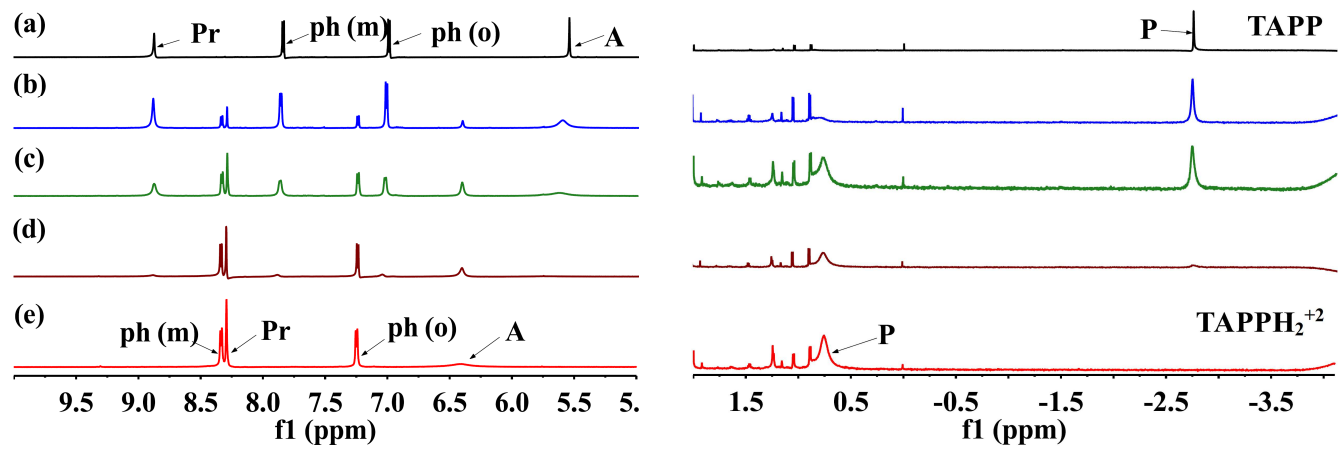

(II)



(III) 

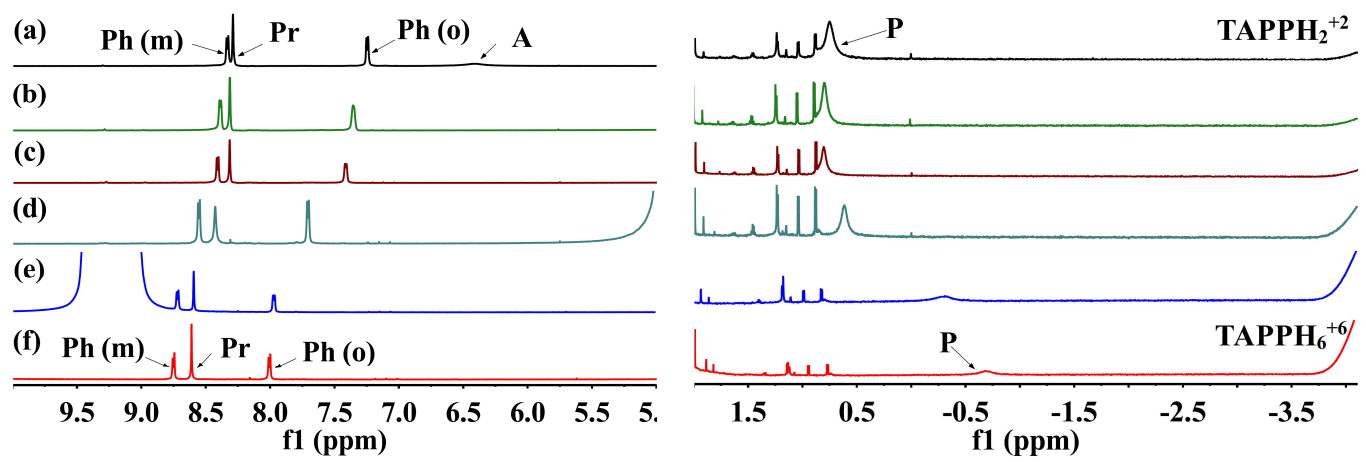

(IV)

Figure 25. The 1 H-NMR spectra of TAPP protonation from TAPP to TAPPHz ${ }^{+2}$.

(I) UV-vis spectroscopy, (II) the NMR spectra (color coordinated with (I)); from

TAPPH $_{2}{ }^{+2}$ to TAPPH $_{6}{ }^{+6}$ : (III) UV-vis spectroscopy, (IV) the NMR spectra (color coordinated with (III)).

A3PyP. Both the spectroscopy and the NMR spectral changes of $\mathbf{A}_{3} \mathbf{P y} \mathbf{P}$ are comparable to those of TAPP (Fig. 26). The initial protonations also occur on the interior porphyrin nitrogens and induce the hyperporphyrin effect $\left(\mathbf{A}_{3} \mathbf{P y P H} \mathbf{H}^{+3}\right)$. The unique feature of $\mathbf{A}_{3} \mathbf{P y P H}_{3}{ }^{+3}$ is that an additional resonance can take place between the pyridinium and the remaining aminophenyl group, thus creating a novel hyperporphyrin effect, which we call the type D hyperporphyrin. In the UV-vis spectroscopy, this additional resonance effect produces a large absorbance in the hyperporphyrin region at $788 \mathrm{~nm}$ (Fig. 26 (I)). In the NMR spectrum (Fig. 26 (II)), the difference leads to the phenyl signals split into two groups with the intensity ratio close to $2: 1$, which can be explained as two aminophenyl groups in the cis orientation 
to the pyridyl group can either interact with the protonated pyrrolic $\mathrm{N}-\mathrm{H}$ or the protonated pyridyl group, while the remaining aminophenyl in the trans orientation can only interact with the internal nitrogens. The $2: 1$ amino $\left(-\mathrm{NH}_{2}\right)$ peaks can also be explained in the same way. The changes of pyridinium proton signals here are also interesting and will be discussed in detail later. The free base and the hyperporphyrin are in slow exchange judging by the coexistence of signals for both forms. The internal N-H signals also move downfield and also splits into two signals, especially notable in the spectrum prior to the hyperporphyrin (Fig. 26 (II) (e)).

As with TAPP, the final stage of titration to $\mathbf{A}_{3} \mathbf{P y P H}_{6}{ }^{+6}$ also features the deformation of the hyperporphyrin, which shows in the spectroscopy as the growth of one Soret band at $447 \mathrm{~nm}$ from $403 \mathrm{~nm}$ and the development of one Q band at $650 \mathrm{~nm}$ from hyperporphyrin band at $788 \mathrm{~nm}$ (Fig. 26 (III)). In the NMR spectrum (Fig. 26 (IV)), this process is characterized by the gradual downfield shift of all the proton signals, suggesting rapid proton exchange.

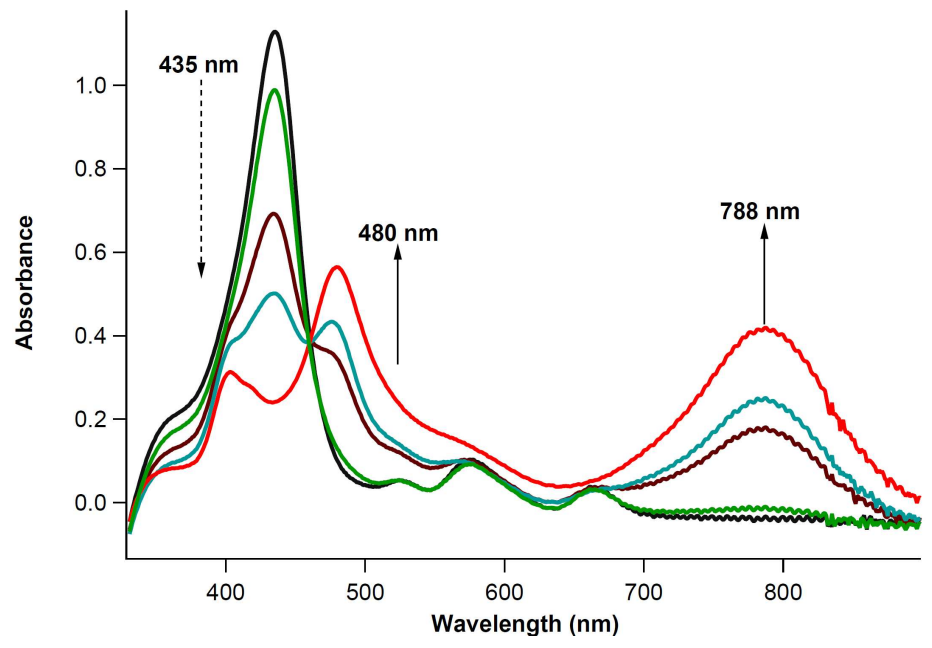


(I)
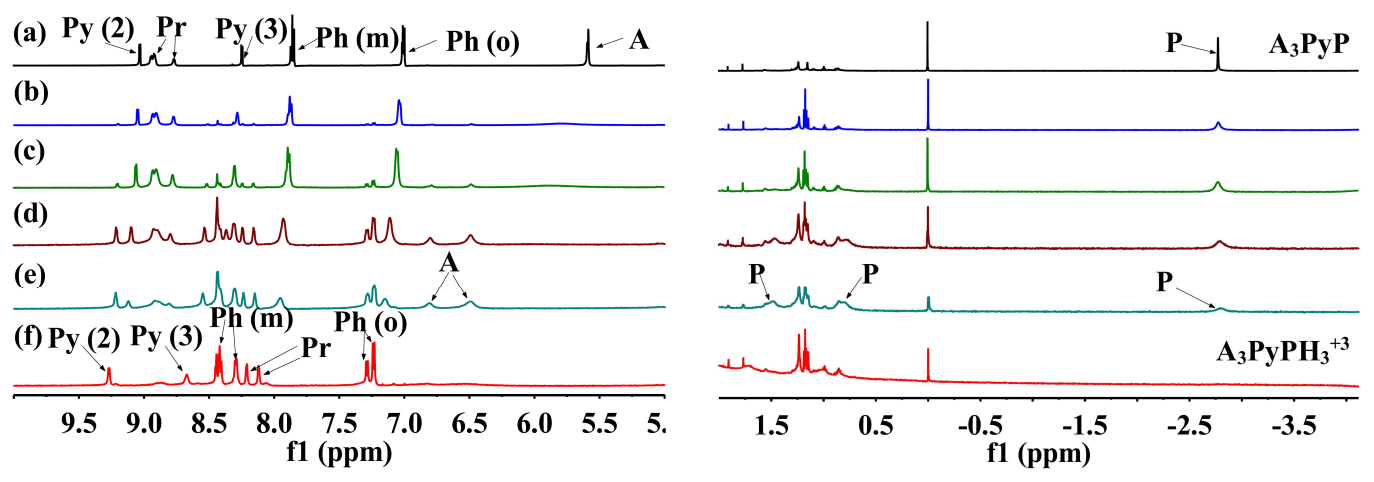

(II)

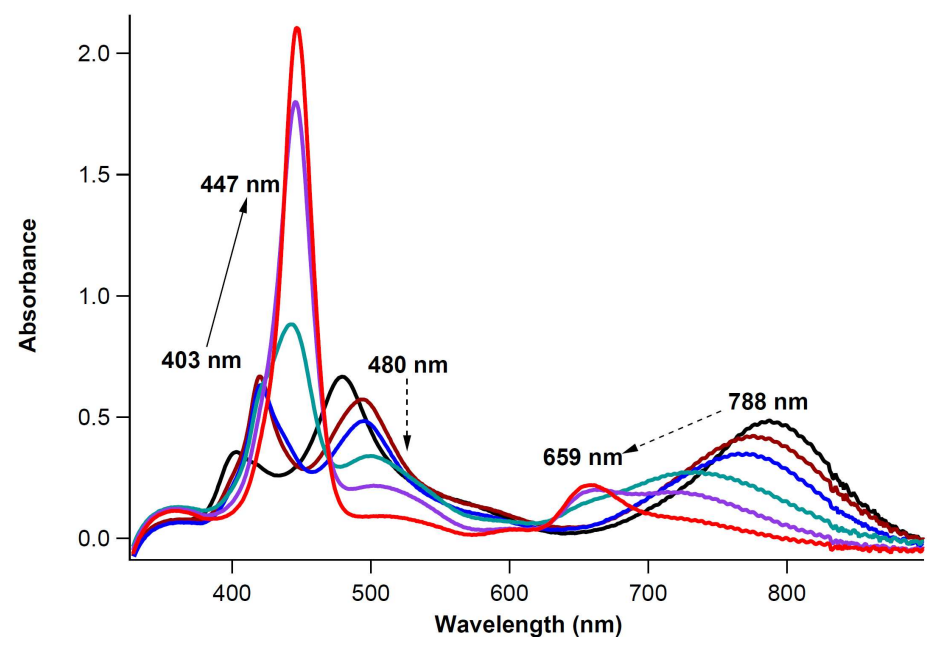

(III)

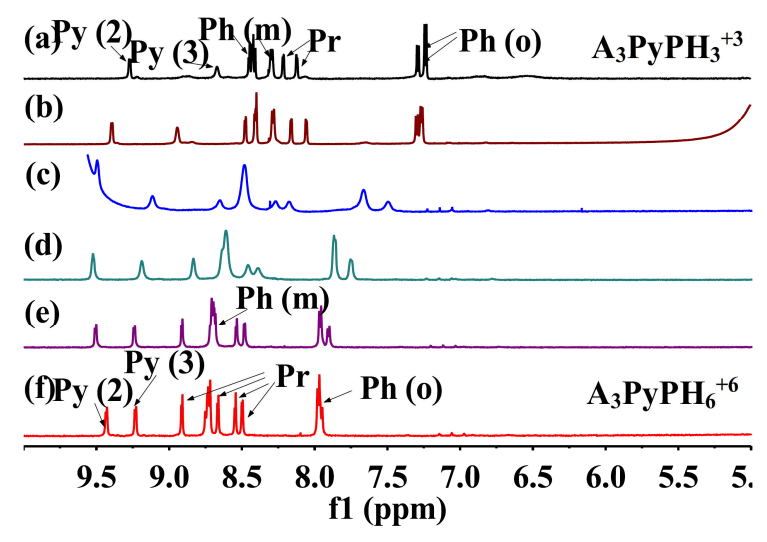

(IV) 
Figure 26. The 1 H-NMR spectra of $\mathbf{A} 3 \mathbf{P y P}$ protonation from $\mathbf{A} 3 \mathbf{P y P}$ to $\mathbf{A} 3 \mathbf{P y} \mathbf{P} \mathbf{H}_{3}{ }^{+3}$.

(I) UV-vis spectroscopy, (II) the NMR spectra (color coordinated with (I)); from $\mathbf{A}_{3} \mathbf{P y P H}_{3}{ }^{+3}$ to $\mathbf{A}_{3} \mathbf{P y P H}_{6}{ }^{+6}$ : (III) UV-vis spectroscopy, (IV) the NMR spectra (color coordinated with (III)).

cis- $\mathbf{A}_{2} \mathbf{P y} \mathbf{y}_{2} \mathbf{P} \& \mathbf{A P y} \mathbf{P}$. The NMR spectra of protonated cis- $\mathbf{A}_{2} \mathbf{P y} \mathbf{y}_{2} \mathbf{P}$ and $\mathbf{A P y}_{3} \mathbf{P}$ are discussed together here because of their similarities. They are also of somewhat less interest and are substantially more complex. Two stages can be traced in both of their acid titrations. In cis- $\mathbf{A}_{2} \mathbf{P} \mathbf{y}_{2} \mathbf{P}$, protonations first happen on both the porphyrin nitrogens and the pyridyl groups, generating a small blue shift and decrease of the Soret band at $422 \mathrm{~nm}$, increased intensities of several Q bands (505, 546, and $586 \mathrm{~nm}$ ), and a large absorbance at $772 \mathrm{~nm}$ arising from the hyperporphyrin (Fig. 27 (I)). Meanwhile, three pyridyl groups of $\mathbf{A P y} 3 \mathbf{P}$ are protonated initially, leading to only small changes in the spectrum, such as the Soret band red shift from $416 \mathrm{~nm}$ to 422 nm (Fig. 28 (I)). The NMR spectra of both compounds at this stage (Fig. 27 (II) and Fig. 28 (II)) are characterized by downfield shifts of the protons on both the phenyl and pyridyl groups and disappearances of both amino $-\mathrm{NH}_{2}$ and porphyrin $\mathrm{N}-\mathrm{H}$ signals.

The second stage of acid titration on cis- $\mathbf{A}_{2} \mathbf{P y} 2 \mathbf{P}$, from $\operatorname{cis}-\mathbf{A}_{2} \mathbf{P y}_{2} \mathbf{P H}_{4}{ }^{+4}$ to cis- $\mathbf{A}_{2} \mathbf{P y}_{2} \mathbf{P H}_{6}{ }^{+6}$, occurs on the aminophenyl moieties, resulting in the fully protonated porphyrin. In the spectroscopy, the Soret band at $421 \mathrm{~nm}$ red shifts to $450 \mathrm{~nm}$, while the huge absorbance at $772 \mathrm{~nm}$ blue shifts to an absorbance at $655 \mathrm{~nm}$ (Fig. 27 (III)). 
Meanwhile, in $\mathbf{A P y} \mathbf{P} \mathbf{P}$, the porphyrin nitrogens are protonated, forming a weak hyperporphyrin via charge-transfer. Continued protonation on the aminophenyl group leads to the loss of hyperporphyrin and fully protonated porphyrin. These stages are not easily differentiated. The spectroscopy that describes these stages feature the Soret band red shift from $422 \mathrm{~nm}$ to $451 \mathrm{~nm}$, the development of a major Q band at $653 \mathrm{~nm}$, and a weak hyperporphyrin absorption in between (as shown in the inset of Fig. 28 (IV)). In both of the NMR spectra here (Fig. 27 (IV) and Fig. 28 (IV)), one of the phenyl protons in meta position and one of the pyridyl protons in ortho position keep moving downfield, while pyrrole $\mathrm{H}_{\beta}$ move upfield until they reach the original pyrrole position.

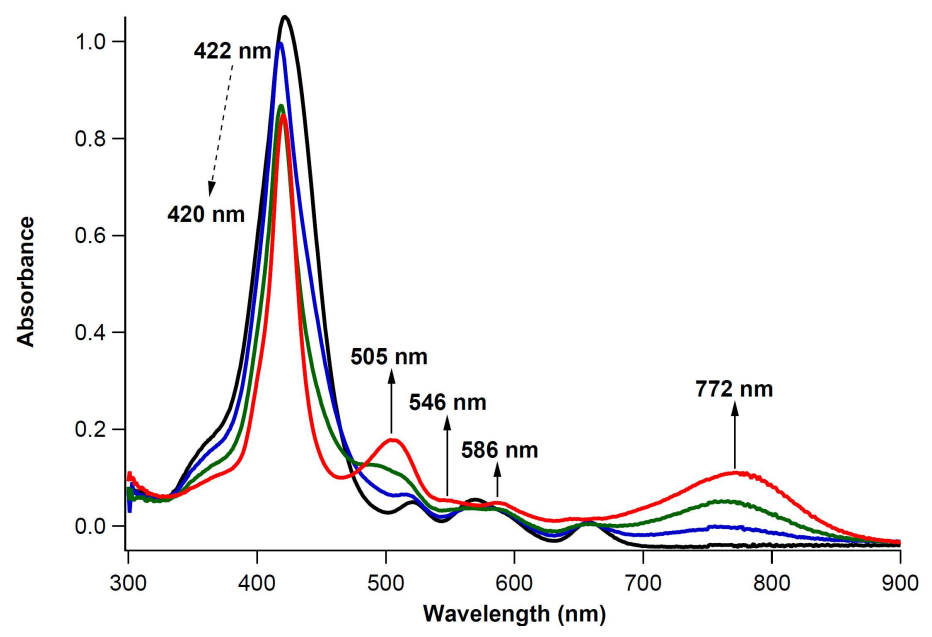

(I) 




(c)
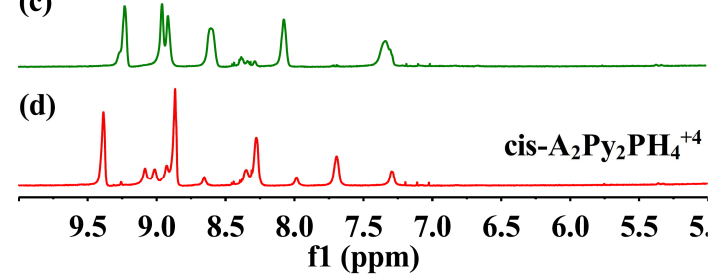

(II)

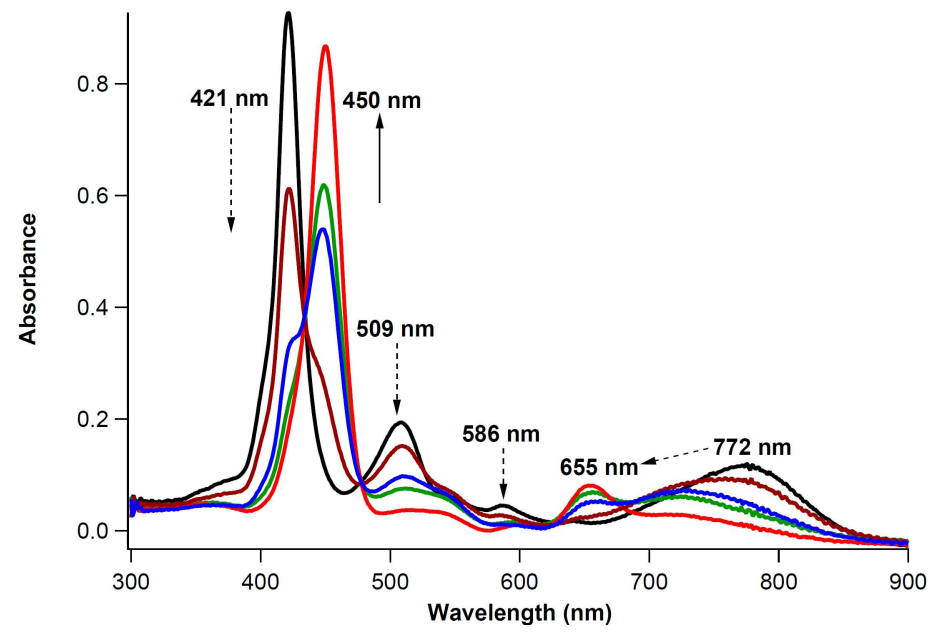

(III)

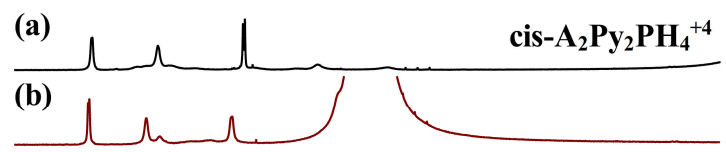

(c)
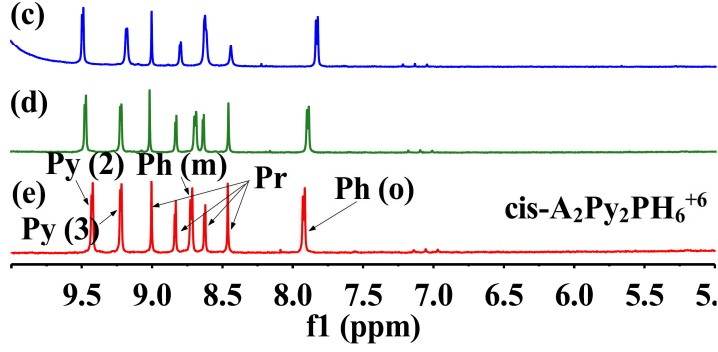

(IV)

Figure 27. The $1 \mathrm{H}-\mathrm{NMR}$ spectra of cis- $\mathbf{A}_{2} \mathbf{P y} \mathbf{y}_{2} \mathbf{P}$ protonation. 
from cis- $\mathbf{A}_{2} \mathbf{P y} 2 \mathbf{P}$ to cis- $\mathbf{A}_{2} \mathbf{P y} \mathbf{P H}_{2}{ }^{+4}$ : (I) UV-vis spectroscopy, (II) the NMR spectra (color coordinated with (I)); from cis- $\mathbf{A}_{2} \mathbf{P y}_{2} \mathbf{P H}_{4}{ }^{+4}$ to cis- $\mathbf{A}_{2} \mathbf{P y}_{2} \mathbf{P H}_{6}{ }^{+6}$ : (III) UV-vis spectroscopy, (IV) the NMR spectra (color coordinated with (III)).

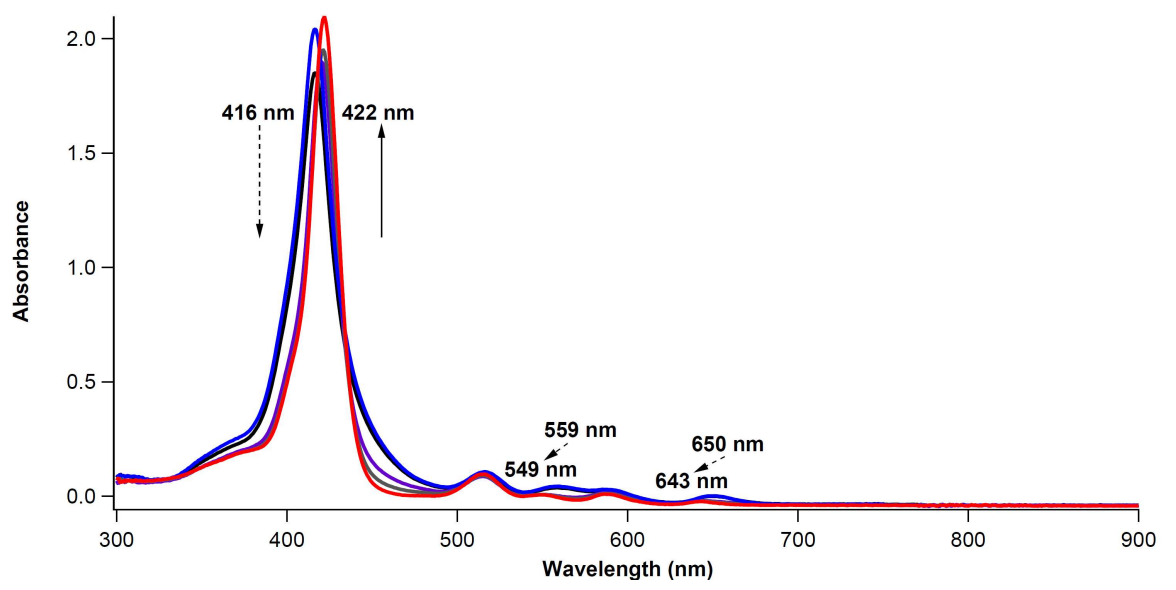

(I)
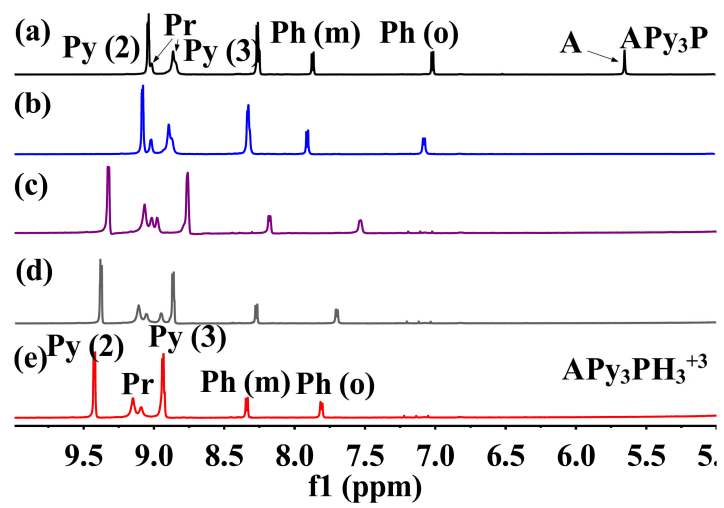

(II) 


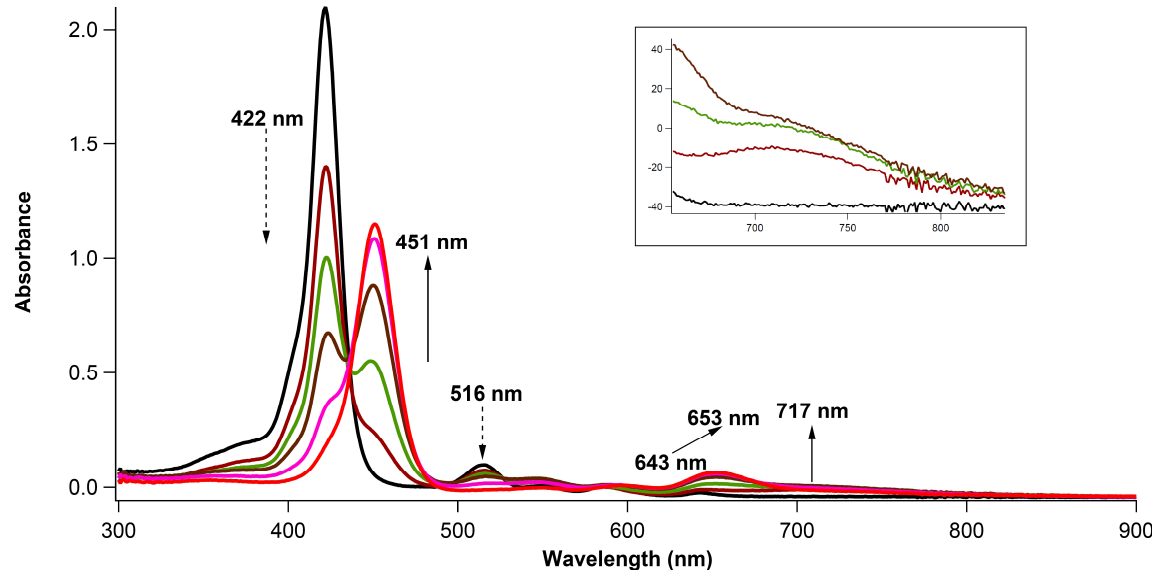

(III)

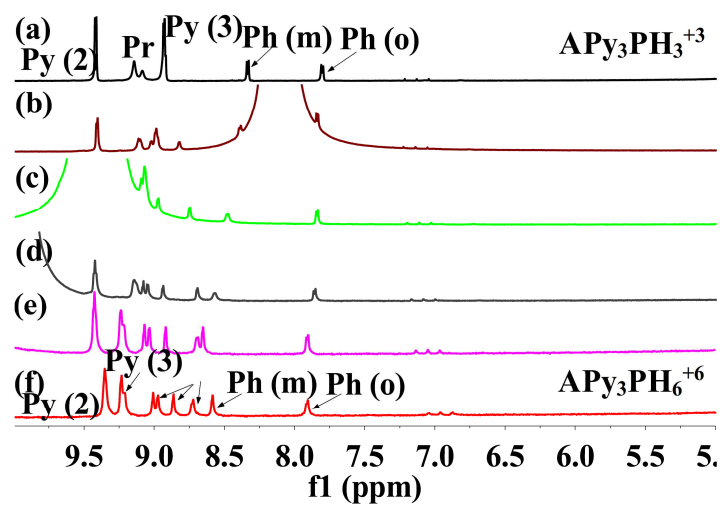

(IV)

Figure 28. The 1 H-NMR spectra of $\mathbf{A P y} \mathbf{3} \mathbf{P}$ protonation.

from $\mathbf{A P y}_{3} \mathbf{P}$ to $\mathbf{A P y}_{3} \mathbf{P H}_{3}{ }^{+3}$.(I) UV-vis spectroscopy, (II) the NMR spectra (color coordinated with (I)); from $\mathbf{A P y} \mathbf{P H}_{3}{ }_{3}{ }^{+}$to $\mathbf{A P y} \mathbf{P H}_{6}{ }^{+6}$ : (III) UV-vis spectroscopy, (IV) the NMR spectra (color coordinated with (III)). 


\subsection{Comparison of NMR spectra at different states}

Table 4 summarizes the NMR features of the four aminophenyl/pyridyl porphyrins in each state (free base, hyperporphyrin, and fully protonated). These features will be further discussed in the following section.

\begin{tabular}{|c|c|c|c|c|c|c|c|}
\hline & \multicolumn{2}{|c|}{$\mathrm{Ph}$} & \multirow{2}{*}{$\begin{array}{c}\text { Pyrrole } \\
\mathrm{H}_{\beta} \\
\end{array}$} & \multirow[t]{2}{*}{$-\mathrm{NH}_{2}$} & \multirow{2}{*}{$\begin{array}{c}\text { Pyrrole } \\
\mathrm{N}-\mathrm{H}\end{array}$} & \multicolumn{2}{|c|}{ pyridine } \\
\hline & o & $\mathrm{m}$ & & & & 2 & 3 \\
\hline \multicolumn{8}{|c|}{ Free base } \\
\hline TPyP & \multicolumn{2}{|c|}{--------- } & $9.06-9.07$ & ------- & -2.93 & 9.07 & 8.16 \\
\hline $\mathrm{APy}_{3} \mathrm{P}$ & 7.02 & 7.87 & $8.80-9.03$ & 5.65 & -2.93 & 9.05 & 8.26 \\
\hline $\operatorname{cis} \mathrm{A}_{2} \mathrm{Py}_{2} \mathrm{P}$ & 7.01 & 7.87 & $8.77-9.01$ & 5.62 & -2.83 & 9.03 & 8.25 \\
\hline $\mathrm{A}_{3} \mathrm{PyP}$ & 7.00 & 7.86 & $8.75-8.96$ & 5.59 & -2.77 & 9.03 & 8.24 \\
\hline TAPP & 7.00 & 7.85 & 8.88 & 5.56 & -2.74 & \multicolumn{2}{|c|}{---------- } \\
\hline \multicolumn{8}{|c|}{ Partially Protonated } \\
\hline $\mathrm{TPyPH}_{4}{ }^{+4}$ & \multicolumn{2}{|c|}{----------- } & \multicolumn{2}{|l|}{$9.14-9.18$} & ---------- & 9.41 & 8.92 \\
\hline $\mathrm{APy}_{3} \mathrm{PH}_{5}{ }^{+5}$ & 7.84 & 8.39 & $8.78-9.15$ & ------------ & --------- & 9.41 & 8.99 \\
\hline $\begin{array}{c}\text { cis } \\
\mathrm{A}_{2} \mathrm{Py}_{2} \mathrm{PH}_{4}{ }^{+4}\end{array}$ & 7.69 & 8.27 & ----------- & ---------- & ---------- & 9.38 & 8.87 \\
\hline $\mathrm{A}_{3} \mathrm{PyPH}_{3}{ }^{+3}$ & 7.23 & 7.29 & $8.08-8.49$ & ----------- & ---------- & 9.27 & 8.67 \\
\hline & 8.29 & 8.42 & & & & & \\
\hline $\mathrm{TAPPH}_{2}{ }^{+2}$ & 7.25 & 8.34 & 8.29 & 6.41 & 0.76 & \multicolumn{2}{|c|}{------------ } \\
\hline \multicolumn{8}{|c|}{ Fully Protonated } \\
\hline $\mathrm{TPyPH}_{6}{ }^{+6}$ & \multicolumn{2}{|c|}{-------- } & $9.08-9.15$ & ---------- & ---------- & 9.34 & 9.05 \\
\hline $\mathrm{APy}_{3} \mathrm{PH}_{6}{ }^{+6}$ & 7.91 & 8.58 & $\begin{array}{c}8.72 / 8.86 / \\
8.99 \\
\end{array}$ & ---------- & ---------- & 9.35 & 9.22 \\
\hline $\begin{array}{c}\text { cis } \\
\mathrm{A}_{2} \mathrm{Py}_{2} \mathrm{PH}_{6}{ }^{+6}\end{array}$ & 7.92 & 8.72 & $\begin{array}{l}8.46 / 8.62 / \\
8.83 / 9.00 \\
\end{array}$ & ---------- & ---------- & 9.42 & 9.22 \\
\hline $\mathrm{A}_{3} \mathrm{PyPH}_{6}{ }^{+6}$ & 7.97 & 8.73 & $\begin{array}{l}8.50 / 8.54 / \\
8.66 / 8.91 \\
\end{array}$ & ---------- & ---------- & 9.43 & 9.23 \\
\hline TAPPH $_{6}{ }^{+6}$ & 8.01 & 8.75 & 8.61 & ---------- & $\begin{array}{l}-0.70 \\
(\mathrm{Br})\end{array}$ & ----- & \\
\hline
\end{tabular}


Table 4. The proton chemical shifts from all the functional groups of aminophenyl/pyridyl porphyrins in each protonation state.

\subsection{D NMR for A3PyP}

In order to accurately assign each proton signal to individual hydrogens, COSY (hydrogen-hydrogen) spectra of $\mathbf{A} \mathbf{3} \mathbf{P y} \mathbf{P}$ in each state (hyperporphyrin and fully protonated) were studied here. As shown in Fig. 29 (a) for $\mathbf{A}_{3} \mathbf{P y} \mathbf{P H}_{3}{ }^{+\mathbf{3}}$ hyperporphyrin, the meta phenyl protons at 7.23 and $7.29 \mathrm{ppm}$ correlate with the ortho protons at 8.29 and $8.42 \mathrm{ppm}$. Therefore, although the range from 8.1 to $8.5 \mathrm{ppm}$ is where pyrrole $\beta$ hydrogen and the phenyl hydrogen overlap and it is difficult to distinguish the phenyl proton signals, the proton signals at 8.29 and $8.42 \mathrm{ppm}$ could clearly be assigned to the phenyl proton signals. COSY of the fully protonated $\mathbf{A}_{3} \mathbf{P y P H}_{\mathbf{6}}{ }^{+\mathbf{6}}$ also shows the correlation of the phenyl o- $\mathrm{H}$ and $\mathrm{m}-\mathrm{H}$, and another weak correlation between two pyrroles. 

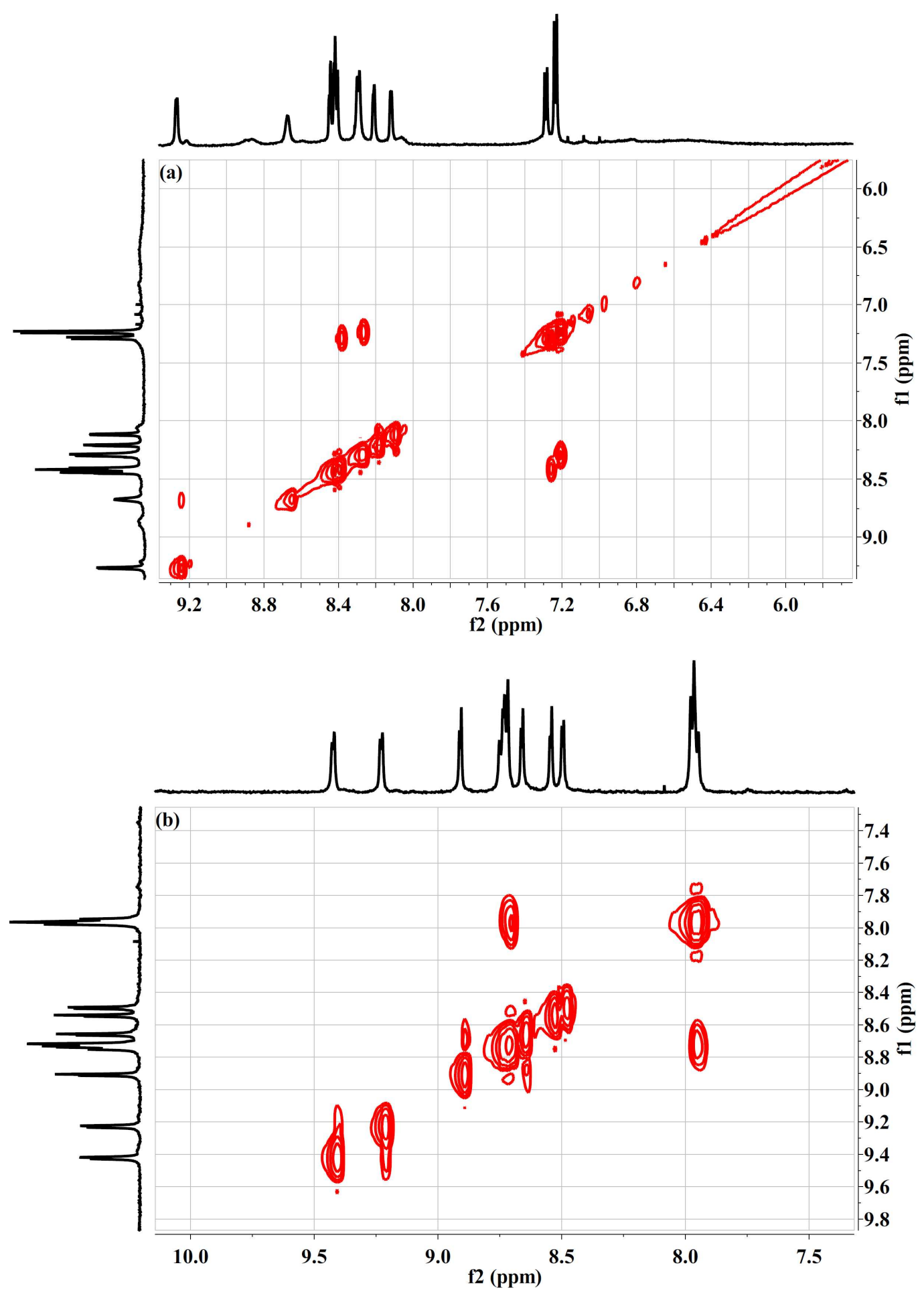

Figure 29. COSY of protonated $\mathbf{A}_{\mathbf{3}} \mathbf{P y P}$.

a. hyperporphyrin $\left(\mathbf{A}_{3} \mathbf{P y} \mathbf{P H}_{3}{ }^{+3}\right)$; b. fully protonated $\left(\mathbf{A}_{3} \mathbf{P y P H}_{6} \mathbf{P H}^{+6}\right)$ 
The other 2D NMR (Fig. 30) that was studied is NOESY, with the purpose of investigating how the adjacent protons correlate through space in each state. In the free base porphyrin (Fig. 30 (a)), the ortho hydrogens at 7.00 ppm on the aminophenyl groups have both interactions with the amino hydrogens at $5.59 \mathrm{ppm}$ and the meta hydrogens on the aminophenyl groups at $7.86 \mathrm{ppm}$. The 2 and 3 hydrogens at 9.03 and $8.24 \mathrm{ppm}$ on the pyridyl group also interact weakly with each other.

At the hyperporphyrin stage, all of the interactions are stronger. The ortho phenyl hydrogens at 7.23 and 7.29 ppm still interact with the meta phenyl hydrogens at 8.29 and $8.42 \mathrm{ppm}$. The meta phenyl hydrogens, on the other hand, can interact with two pyrrole $\beta$ hydrogens at 8.12 and $8.21 \mathrm{ppm}$. Additionally, the interaction between position 3 hydrogens on the pyridyl groups $(8.67 \mathrm{ppm})$ and pyrrole $\beta$ hydrogens $(8.45$ ppm) can be noticed. The interaction between pyridyl 2 and 3 hydrogens at 9.27 and 8.67 ppm still remains.

When the porphyrin was fully protonated, the interactions between pyrrole $\beta$ hydrogens became stronger, with the ones at 8.50 and $8.54 \mathrm{ppm}$ correlated and the other ones at 8.66 and $8.91 \mathrm{ppm}$ correlated. The interactions of meta hydrogens on the phenyl groups $(8.73 \mathrm{ppm})$ with pyrrole $\beta$ hydrogens $(8.50$ and $8.54 \mathrm{ppm})$ decrease compared to the hyperporphyrin, as well as the interactions of 3 hydrogens on the pyridyl groups (9.23 ppm) and pyrrole $\beta$ hydrogens (8.91 ppm). 

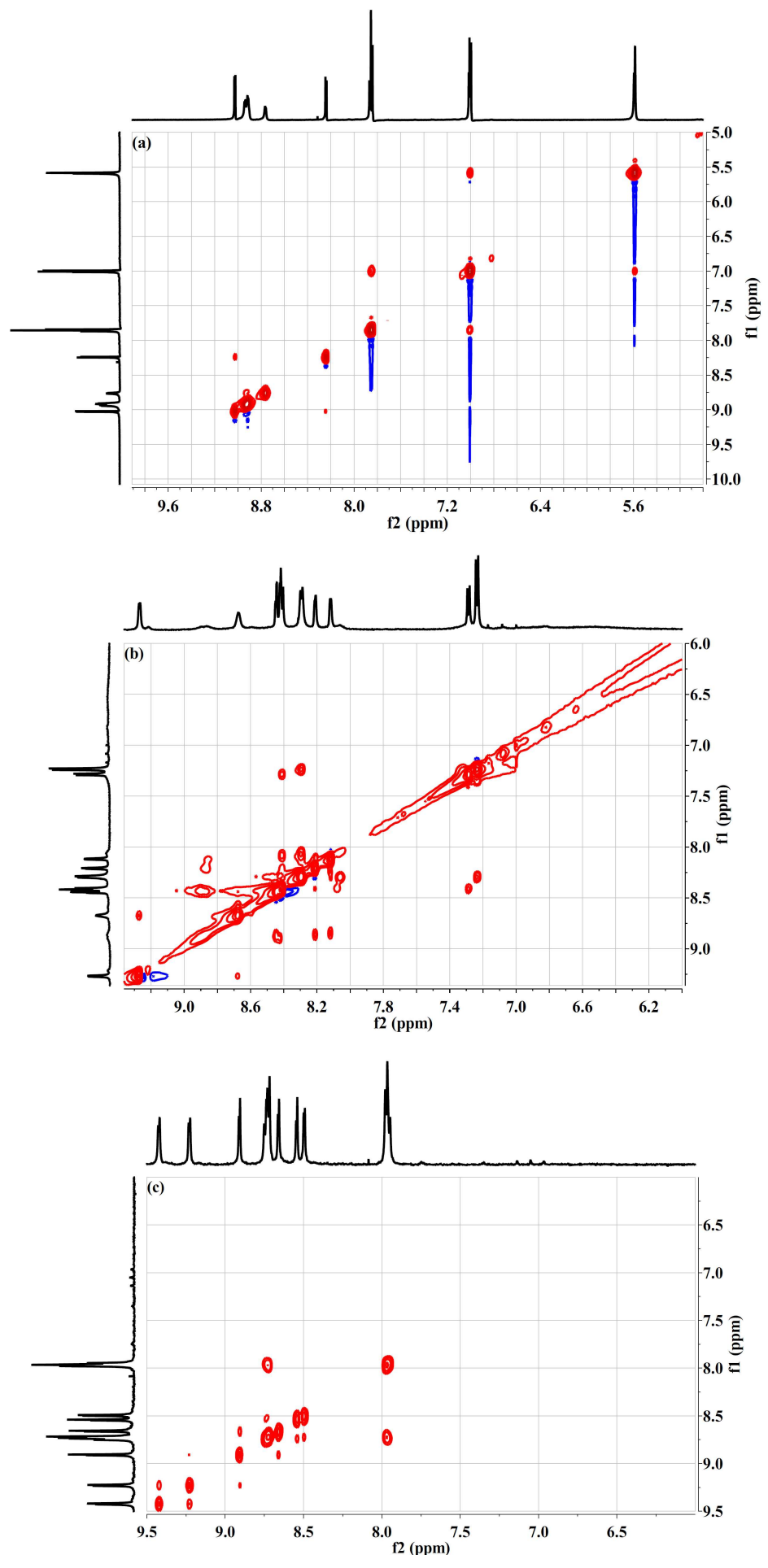

Figure 30. NOESY spectra of protonated $\mathbf{A}_{\mathbf{3}} \mathbf{P y P}$. 
(a. free base (A3PyP); b. hyperporphyrin $\left(\mathbf{A}_{3} \mathbf{P y} \mathbf{P} \mathbf{H}_{3}{ }^{+3}\right)$; c. fully protonated

$\left(\mathrm{A}_{3} \mathrm{PyPH}_{6}{ }^{+6}\right)$.

\subsection{NMR Evidence for Hyperporphyrin Structure}

Earlier we discussed the hyperporphyrin effects of protonated aminophenyl/pyridyl porphyrins from the spectroscopic point of view (Chapter 3). However, specific structural evidence would be valuable to validate the concept of the novel D-type hyperporphyrin. In this section, we applied NMR spectroscopy to investigate changes of aminophenyl/pyridyl porphyrin structures during protonation. NMR spectroscopy of the hyperporphyrin effect has been studied before on dimethylaminophenylporphyrins. ${ }^{45,72}$ However, the effect of electron-withdrawing groups on such hyperporphyrins has not been studied. Pyridinium originating from pyridine after protonation is a strong electron-withdrawing group, and here we are studying that combination with the well-documented aminophenylporphyrin hyperporphyrins. Evidence for the D type of hyperporphyrin that involves charge transfer between pyridinium and aminophenyl will be presented.

In the series of aminophenyl/pyridyl porphyrins we studied here, the sequence in which the aminophenyl, pyridyl, and pyrrole nitrogens are protonated plays an important role in the NMR spectra. In TPyP and $\mathbf{A P y} \mathbf{P}_{3} \mathbf{P}$, the basicity of the pyridyl groups are stronger than that of the pyrrole nitrogens, therefore pyridyl groups are converted to pyridinium first. ${ }^{33}$ However, in $\mathbf{c i s}-\mathbf{A}_{2} \mathbf{P} \mathbf{y}_{2} \mathbf{P}$ and $\mathbf{A}_{3} \mathbf{P y} \mathbf{P}$, the aminophenyl 
groups enhance the basicity of the pyrrole nitrogen, so the protonations of pyridyl groups and pyrrole nitrogens are observed at the same time. It has also been postulated that in $\mathbf{A}_{3} \mathbf{P y} \mathbf{P}$ the protonation of pyrrole nitrogens is prior to the protonation of pyridyl groups, but in the spectroscopy it is too subtle to distinguish them. ${ }^{33}$

The proton NMR spectra of porphyrins has been determined to be dominated by the large $\pi$-electron ring current of the macrocycles and the inductive effect of the peripheral groups. ${ }^{73}$ Hyperporphyrin effect requires significant coplanarity of the functional groups with the macrocycle to facilitate the charge transfer. In order to accommodate the coplanarity, the adjacent pyrroles need to tilt, which results in the distortion of the macrocycle. The ring current decreases in consequence, with the characteristic movements upfield for $\mathrm{H}_{\beta}$ and downfield for the internal N-H proton. ${ }^{74}$ Although they all show hyperporphyrin effect, the NMR spectra of $\mathbf{A P y} 3 \mathbf{P}$, cis- $\mathbf{A}_{2} \mathbf{P y} \mathbf{y}_{2} \mathbf{P}$ and $\mathbf{A}_{3} \mathbf{P y} \mathbf{P}$ under acidification here are quite different. While $\mathbf{A}_{3} \mathbf{P y} \mathbf{P}$ can exhibit the characteristic $\mathrm{H}_{\beta}$ movement of hyperporphyrin, $\mathbf{A P y}_{3} \mathbf{P}$ and $\mathbf{c i s}-\mathbf{A}_{2} \mathbf{P} \mathbf{y}_{2} \mathbf{P}$ move their $\mathrm{H}_{\beta}$ downfield instead. This phenomenon could be explained via the sequence of protonation of different functional groups. In $\mathbf{A P y}_{3} \mathbf{P}$ and $\boldsymbol{c i s}_{\mathbf{s}}-\mathbf{A}_{2} \mathbf{P y} \mathbf{y}_{2} \mathbf{P}$, pyridyl groups are protonated either prior to or together with the protonation of the pyrrole nitrogens, while in A3PyP the protonation of pyridyl lags behind pyrrole. The inductive effect of pyridinium is stronger than the ring distortion in $\mathbf{A P y}_{3} \mathbf{P}$ and cis- $\mathbf{A}_{2} \mathbf{P} \mathbf{y}_{2} \mathbf{P}$, thus moving $\mathrm{H}_{\beta}$ downfield. ${ }^{75}$ 
TAPP has been recognized as the special case of $\mathrm{C}$ type hyperporphyrin. $\mathrm{C}$ type hyperporphyrin is described as charges from the two pyrrolic N-Hs delocalized to two donor groups at cis meso positions. In TAPP, there are four combinations of such donor groups, which means that the chances of TAPP forming $C$ type hyperporphyrin is particularly strong. As shown in Fig. 31, two cis aminophenyl groups accept the positive charges and turn into a protonated iminium, which can exchange proton with the solution, explaining the loss of amino $-\mathrm{NH}_{2}$ signals. The existence of such a stable hyperporphyrin structure could also explain the slow exchange in the early stage of the titration.

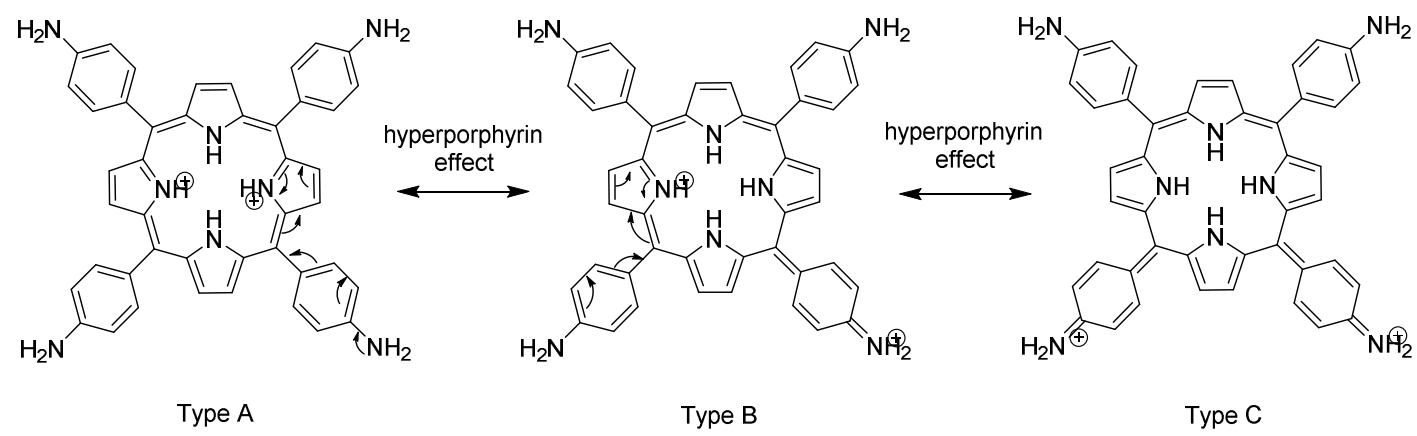

Figure 31. The resonance forms of $\mathbf{T A P P H} \mathbf{2}^{+2}$ hyperporphyrin.

A3PyP is the porphyrin that has been proposed to give rise to D type hyperporphyrin. ${ }^{33}$ As shown in Fig. 32, after being protonated, not only can the two cis aminophenyl groups undergo resonance with the internal pyrrolic $\mathrm{N}-\mathrm{H}$, but the third aminophenyl group can have resonance interaction with pyridinium. 


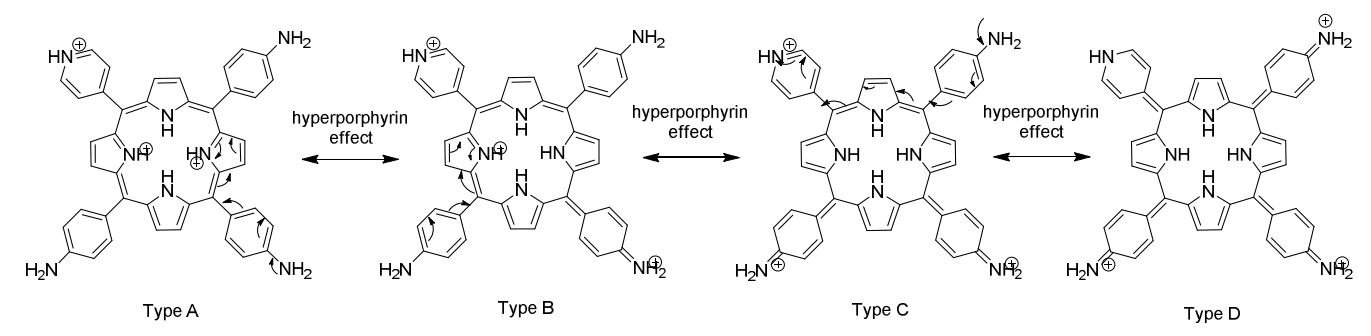

Figure 32. The resonance forms of $\mathbf{A}_{3} \mathbf{P y P H}_{3}{ }^{+\mathbf{3}}$ hyperporphyrin.

Evidence in the 1D and 2D proton NMR spectra of $\mathbf{A}_{3} \mathbf{P y P H} \mathbf{P}^{+\mathbf{3}}$ support the idea of a type D hyperporphyrin form. As with TAPP, the coexistence of both free base and protonated porphyrin in the same spectrum indicate slow exchange between the two states. More importantly, the splitting of the phenyl and amino groups into two signals implies that among the three aminophenyls, two different types were formed, which has been explained earlier as due to the cis and trans orientations of the aminophenyl groups to the pyridyl group. This is an unique feature for $\mathbf{A} 3 \mathbf{P y P}$, not possible in TAPP hyperporphyrin. In TAPP, any two cis aminophenyl groups out of four could interact with the internal nitrogens, and any structural changes required to move between different resonance forms much be so rapid that it impossible to differentiate the aminophenyl groups from the iminium groups, i.e., all aminophenyls appear equivalent in the NMR spectrum. In A3PyP, however, when two cis aminophenyl groups interact with the internal nitrogens, the remaining one also interacts with pyridinium. Because of the requirement for a cis orientation for the type $\mathrm{D}$ resonance, two of the aminophenyls can interact with the pyridinium and one cannot. 


\begin{tabular}{|c|c|c|c|}
\hline & \begin{tabular}{c} 
Pyridyl \\
\hline
\end{tabular} \\
\hline
\end{tabular}

Table 5. The pyridyl and aminophenyl proton chemical shifts compared to standards

(TPyP and TAPP).

Examining the chemical shifts is more useful to detect evidence for the type D hyperporphyrin (Table 5). While the shifts of pyridyl protons in free base TPyP (8.16/9.07) and $\mathbf{A 3} \mathbf{P y P}(8.24 / 9.03)$ are comparable, their shifts (8.92/9.41 and 8.67/9.27) in partially protonated hyperporphyrin forms are significantly different. This indicates that a special more electron-rich form of pyridine is present, for which the dihydropyridine structure of type D would be plausible. The 2D NOESY of A3PyP hyperporphyrin further supports the structure by showing that the adjacent hydrogens on the hyperporphyrin interact more vigorously, in particular the pyrrole $\beta$ hydrogens with the pyridyl-3 and phenyl-m hydrogens. This phenomenon could result from the increased planarity of the meso substituents with the macrocycle. 


\section{Chapter 5. Electrochemical Study of Protonated Aminophenyl/Pyridyl}

\section{Porphyrins}

Keeping track of the protonation states is very important in studying electrochemistry of acidified aminophenyl/pyridyl porphyrins. In order to achieve this goal, thin-layer cell for spectroscopy is still needed here. Since the porphyrins studied here are typically protonated, this chapter will focus on reduction reactions only. The changes of porphyrin structures towards hyperporphyrin upon protonation could complicate the cyclic voltammograms. Scanning different potential ranges through several cycles was adopted here to help clarify that.

\subsection{Cyclic voltammetry of protonated aminophenyl/pyridylporphyrins}

TPP. The basic porphyrin, TPP, has been studied elsewhere ${ }^{54}$ and is mentioned here to provide the knowledge of shifts of redox potentials under acidification (Fig. 33). In TPP, the two internal nitrogens can accept protons and the protonation can result in the formation of $\mathbf{T P P H} \mathbf{H}^{+2}$. The free base TPP has two reduction peak potentials at -1.16 and $-1.33 \mathrm{~V}$, which are the $1^{\text {st }}$ and $2^{\text {nd }}$ reductions of the $\pi$ system respectively. As acid is added, the reduction peak potential at $-0.30 \mathrm{~V}$, which can be assigned as the reduction of $\mathbf{T P P H} \mathbf{H}_{2}{ }^{+2}$, starts to grow while the reduction potential at $-1.33 \mathrm{~V}$ disappears. With the continued titration of acid, two new reduction waves at -0.66 and $-1.18 \mathrm{~V}$ also show up. The reduction wave at $-0.66 \mathrm{~V}$ was designated as the reduction of the singly protonated porphyrin $\left(\mathbf{T P P H}{ }^{+}\right)$, while the wave at $-1.18 \mathrm{~V}$ was 
assigned as the reduction of the free base porphyrin produced from the chemical reaction after the first electron transfer. ${ }^{54}$

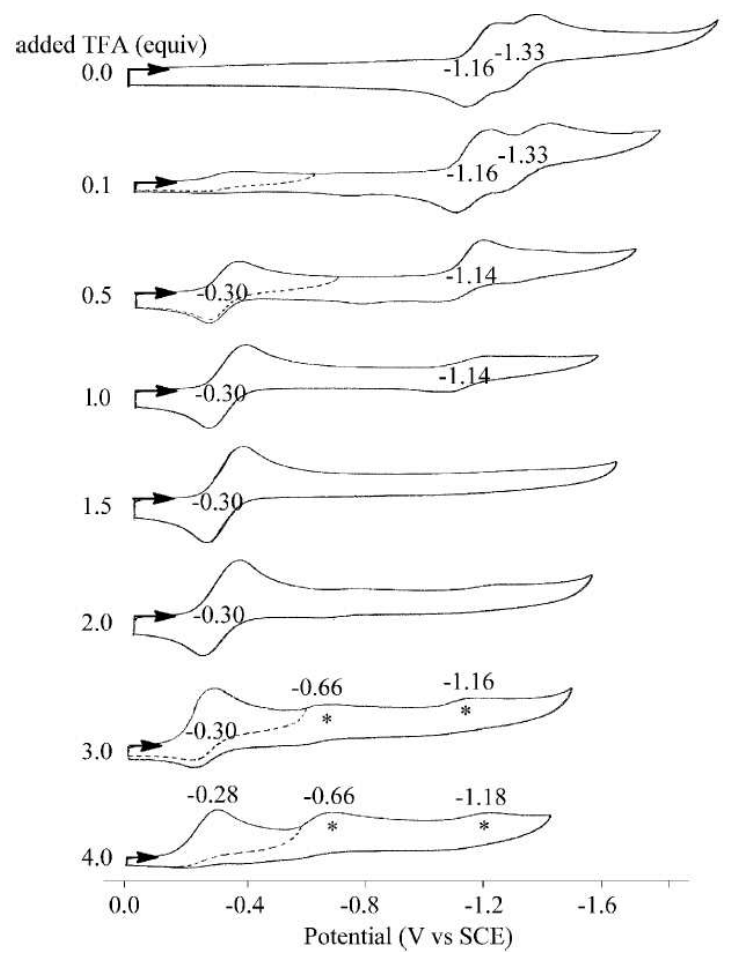

Figure 33. Cyclic voltammograms of protonating TPP (from TPP to $\mathbf{T P P H} \mathbf{2}^{\mathbf{+ 2}}$ ). ${ }^{54}$

TAPP. As described earlier, the decrease of the Soret band from 439 to $390 \mathrm{~nm}$, the development of a new Soret band at $467 \mathrm{~nm}$, and a huge new absorption at $805 \mathrm{~nm}$ all indicate the formation of hyperporphyrin $\mathbf{T A P P H}{ }_{2}{ }^{+2}$, which arises from the charge transfer between the protonated internal nitrogens and aminophenyl groups (Fig. 34). 


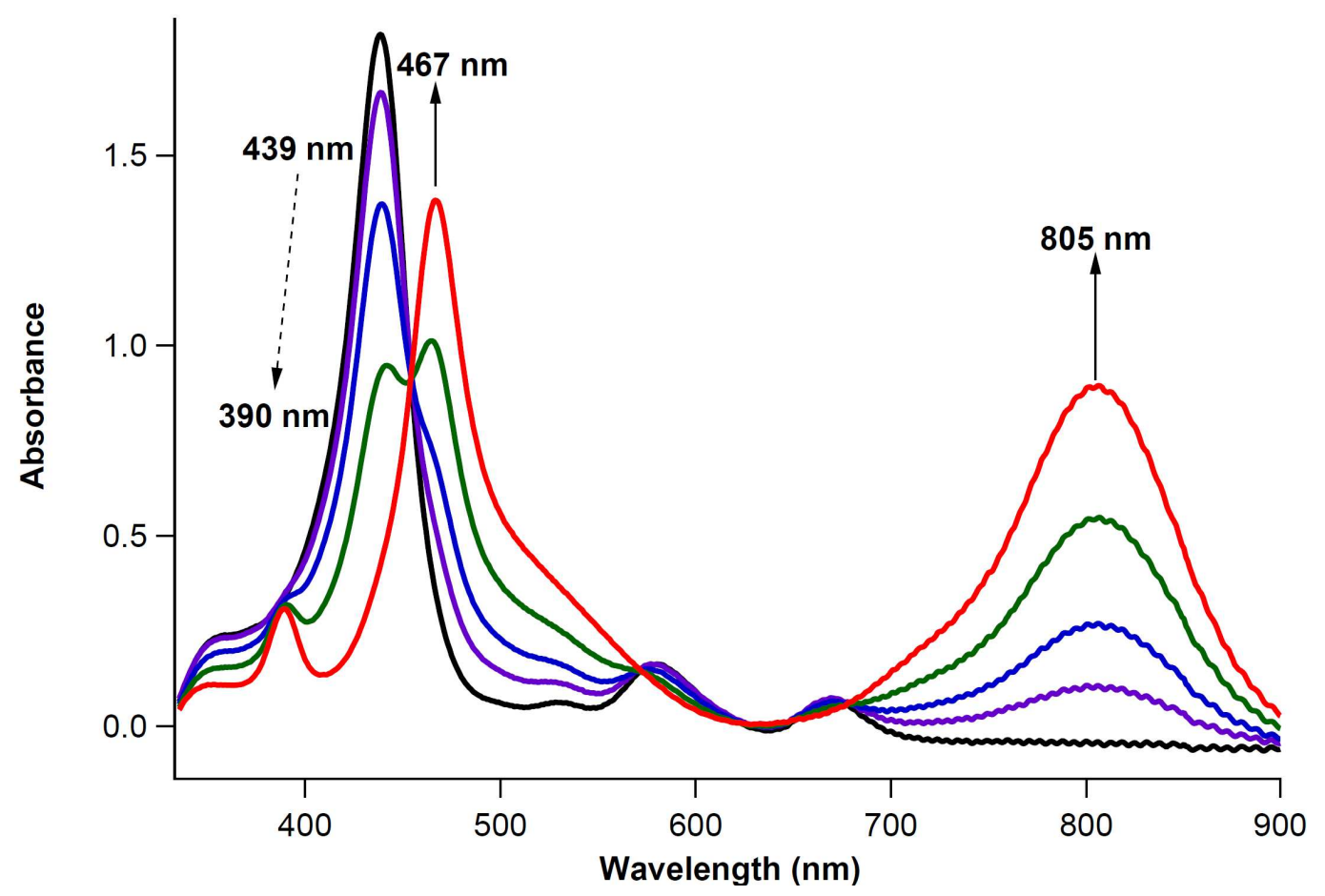

Figure 34. UV-vis spectroscopy of TAPP from free base to hyperporphyrin $\left(\mathrm{TAPPH}_{2}{ }^{+2}\right)$.

In the cyclic voltammetry of protonated TAPP (Fig. 35), the free base CV is characterized by two reversible redox waves at $-1.17 /-1.09 \mathrm{~V}$ and $-1.58 /-1.50 \mathrm{~V}$. It has been explained that these two redox potentials are attributed to the reduction/oxidations on the internal $\pi$ system. ${ }^{54}$ For intermediate stage of protonation between free base and hyperporphyrin, the cyclic voltammograms scanning between 0 and $-2 \mathrm{~V}$ all look similar to the free base $\mathrm{CV}$. The new peaks due to reduction of hyperporphyrin are weak and difficult to see if the full range is scanned. Only at the completion of the titration (bottom, red CV in Fig. 35) are the new peaks clearly visible. 

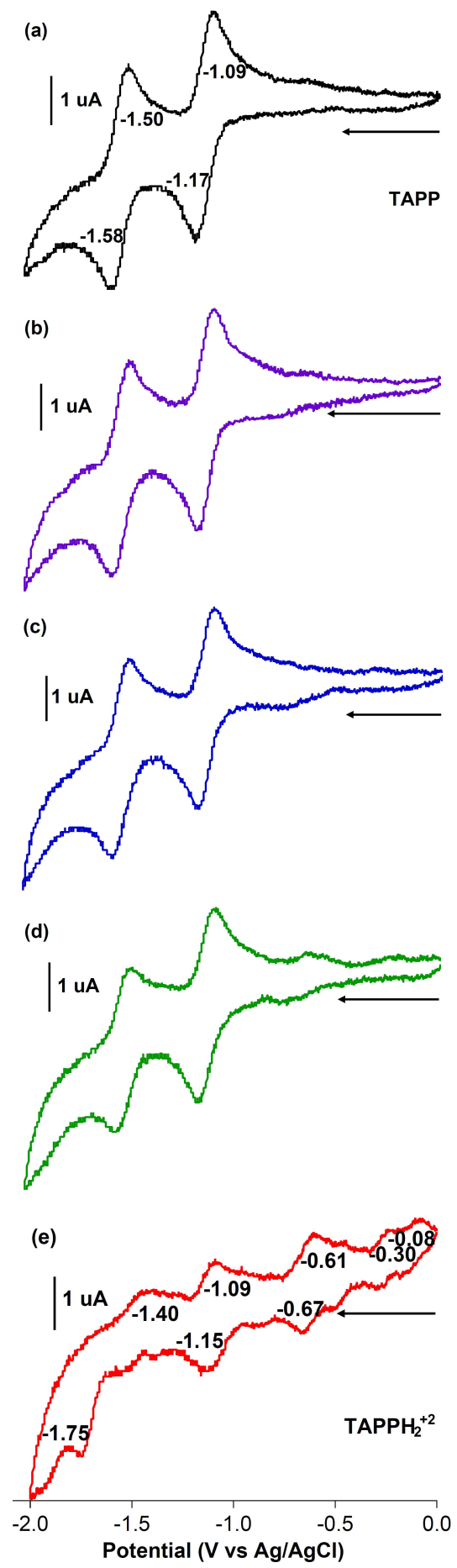

Figure 35. Cyclic voltammetry of TAPP from free base to hyperporphyrin $\mathbf{T A P P H} \mathbf{H}_{2}{ }^{+2}$.

(color coordinated with Fig. 34). 


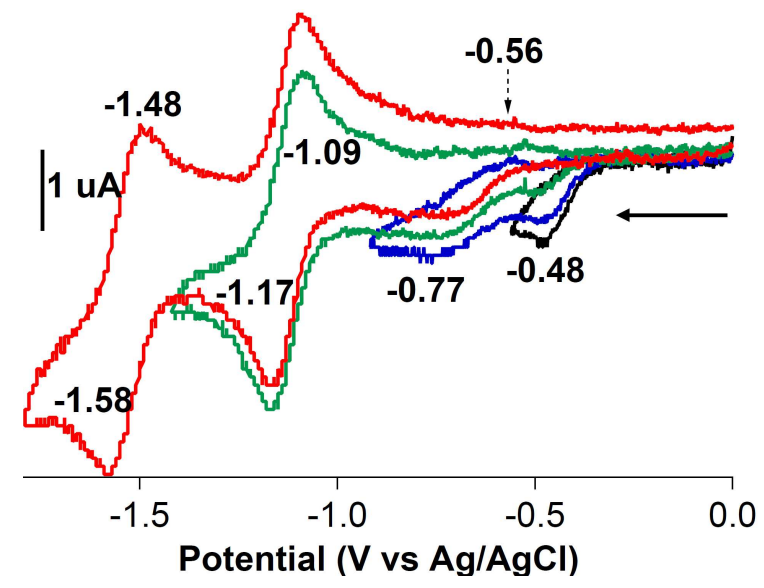

(I)

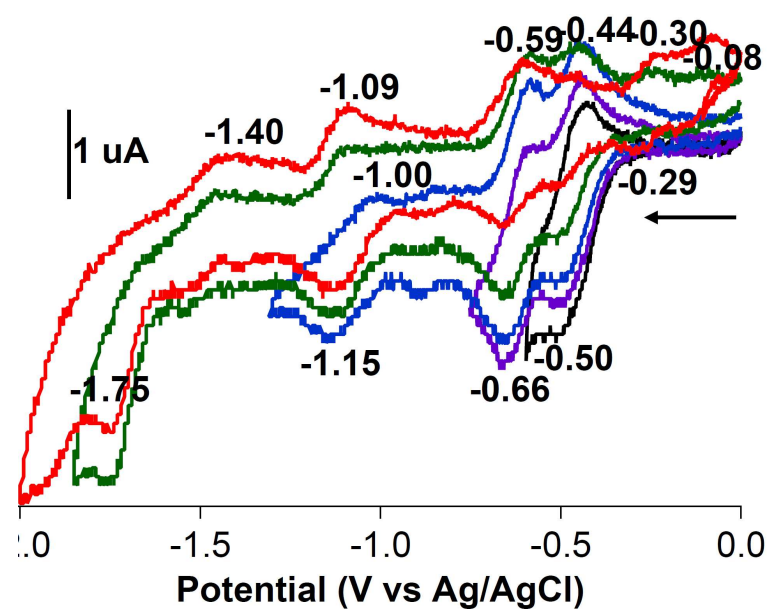

(II)

Figure 36. Cyclic voltammetry scanning different potential ranges in protonated

TAPP. (I: protonated TAPP between free base and hyperporphyrin; II:

$$
\text { hyperporphyrin } \mathbf{T A P P H}_{2}{ }^{+2} \text { ). }
$$

Figure 36 illustrates that scans over smaller ranges generate different CVs. For the partial titration that includes both free base and hyperporphyrin, partial CV scans are shown in Fig. 36 (I). In scanning between 0 and $-0.91 \mathrm{~V}$, two reduction waves at -0.49 
and $-0.77 \mathrm{~V}$ can be found. While the wave at $-0.77 \mathrm{~V}$ has a quasi-reversible oxidation wave at $-0.56 \mathrm{~V}$, the wave at $-0.49 \mathrm{~V}$ doesn't show a corresponding oxidation wave. In a wider scan to $-1.42 \mathrm{~V}$, the reduction wave at $-0.49 \mathrm{~V}$ is very small and completely disappears after the scan extends to $-1.7 \mathrm{~V}$.

When TAPP is fully converted into hyperporphyrin (Fig. 35 (e)), scanning different ranges generate quite different curves (Fig. 36). In the scans from 0 to $-1.3 \mathrm{~V}$, three reversible reduction/oxidations can be located. The reductions at -0.50 and $-0.66 \mathrm{~V}$ have been discussed before on electrochemical studies of protonated TAPP. ${ }^{76}$ In that study, it was validated that the two reductions at -0.50 and $-0.66 \mathrm{~V}$ are not caused by two species interconversion. Moreover, these two reduction waves disappeared for CuTAPP, thus they could be assigned to the inner ring protonated porphyrin species. These two reductions at $-0.50 \mathrm{~V}$ and $-0.66 \mathrm{~V}$ are assigned to the reductions of $+2 \rightarrow+1$ and $+1 \rightarrow 0$, the reductions at -1.15 can be assigned as the reduction of the porphyrin to -1 . Further scanning from 0 to $-1.8 \mathrm{~V}$ gives another reduction wave at $-1.75 \mathrm{~V}$ and can be assigned as the second reduction of the porphyrin. Meanwhile, it is noteworthy that the reduction wave at $-0.50 \mathrm{~V}$ decreases significantly upon repeated scans. A reasonable explanation for this phenomenon is the decomposition of the new species. The hyperporphyrin apparently decomposes slowly upon reduction, especially when reduction is carried to more negative potentials.

A3PyP. In the spectroscopy, the protonation of $\mathbf{A 3} \mathbf{P y} \mathbf{P}$ towards hyperporphyrin can be described as the Soret band decreasing from 436 to $405 \mathrm{~nm}$, another Soret band increasing at $481 \mathrm{~nm}$, and a huge absorption increasing at $778 \mathrm{~nm}$ (Fig. 37). 


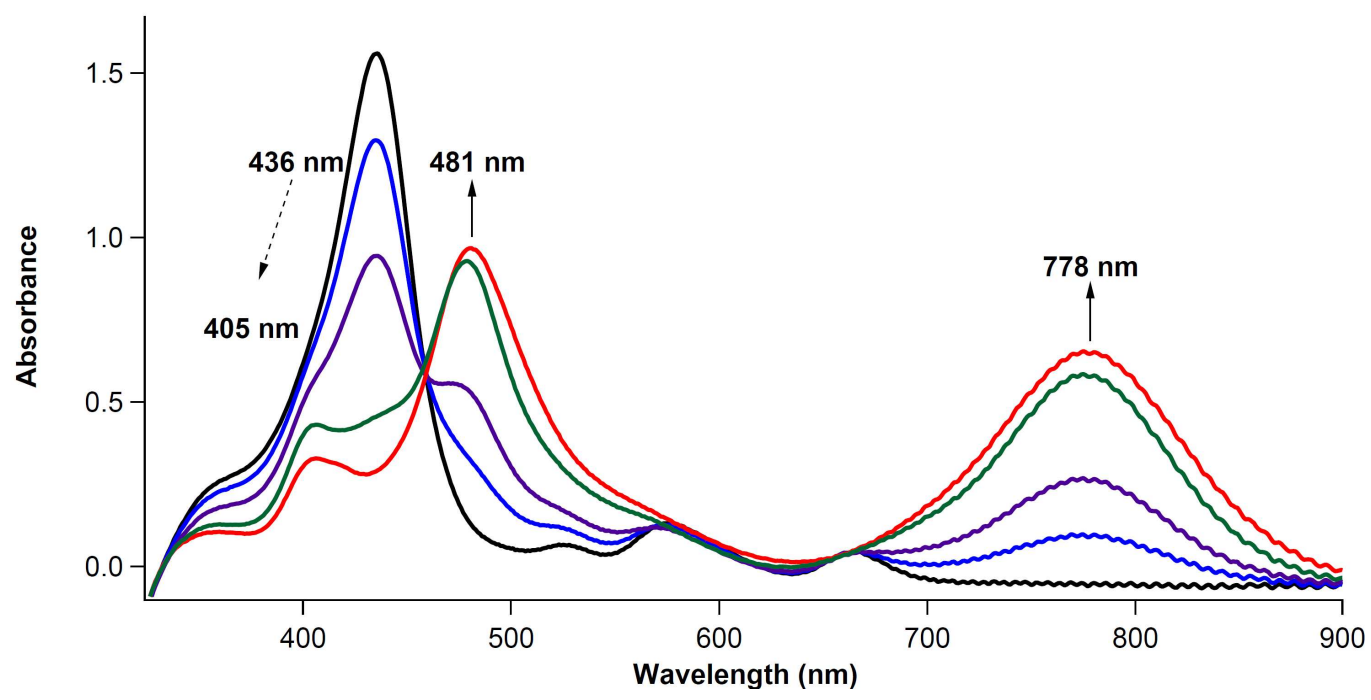

Figure 37. UV-vis spectroscopy of $\mathbf{A}_{\mathbf{3}} \mathbf{P} \mathbf{P} \mathbf{P}$ from free base to hyperporphyrin

\section{$\left(\mathrm{A}_{3} \mathrm{PyPH}_{3}{ }^{+3}\right)$.}

In the cyclic voltammetry of protonated A3PyP (Fig. 38 (a)), there are also two reductions of the $\pi$ systems at -1.09 and $-1.51 \mathrm{~V}$ as in TAPP. Moreover, the introduction of pyridyl group brings in one more reduction at $-1.75 \mathrm{~V}$ with a quasi-reversible oxidation wave at $-1.64 \mathrm{~V}$. There are two extra oxidation waves on the return scan at -0.78 and $-0.32 \mathrm{~V}$ that cannot be assigned. For the stage of titration between free base and hyperporphyrin, the reduction potentials from the free base species keep moving to less negative values. A new reduction wave at $-0.32 \mathrm{~V}$ arises with the formation of hyperporphyrin. At the stage where only hyperporphyrins exist, the reduction waves can be located at -0.41 and $-1.46 \mathrm{~V}$ with two oxidation waves at -0.38 and $0.18 \mathrm{~V}$. 

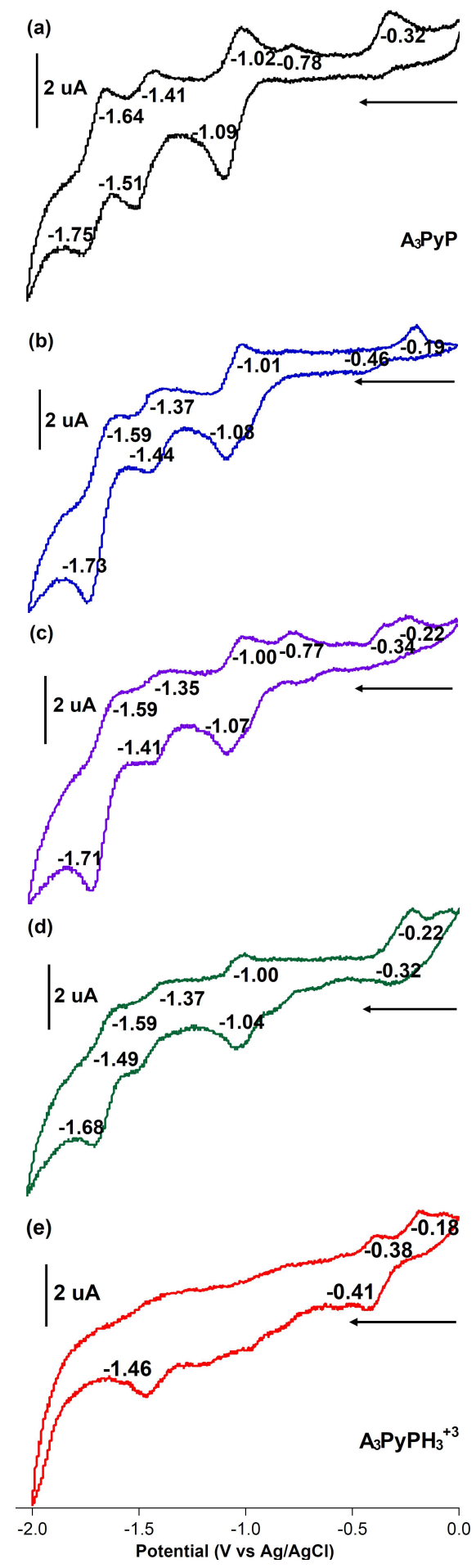

Figure 38. Cyclic voltammetry of $\mathbf{A} \mathbf{3} \mathbf{P y P}$ from free base to hyperporphyrin $\mathbf{A}_{3} \mathbf{P y P H}_{3}{ }^{+3}$ (color coordinated with Fig. 37). 
More informative data can be achieved by scanning over smaller ranges (Fig. 39). When $\mathbf{A}_{\mathbf{3}} \mathbf{P y P}$ is partially protonated to hyperporphyrin (Fig. 39 (I)), the reduction potentials come from both free base and hyperporphyrin. In scanning from 0 to $-0.6 \mathrm{~V}$, the reduction of hyperporphyrin at $-0.43 \mathrm{~V}$ has a reversible oxidation at $-0.35 \mathrm{~V}$. Extensions of the scan to $-0.9 \mathrm{~V}$ or $-1.25 \mathrm{~V}$ produce extra oxidation waves on the reverse scan at $-0.20 \mathrm{~V}$ and $-0.51 \mathrm{~V}$. In wider scan range to $-2.0 \mathrm{~V}$, an additional reduction wave at $-1.70 \mathrm{~V}$ is assigned to the pyridyl group, and leads to two extra oxidations at $-0.75 \mathrm{~V}$ and $-0.28 \mathrm{~V}$ on the reverse scan.

In the smaller range scanning of hyperporphyrin (Fig. 39 (II)), five reductions can be traced, with the reduction peak potentials at $-0.40,-0.80,-0.98,-1.28$, and $-1.50 \mathrm{~V}$ Similar to TAPP, these five reduction potentials can also be assigned to $1^{\text {st }}, 2^{\text {nd }}, 3^{\text {rd }}$, $4^{\text {th }}, 5^{\text {th }} \mathrm{e}^{-}$reductions, from $\mathrm{A}_{3} \mathrm{PyPH}_{3}{ }^{+3}$ to $\mathrm{A}_{3} \mathrm{PyPH}_{3}{ }^{-2}$. However, it is worth noting that the initial reduction wave of $\mathbf{A}_{3} \mathbf{P y P H}_{3}{ }^{+3}$ (at $-0.40 \mathrm{~V}$ ) doesn't change between the cycles, indicating that the hyperporphyrin doesn't decompose, unlike that from TAPP. 


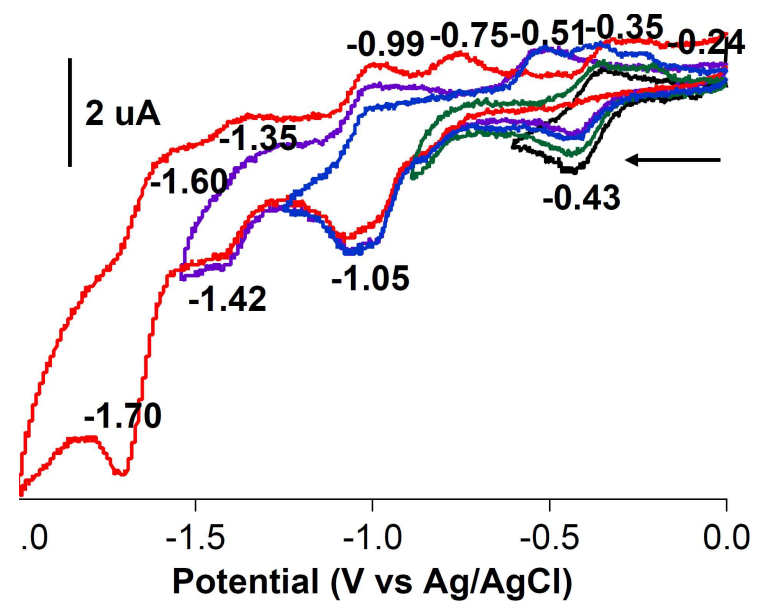

(I)

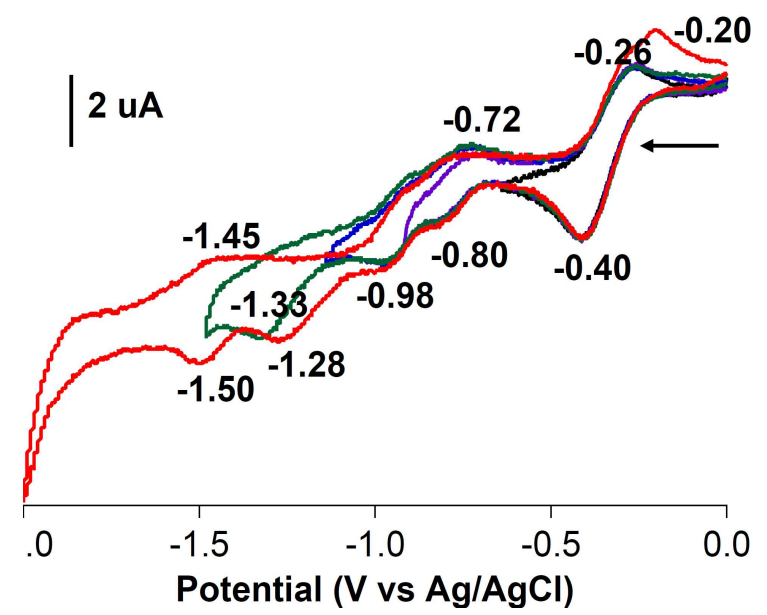

(II)

Figure 39. Cyclic voltammetry of scanning different potential ranges in protonated A3 PyP (I: protonated A3PyP between free base and hyperporphyrin; II: hyperporphyrin $\mathbf{A}_{3} \mathbf{P y P H}_{3}{ }^{+3}$ ).

The reduction at $-0.40 \mathrm{~V}$ was investigated further, in part because it was speculated to generate hydrogen. An investigation was performed using different scan rates to scan this range ( 0 to $-0.7 \mathrm{~V}$ ) (Fig. 40$)$. The correlation of current and scan rate can be 
described by Eq (1): 77

$\mathrm{i}_{\mathrm{p}}=\left(2.99 \times 10^{5}\right) n\left(\alpha n_{\alpha}\right)^{1 / 2} A C D^{1 / 2} v^{1 / 2}$

where $i_{p}$ is peak current, $n$ is the number of electrons, $A$ the electrode area (in $\mathrm{cm}^{2}$ ), C the concentration (in $\mathrm{mol} / \mathrm{cm}^{3}$ ), D the diffusion coefficient (in $\mathrm{cm}^{2} / \mathrm{s}$ ), $v$ the scan rate (in $\mathrm{V} / \mathrm{s}$ ), $\alpha$ is the transfer coefficient, and $\mathrm{n}_{\mathrm{a}}$ is the number of electrons involved in the charge-transfer step. Therefore, the peak current should be proportional to square root of scan rate. By plotting the correlation between the two parameters (Fig. 41), we can see on the reduction side, the linear correlation is well maintained. However, on the oxidation side, under the lower scan rate, the current drops starting at $100 \mathrm{mV} / \mathrm{s}$. The reduced species from $-0.40 \mathrm{~V}$ depletes more and more at lower scan rate. This could be a typical EC process where at higher scan rate, no reduced species have time to chemically react. When the scan rate is low enough to allow chemical reaction, the species is depleted before it can reoxidized.

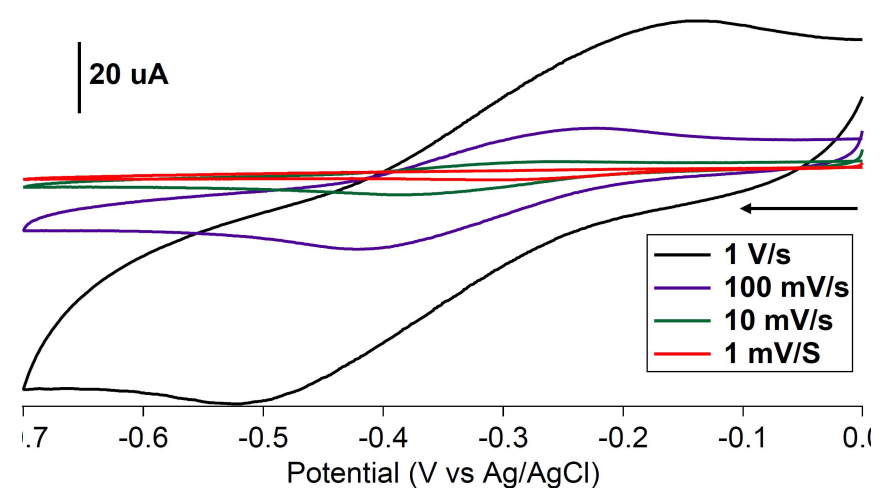

(I) 

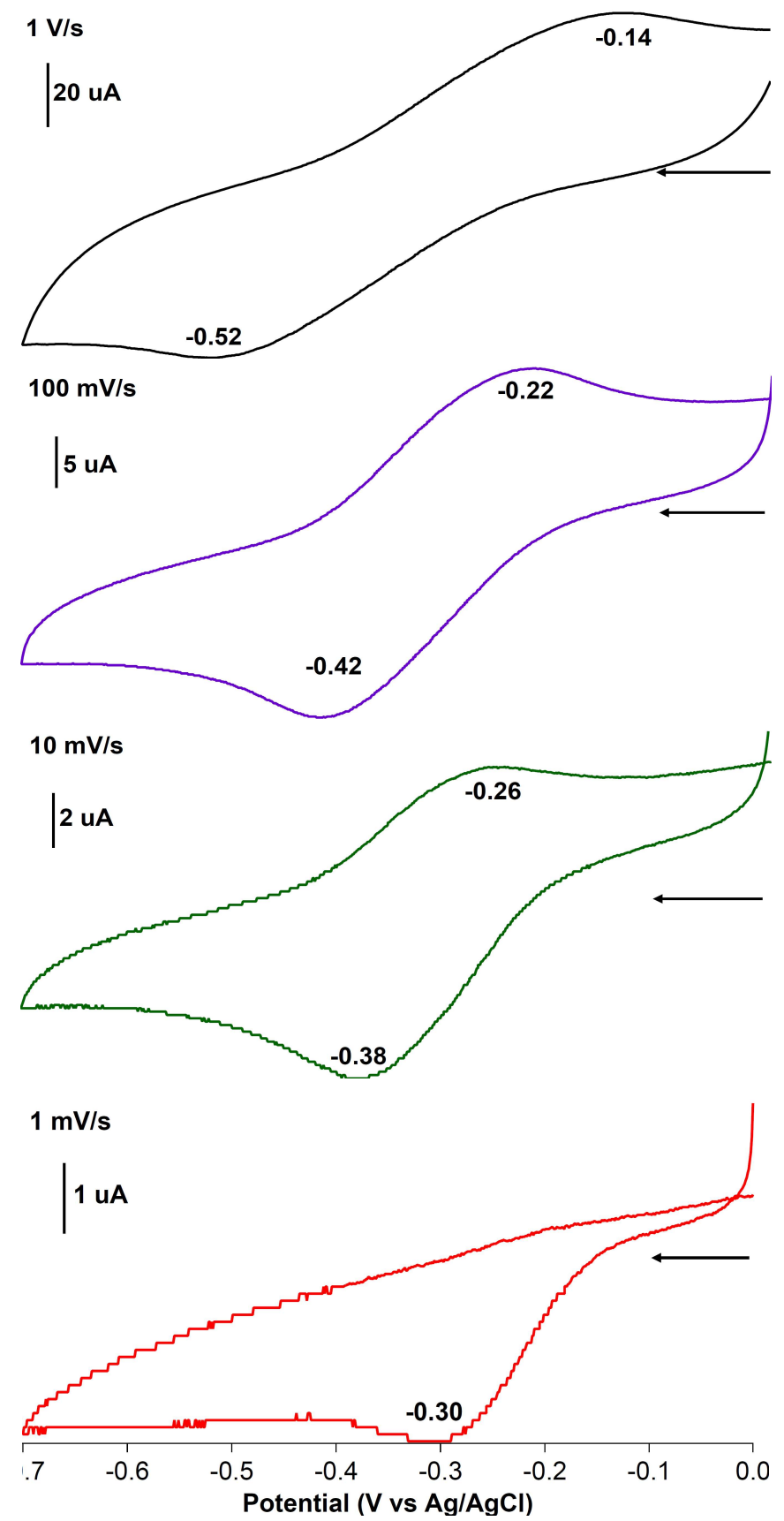

(II)

Figure 40. Reduction of $\mathbf{A}_{3} \mathbf{P y} \mathbf{P H}_{3}{ }^{+3}$ hyperporphyrin at different scan rates from 0 to $-0.7 \mathrm{~V}$ (I) Stacked CV; (II) CV aligned based on the scan rates. 


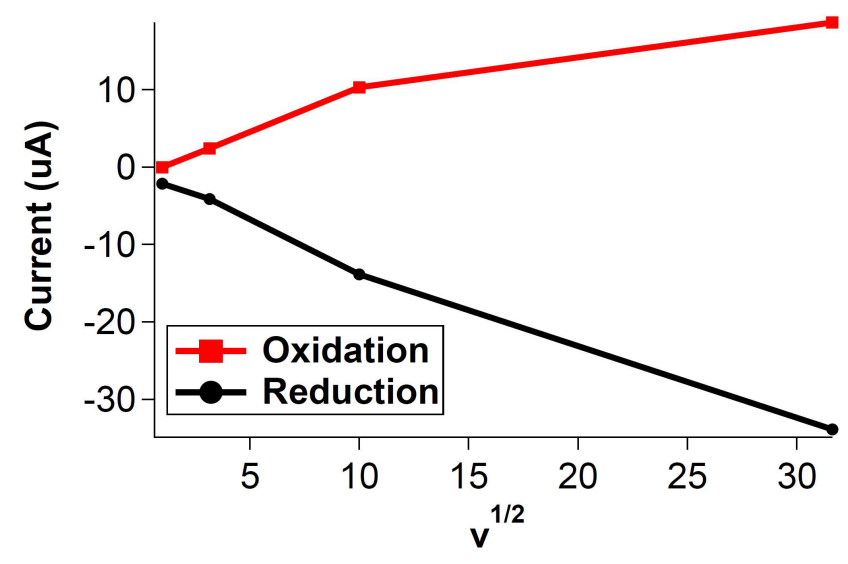

Figure 41. Correlation of current with scan rate using data from Fig. 40.

cis- $\mathbf{A}_{2} \mathbf{P y} y_{2} \mathbf{P} \&$ trans- $\mathbf{A}_{2} \mathbf{P y} 2 \mathbf{P}$. cis- $\mathbf{A}_{2} \mathbf{P y} 2 \mathbf{P}$ and trans- $\mathbf{A}_{2} \mathbf{P y} \mathbf{y}_{2} \mathbf{P}$ are both discussed here considering their structural similarities. In the spectroscopy of cis- $\mathbf{A}_{2} \mathbf{P y} \mathbf{y}_{2} \mathbf{P}$ and trans- $\mathbf{A}_{2} \mathbf{P} \mathbf{y}_{2} \mathbf{P}$, the Soret band at $422 \mathrm{~nm}$ decreases to $420 \mathrm{~nm}$ in cis- $\mathbf{A}_{2} \mathbf{P} \mathbf{y}_{2} \mathbf{P}$ while the Soret band at $420 \mathrm{~nm}$ increases to $421 \mathrm{~nm}$ in trans- $\mathbf{A}_{2} \mathbf{P y} \mathbf{2} \mathbf{P}$. The two compounds both have another Soret peak increasing and a new absorption in the hyperporphyrin range (Fig. 42 and 45).

The cyclic voltammetry of both cis- $\mathbf{A}_{2} \mathbf{P y} \mathbf{y}_{2} \mathbf{P}$ and $\operatorname{trans}-\mathbf{A}_{2} \mathbf{P y} \mathbf{y}_{2} \mathbf{P}$ in the form of free base each have three reduction potentials at $-1.02,-1.42$, and $-1.70 \mathrm{~V}$ and at -0.99 , -1.42 , and $-1.67 \mathrm{~V}$. These are assigned to two reductions of the porphyrin $\pi$ system and reduction of the pyridyl group. Two oxidation potentials on the reverse scans that cannot be assigned also appear. When the acid is titrated into the solution, the partially protonated forms involve potentials at $-0.97 /-0.72 \mathrm{~V}$ and $-1.18 \mathrm{~V}$. In the hyperporphyrins, the reduction potentials move to $-0.74 /-1.35 \mathrm{~V}$ and $-1.42 \mathrm{~V}$. 
For smaller range scannings, the free base and the partially protonated porphyrins are studied here. In the free base both $\mathbf{c i s}-\mathbf{A}_{2} \mathbf{P y} \mathbf{y}_{2} \mathbf{P}$ and $\operatorname{trans}-\mathbf{A}_{2} \mathbf{P y} \mathbf{y}_{2} \mathbf{P}$, the reductions of the porphyrin $\pi$ system and the pyridyl group could still be found. Interestingly, one reduction wave at $-0.79 \mathrm{~V}$ drops when the porphyrin starts to be reduced in cis- $\mathbf{A}_{2} \mathbf{P y}{ }_{2} \mathbf{P}$, which couldn't be explained so far. The oxidation waves at $-0.72 /-0.22 \mathrm{~V}$ in cis- $\mathbf{A}_{2} \mathbf{P y} 2 \mathbf{P}$ and $-0.65 /-0.19 \mathrm{~V}$ are also still under study. As for the intermediate between free base and hyperporphyrin, in cis- $\mathbf{A}_{2} \mathbf{P} \mathbf{y}_{2} \mathbf{P}$ there are two reduction waves at 0.97 and $-0.7 \mathrm{~V}$. The $-0.70 \mathrm{~V}$ wave could be the reduction of hyperporphyrin formed from protonated cis- $\mathbf{A}_{2} \mathbf{P y} \mathbf{y}_{2} \mathbf{P}$. In trans- $\mathbf{A}_{2} \mathbf{P} \mathbf{y}_{2} \mathbf{P}$, no new reduction wave showed up. This could be due to in cis- $\mathbf{A}_{2} \mathbf{P y} \mathbf{y}_{2} \mathbf{P}$, a $\mathbf{C}$ type hyperporphyrin could form which is more stable than $\mathbf{B}$ type hyperporphyrin from trans- $\mathbf{A}_{2} \mathbf{P} \mathbf{y}_{2} \mathbf{P}$.

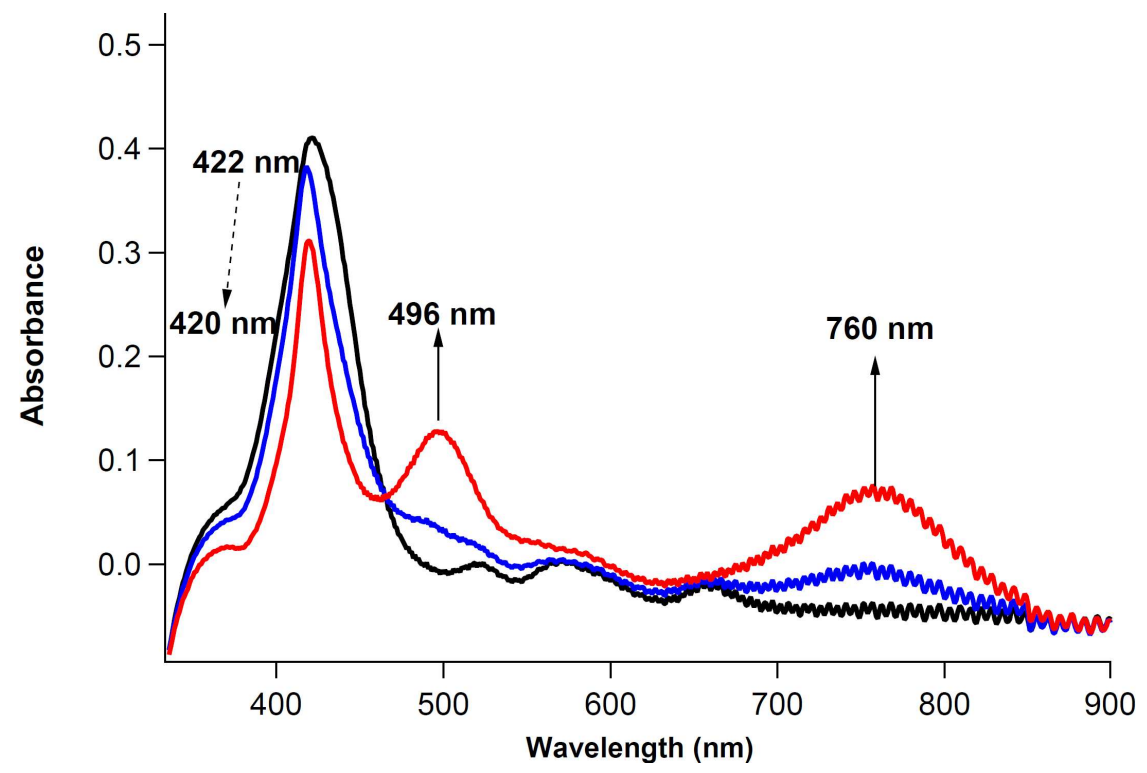

Figure 42. UV-vis spectroscopy of cis- $\mathbf{A}_{2} \mathbf{P} \mathbf{y}_{2} \mathbf{P}$ from free base to hyperporphyrin 


\section{$\left(\right.$ cis- $\left.\mathrm{A}_{2} \mathrm{Py}_{2} \mathrm{PH}_{4}{ }^{+4}\right)$.}
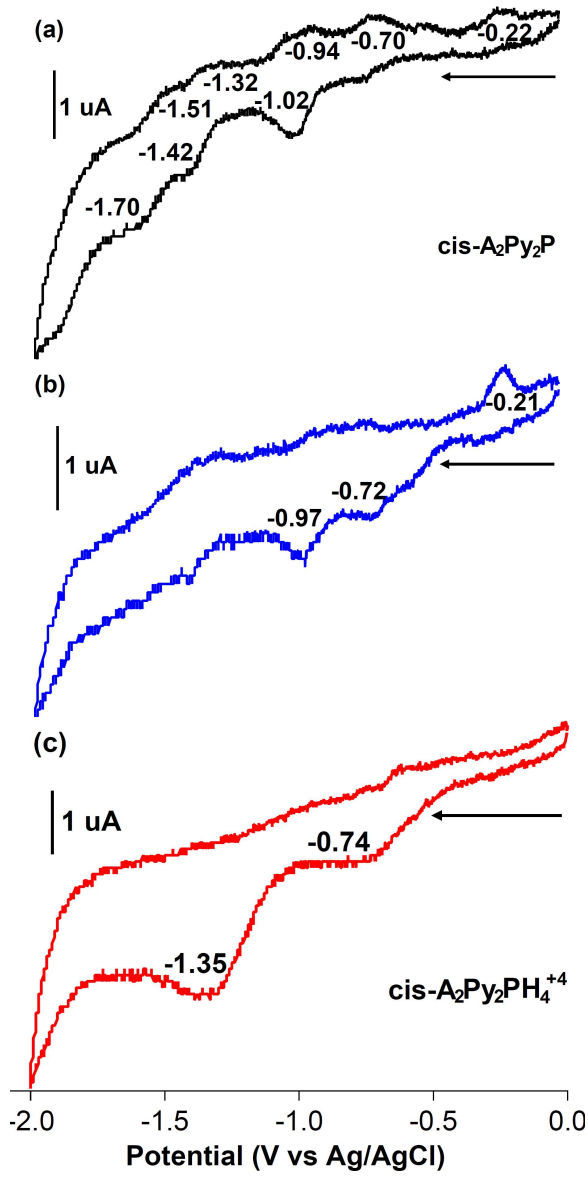

Figure 43. Cyclic voltammetry of cis- $\mathbf{A}_{2} \mathbf{P} \mathbf{y}_{2} \mathbf{P}$ from free base to hyperporphyrin cis- $\mathrm{A}_{2} \mathrm{Py}_{2} \mathrm{PH}_{4}{ }^{+4}$ (color coordinated with Fig. 42). 


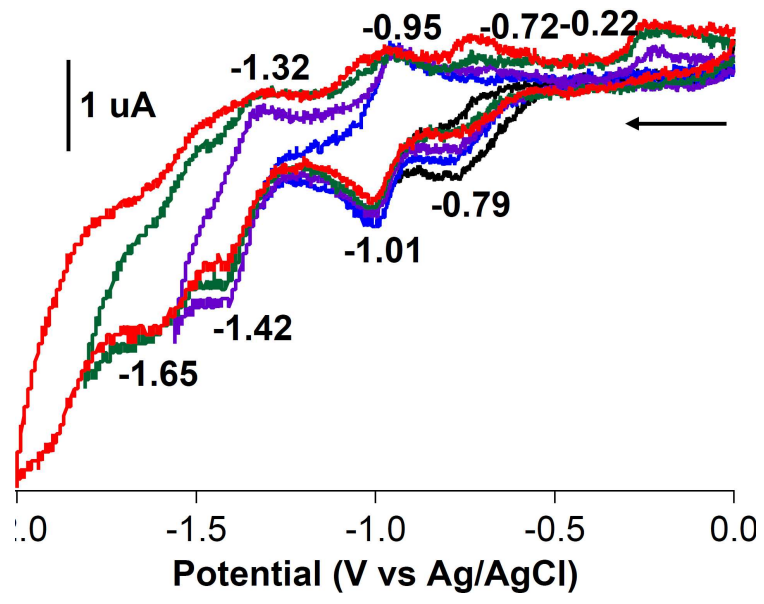

(I)

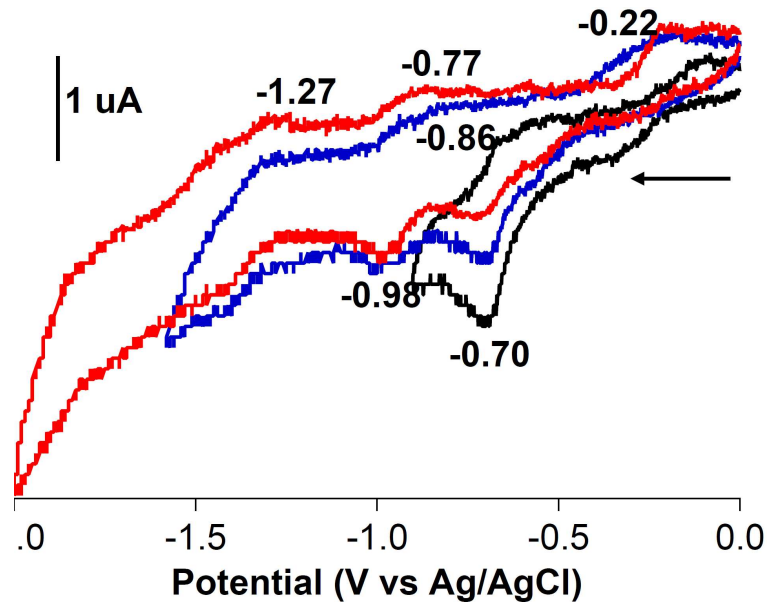

(II)

Figure 44. Cyclic voltammetry scanning different potential ranges in protonated cis- $\mathbf{A}_{2} \mathbf{P y} 2 \mathbf{P}$ (I: free base cis- $\mathbf{A}_{2} \mathbf{P y} \mathbf{y}_{2} \mathbf{P}$; II: cis- $\mathbf{A}_{2} \mathbf{P y} \mathbf{y}_{2} \mathbf{P}$ between free base and hyperporphyrin). 


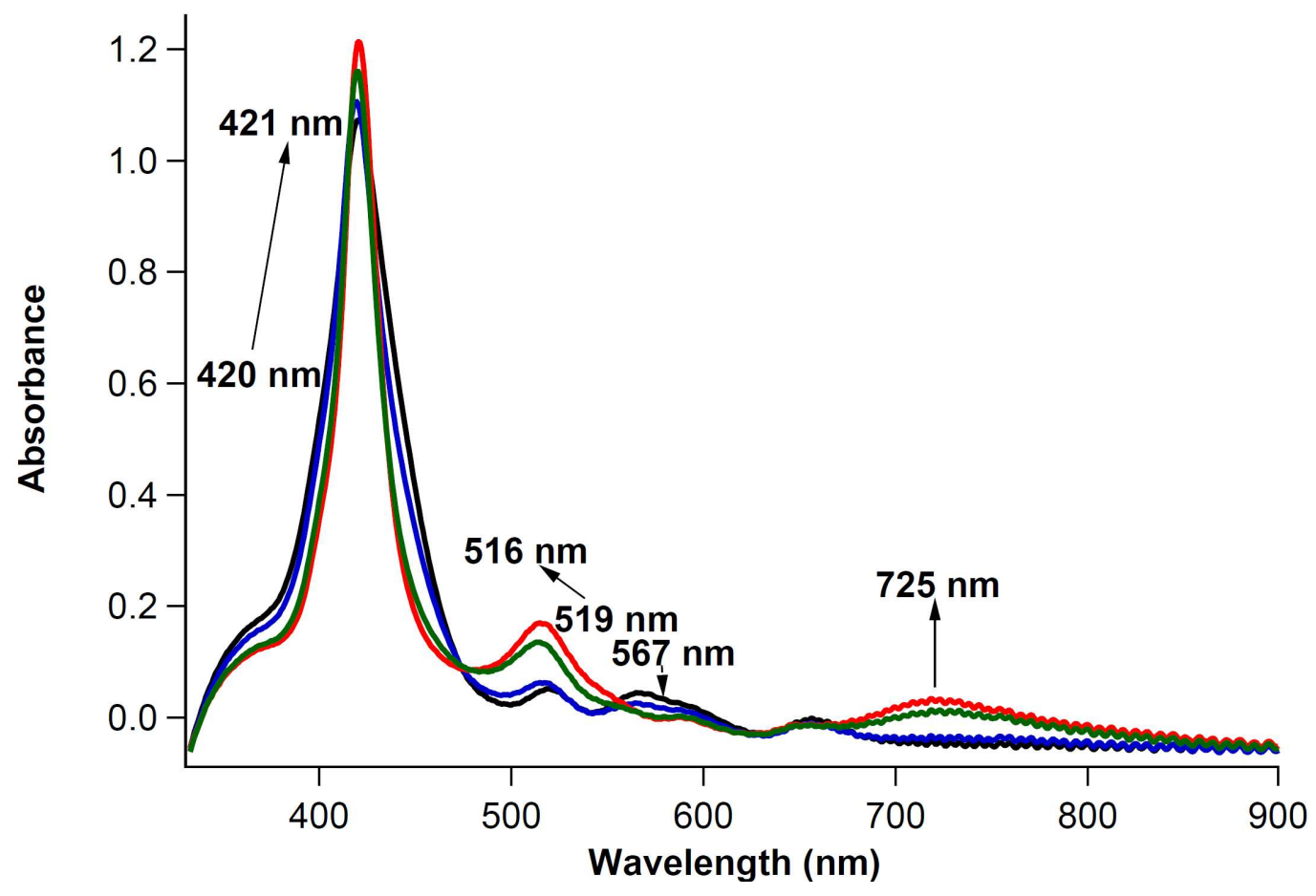

Figure 45. UV-vis spectroscopy of trans- $\mathbf{A}_{2} \mathbf{P} \mathbf{y}_{2} \mathbf{P}$ from free base to hyperporphyrin $\left(\right.$ trans- $\left.\mathrm{A}_{2} \mathrm{Py}_{2} \mathrm{PH}_{4}{ }^{+4}\right)$.
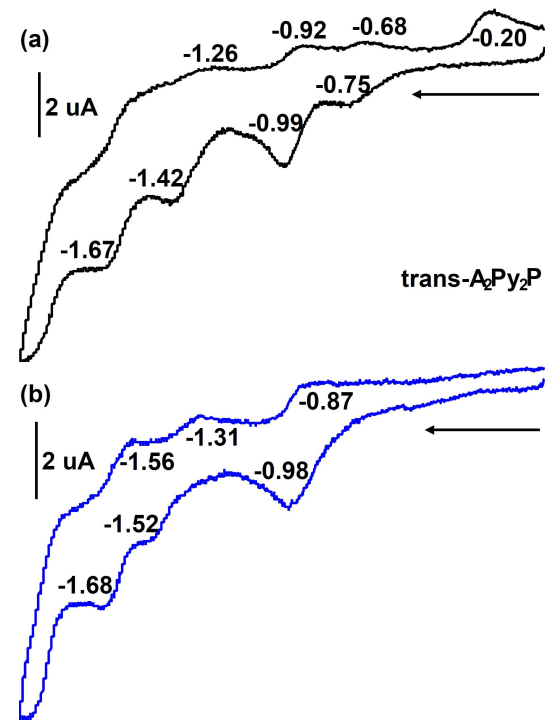

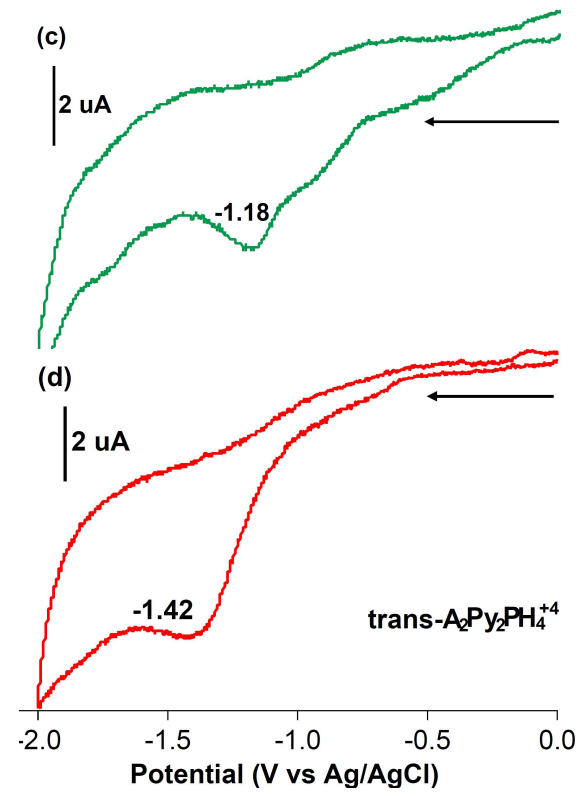

Figure 46. Cyclic voltammetry of trans- $\mathbf{A}_{2} \mathbf{P} \mathbf{y}_{2} \mathbf{P}$ from free base to hyperporphyrin trans- $\mathrm{A}_{2} \mathrm{Py}_{2} \mathrm{PH}_{4}{ }^{+4}$ (color coordinated with Fig. 45).

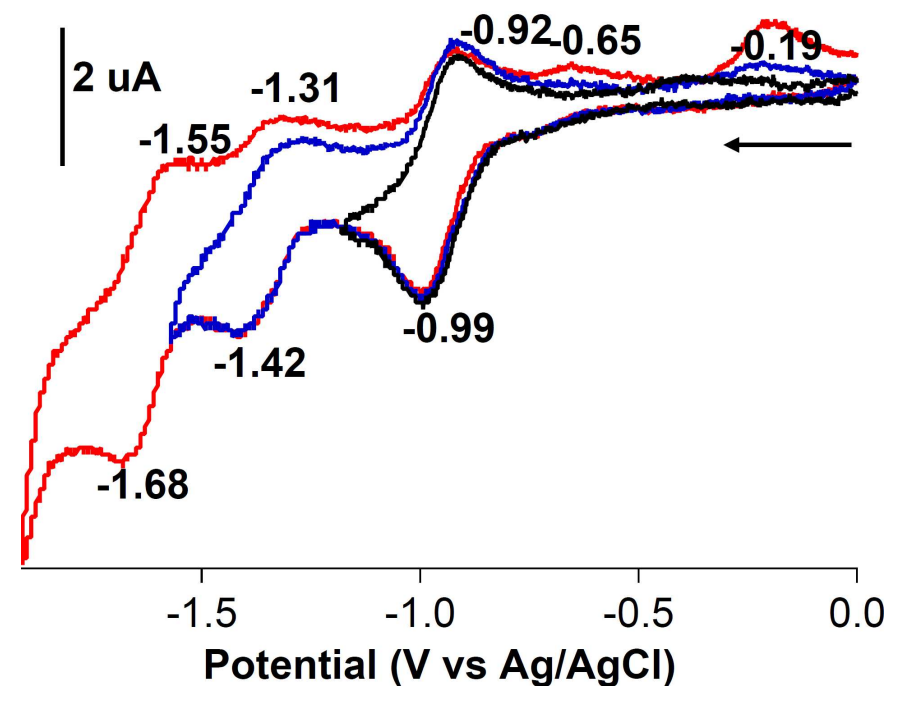

(I) 


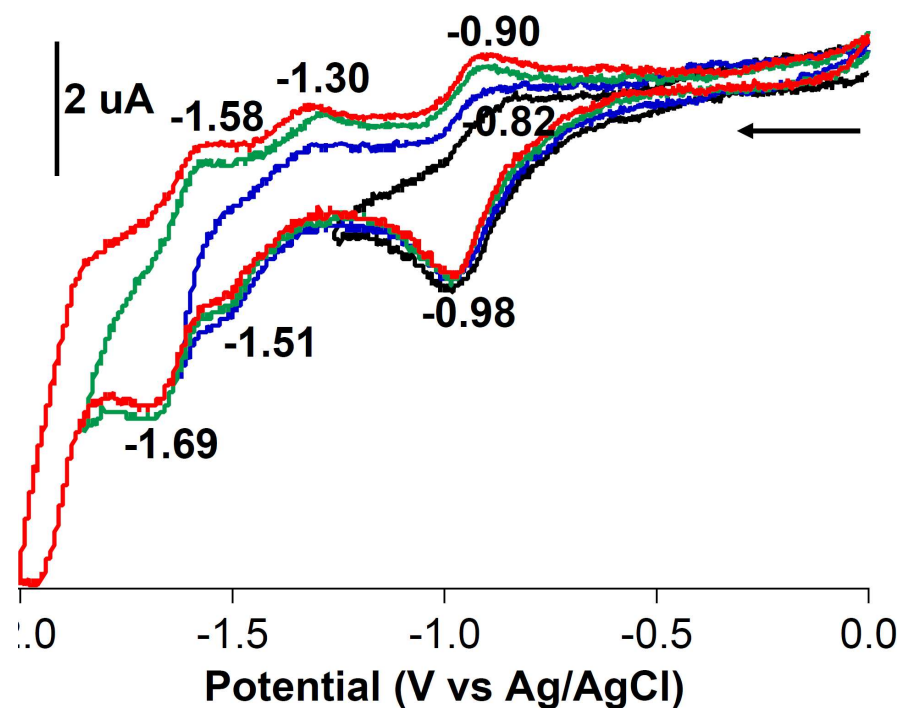

(II)

Figure 47. Cyclic voltammetry scanning different potential ranges in protonated trans- $\mathbf{A}_{2} \mathbf{P y} \mathbf{y}_{2} \mathbf{P}$ (I: free base trans- $\mathbf{A}_{2} \mathbf{P y} \mathbf{y}_{2} \mathbf{P}$; II: trans- $\mathbf{A}_{2} \mathbf{P y} \mathbf{y}_{2} \mathbf{P}$ between free base and hyperporphyrin).

\subsection{Comparison of reduction potentials in different protonation states}

Table 6 summarizes the reduction potentials of the aminophenyl/pyridyl porphyrins in each state (free base, hyperporphyrin). These features will be further discussed in the following section. 


\begin{tabular}{|c|c|c|c|c|c|c|c|c|}
\hline & $\underset{0 \rightarrow-1}{P}$ & $\begin{array}{c}P \\
-1 \rightarrow-2\end{array}$ & $\begin{array}{c}\mathrm{PH}_{2} \\
+3 \rightarrow+2\end{array}$ & $\begin{array}{c}\mathrm{PH}_{2} \\
+2 \rightarrow+1\end{array}$ & $\begin{array}{c}\mathrm{PH}_{2} \\
+1 \rightarrow 0\end{array}$ & $\begin{array}{c}\mathrm{PH}_{2} \\
0 \rightarrow-1\end{array}$ & $\begin{array}{c}\mathrm{PH}_{2} \\
-1 \rightarrow-2\end{array}$ & $\begin{array}{c}\text { Py } \\
0 \rightarrow-1\end{array}$ \\
\hline TPP & -1.16 & -1.33 & & & & & & \\
\hline $\mathrm{TPPH}_{2}{ }^{+2}$ & -1.16 & & & \multicolumn{2}{|c|}{-0.30} & & & \\
\hline TAPP & -1.17 & -1.58 & & & & & & \\
\hline $\mathrm{TAPPH}_{2}+2$ & & & & -0.50 & -0.66 & -1.15 & -1.75 & \\
\hline $\mathrm{A}_{3} \mathrm{PyP}$ & -1.09 & -1.51 & & & & & & -1.75 \\
\hline $\mathrm{A}_{3} \mathrm{PyPH}_{3}+3$ & & & -0.40 & -0.80 & -0.98 & -1.28 & -1.50 & \\
\hline cis- $\mathrm{A}_{2} \mathrm{Py}_{2} \mathrm{P}$ & -1.02 & -1.42 & & & & & & -1.70 \\
\hline cis- $\mathrm{A}_{2} \mathrm{Py}_{2} \mathrm{PH}_{4}+4$ & & -1.35 & & -0.74 & & & & \\
\hline trans- $\mathrm{A}_{2} \mathrm{Py}_{2} \mathrm{P}$ & -0.99 & -1.42 & & & & & & -1.67 \\
\hline trans- $\mathrm{A}_{2} \mathrm{Py}_{2} \mathrm{PH}_{4}{ }^{+4}$ & & -1.42 & & & & & & \\
\hline
\end{tabular}

Table 6 . The reduction potentials of aminophenyl/pyridyl porphyrins in each protonation state.

The shift of porphyrin reduction potentials under protonation can be explained by both structure changes and charge distribution. TPP, as one of the well studied compounds in this field, has been discussed before. ${ }^{54}$ The reduction of porphyrins mainly happens on the LUMO level $\left(\mathrm{e}_{\mathrm{g}}\right)$. The easier reduction of protonated TPP compared to free base TPP indicates the stabilization of the $e_{g}$ orbital, which could be affected by acidification in two repects. First, a saddled conformation of TPP could be formed upon the addition of protons, which decreases the conjugation of the macrocycle and the interaction between $\mathrm{e}_{\mathrm{g}}$ and $\mathrm{a}_{2 \mathrm{u}}, \mathrm{a}_{1 \mathrm{u}}$ repectively. ${ }^{75}$ Also, the electron density of the $\pi$ system shifting from the macrocycle to the protonated nitrogen in the porphyrin-acid adducts can lead to easier reduction of the $\pi$ system. ${ }^{7}$

When aminophenyl/pyridyl porphyrins are considered, their reduction potential shifts could also be explained in such manner even though hyperporphyrin effects are 
involved. TAPP, as has been elucidated before, could delocalize the positive charges to aminophenyl substituents from the protonated internal nitrogens, therefore generating hyperporphyrin effect. The formation of the hyperporphyrin destroys the conjugated structure of the macrocycle, stabilizing the $e_{g}$ orbital, thus also making the reductions easier. Moreover, the positive charges are delocalized to aminophenyl groups and make aminophenyl groups electron-withdrawing. The charge distribution of the $\pi$ system is therefore decreased.

cis- $\mathbf{A}_{2} \mathbf{P y} \mathbf{y}_{2} \mathbf{P}$ and trans- $\mathbf{A}_{2} \mathbf{P} \mathbf{y}_{2} \mathbf{P}$, contrary to TAPP, don't show easier reduction potentials. This can be attributed to the fast exchange between hyperporphyrin and free base porphyrins. With aminophenyl as the substituents, both cis- $\mathbf{A}_{2} \mathbf{P} \mathbf{y}_{2} \mathbf{P}$ and trans- $\mathbf{A}_{2} \mathbf{P y} \mathbf{y}_{2} \mathbf{P}$ can form hyperporphyrins upon acidification. While cis- $\mathbf{A}_{2} \mathbf{P} \mathbf{y}_{2} \mathbf{P}$ can do type $\mathrm{C}$ hyperporphyrin, trans- $\mathbf{A}_{2} \mathbf{P} \mathbf{y}_{2} \mathbf{P}$ can do only type B hyperporphyrin. However, the hyperporphyrins in these two cases are not stable. Instead they undergo fast exchange, which can be seen from the proton NMR spectra.

At hyperporphyrin stage, both $\mathbf{A} \mathbf{3} \mathbf{P y} \mathbf{P}$ and $\mathbf{T A P P}$ are observed to have several reduction waves. We speculate that they can both be reduced all the way to -2 charges. In both compounds, several iminium structures form in the hyperporphyrins. The reduction first happens to these iminiums. Reduction of $\mathbf{A}_{3} \mathbf{P y P H} \mathbf{H}^{+\mathbf{3}}$ by two electrons generates a reduced dihydroporphyrin that still has the possibility of Type D resonance interactions with pyridinium (Scheme 4). This reduced pyridinium form can react with $\mathrm{H}^{+}$to generate hydrogen in a catalytic cycle that regenerates the original hyperporphyrin. 
It was considered that a persistent peak at $-0.24 \mathrm{~V}$ in the reverse oxidative waves from the $\mathbf{A}_{3} \mathbf{P y}_{\mathbf{P H}}{ }_{3}{ }^{+3}$ reduction might have been due to the oxidation of hydrogen. A brief attempt to detect the presence of hydrogen was made. Cyclic voltammetry was run after purging $\mathrm{H}_{2}$ into DMSO containing electrolyte. However, because the solubility of $\mathrm{H}_{2}$ is low in DMSO, it was hard to differentiate the oxidation peak of hydrogen from the noise.

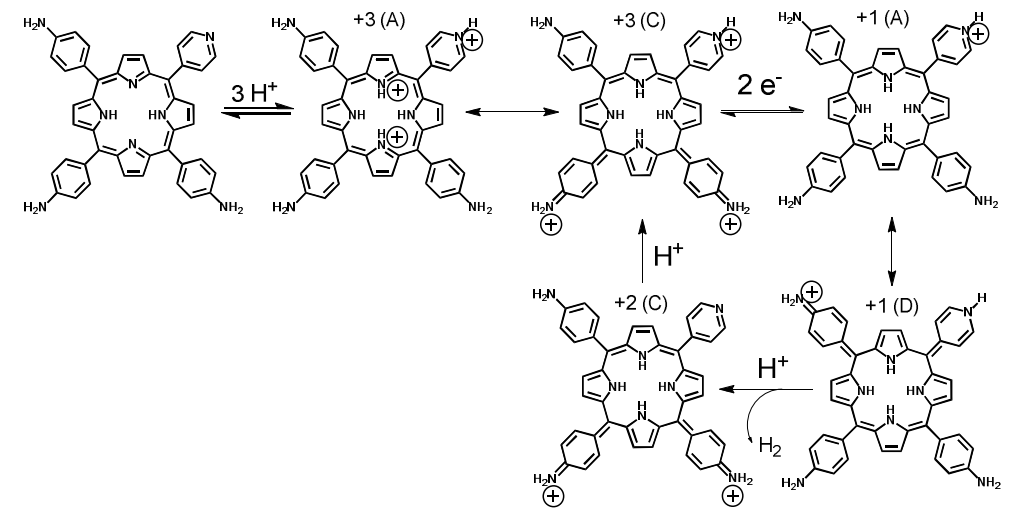

(I)

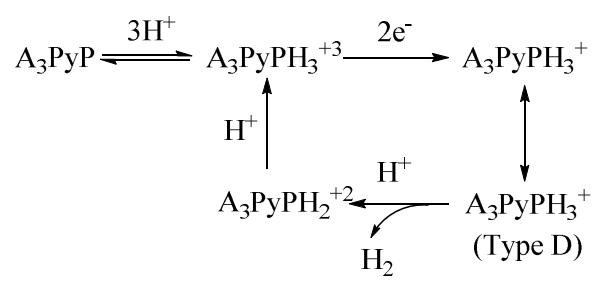

(II)

Scheme 4. Possible mechanism of the reduction of $\mathbf{A 3} \mathbf{3} \mathbf{P} \mathbf{P}$ hyperporphyrin and catalytic generation of hydrogen 


\section{Chapter 6. Conclusions}

The primary novel conclusion of this dissertation research is that 5,10,15-tri(4-aminophenyl)-20-(4-pyridyl)porphyrin (A3 PyP) was proposed to undergo charge delocalizations to produce a novel D-type hyperporphyrin when protonated in DMSO. This new type of hyperporphyrin has also been proposed to have the ability to reduce protons into hydrogen.

In Chapter 3, spectroscopy studies on a series of aminophenyl/pyridyl porphyrins revealed that the sequence of protonating pyridyl or pyrrole nitrogens can be modulated by aminophenyl groups. The titration of TPyP, Zn-TPyP and TMPyP $\mathbf{P}^{+4}$ all led to the conclusion that the protonation of peripheral pyridyl groups is prior to the inner pyrrole nitrogens. When aminophenyl groups are involved, they are always the last to protonate, considering they turn into ammonium ion after resonance and protonating them would decrease the resonance stabilization. The basicity of internal pyrrole nitrogens increases with multiple aminophenyl groups as the substituents. Therefore, the sequence of protonation of pyridyl and pyrrole nitrogen in trans- $\mathbf{A}_{2} \mathbf{P y} 2 \mathbf{P}$, cis- $\mathbf{A}_{2} \mathbf{P y} \mathbf{y}_{2} \mathbf{P}$ and $\mathbf{A}_{3} \mathbf{P y P}$ cannot be distinguished.

To generate hyperporphyrin effect, aminophenyl groups need to be present. The number of aminophenyl groups determines the type of hyperporphyrins that can form. A type spectrum refers to the normal porphyrin spectrum, in which no interaction happens between the substituents and the porphyrin ring. B type spectrum can be seen in $\mathbf{A P y}_{3} \mathbf{P}$ and trans- $\mathbf{A}_{2} \mathbf{P y} \mathbf{2} \mathbf{P}$, which has been defined as one aminophenyl substituent 
interacting with the porphyrin ring. C type spectrum has the porphyrin ring delocalizing charges to two aminophenyl substituents and happens with cis- $\mathbf{A}_{2} \mathbf{P y} 2 \mathbf{P}$, A3PyP, and TAPP. All of these hyperporphyrin spectra are characterized by a strong far red absorption band over $700 \mathrm{~nm}$ and splitting of the Soret band. More aminophenyl groups result in more intense hyperporphyrin absorption and greater red shifts.

The $\mathbf{D}$ type hyperporphyrin arises from the protonation of A3PyP. The alignment of the three aminophenyl groups allows for two different cis orientations to form $\mathbf{C}$ type hyperporphyrin. Yet one aminophenyl group is still left. This aminophenyl group is proposed to donate electrons to the pyridinium group from the protonation of pyridyl group, generating a novel structure in which all the meso groups are interacting with the porphyrin ring, which was indicated by the remarkably strong hyperporphyrin absorption.

Chapter 4 focused on the NMR studies of these hyperporphyrins and more structural information was obtained. The NMR spectra of porphyrins are generally determined by the large $\pi$ system ring current of the macrocycles and the inductive effect of the peripheral groups. The different NMR shifts between $\mathbf{A P y}_{3} \mathbf{P}, \mathbf{c i s}_{\mathbf{2}}-\mathbf{A}_{2} \mathbf{P} \mathbf{y}_{2} \mathbf{P}$, and $\mathbf{A}_{3} \mathbf{P y} \mathbf{P} / \mathbf{T A P P}$ can be attributed to the protonation sequence of the meso substituents. Pyridyl groups protonated into pyridinium first in $\mathbf{A P y}_{3} \mathbf{P}$ and $\mathbf{c i s}-\mathbf{A}_{2} \mathbf{P} \mathbf{y}_{2} \mathbf{P}$ leading to the inductive effect, which is an electron-withdrawing effect dominating the NMR shift.

The formation of hyperporphyrins in $\mathbf{A} \mathbf{A}_{3} \mathbf{P y} \mathbf{P}$ and TAPP leads to more coplanar 
conformations of the macrocycles, therefore has the feature of loss of the conjugation structure. The conclusion that slow exchanges occur in A3PyP and TAPP from free base to hyperporphyrin can also be drawn from their NMR spectra, which show the presence of both species at the same time. In $\mathbf{A}_{3} \mathbf{P y P H} \mathbf{3}^{+3}$, two types of aminophenyls in 2:1 ratio have been noted. The pyridyl group in $\mathbf{A}_{3} \mathbf{P y}_{\mathbf{P H}} \mathbf{P H}^{+\mathbf{3}}$ was also observed to have chemical shifts significantly less downfield compared to pyridinium. The $\mathbf{D}$ type hyperporphyrin can be validated based on these observations. The 2D NOESY NMR showed significantly strong interactions between nearby protons, suggesting greater coplanarity between the meso substituents and the porphyrin macrocycle.

In Chapter 5, the hyperporphyrins were investigated by cyclic voltammetry. The reduction of hyperporphyrins from $\mathbf{A}_{3} \mathbf{P y P}$ and TAPP occur at less negative potentials than their free bases. It was concluded that the charge transfer from the inner ring to aminophenyl groups lowers the LUMO energy level. More importantly, these two hyperporphyrins can go through several one electron reductions. The reductions in both cases start with the peripheral aminophenyl groups that carry positive charges, followed by the reduction of the porphyrin ring itself. The hyperporphyrin from TAPP decomposed when the porphyrin ring was reduced. $\mathbf{A}_{3} \mathbf{P y} \mathbf{P H}_{3}{ }^{+\mathbf{3}}$ hyperporphyrin, on the contrary, was stable throughout the reduction.

A3PyP hyperporphyrin was also proposed to catalyze hydrogen evolution in the reduced form. The porphyrin was protonated and a $\mathbf{C}$ type hyperporphyrin was generated first. The reductions of the iminium substituents induce the interaction between pyridinium and the remaining aminophenyl group (Fig. 48), producing a 
reduced porphyrin with a dihydropyridine substituent which is a good candidate for donating hydride. Hydrogen can be produced from hydride bonding with a proton.

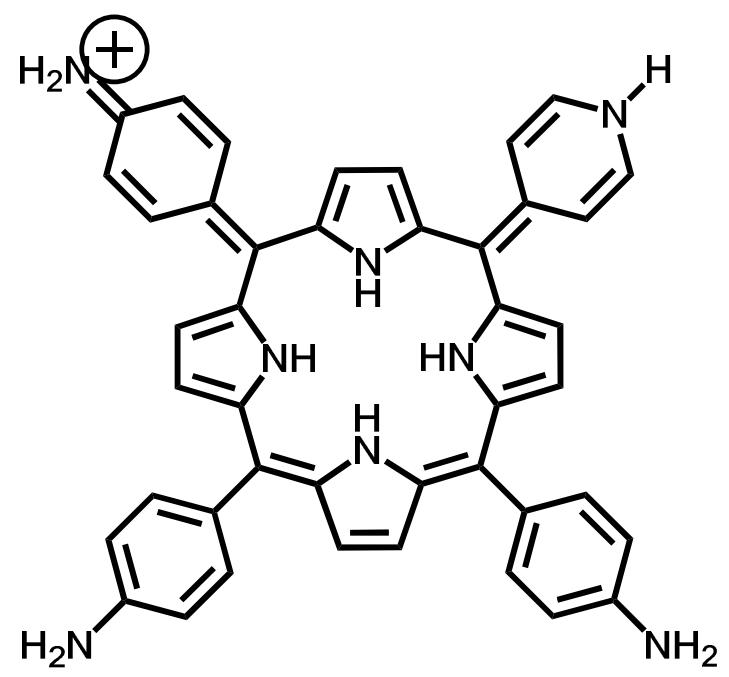

Figure 48. The structure of reduced $\mathbf{D}$ type hyperporphyrin $\left(\mathbf{A}_{3} \mathbf{P y} \mathbf{P} \mathbf{H}_{3}{ }^{+}\right)$.

Pyridine has been known as a good reagent in reducing $\mathrm{CO}_{2} .{ }^{59,62}$ Its role in hydrogen evolution is yet to be explored. Meanwhile, various porphyrins have been used in hydrogen evolution, but they either are metalloporphyrins with the metals as the catalytic center or function as a photosensitizer. ${ }^{78-81}$ Our study here shows promising applications of both porphyrin and pyridyl groups in hydrogen evolution. By properly tuning the meso substituents, the pyridyl porphyrin could be used as both the photosensitizer and the catalyst. 


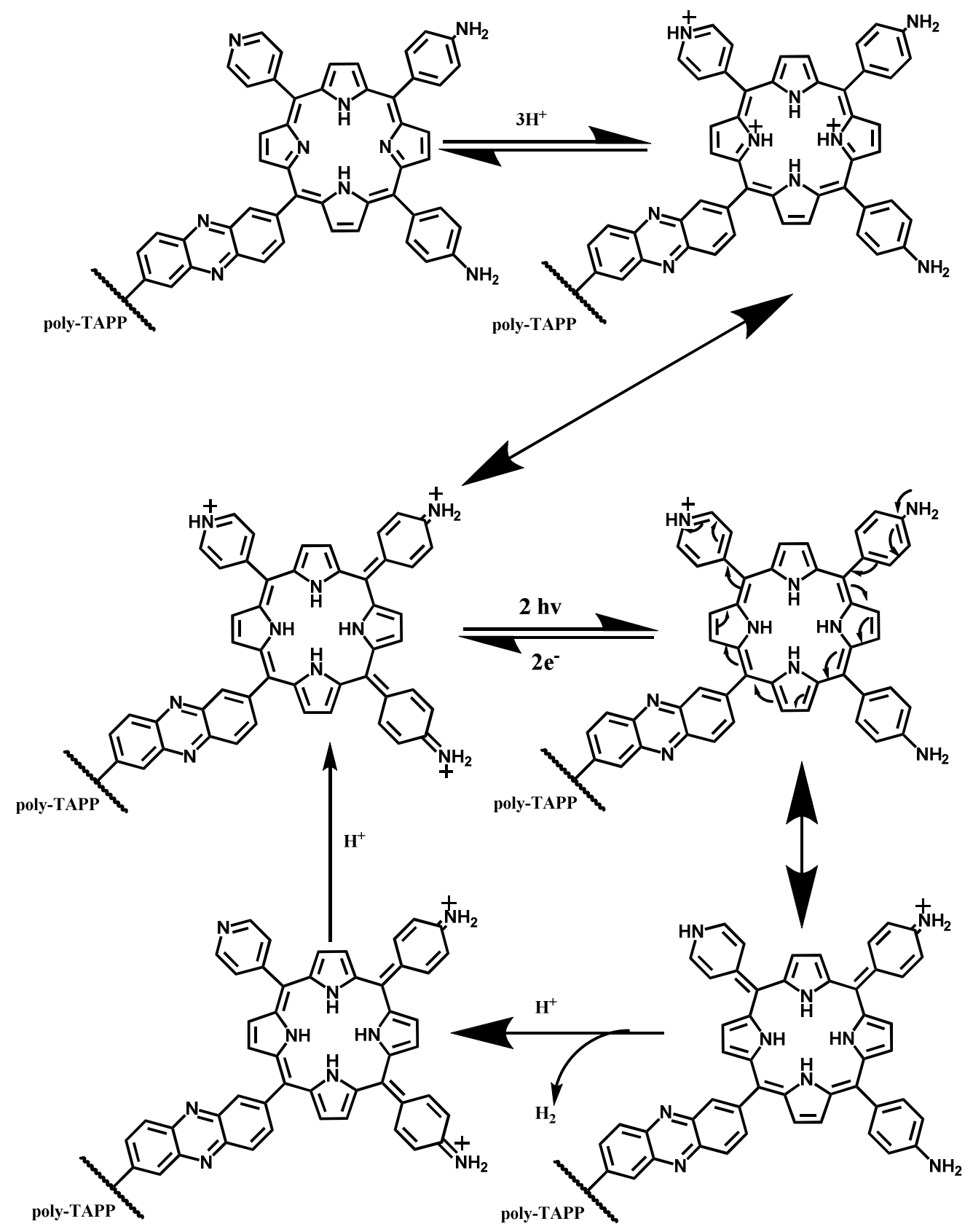

Figure 49. Proposed structure of $\mathbf{A} 3 \mathbf{P y P}$ polymer as catalyst.

Aminophenyl porphyrin polymers are good photosensitizers as well as good electron donors which have been applied in inverse dye-sensitized solar cells. ${ }^{82}$ 
Polymers of TAPP that also include pyridyl groups (Fig. 49) would be an interesting possibility for further study. Upon excitation from a light source, the polymers should be able to donate electrons to the $\mathrm{D}$ type hyperporphyrin, analogous to the electroreductions we have observed. In addition, covalent bonding of aminophenyl groups between the TAPP polymer and pyridyl porphyrin can form a phenazine linkage to increase the electron transfer efficiency. New ways of detecting hydrogen gas such as gas chromatography ${ }^{83}$ will also be studied. 


\section{References}

1. Bowman, S. E. J.; Bren, K. L., The chemistry and biochemistry of hemec: functional bases for covalent attachment. Natural Product Reports 2008, 25 (6), 1118-1130.

2. Tejero, J.; Sparacino-Watkins, C. E.; Ragireddy, V.; Frizzell, S.; Gladwin, M. T., Exploring the mechanisms of the reductase activity of neuroglobin by site-directed mutagenesis of the heme distal pocket. Biochemistry 2015, 54, 722-33.

3. Lakra, N.; Nutan, K. K.; Das, P.; Anwar, K.; Singla-Pareek, S. L.; Pareek, A., A nuclear-localized histone-gene binding protein from rice (OsHBP1b) functions in salinity and drought stress tolerance by maintaining chlorophyll content and improving the antioxidant machinery. Journal of Plant Physiology 2015, 176 (0), $36-46$.

4. Mandal, P.; Sarkar Manna, j.; Das, D.; Mitra, M. K., Excitonic Dynamics of Chlorophyll-a Molecules in Chitosan Hydrogel Scaffold. Photochemical \& Photobiological Sciences 2015 epub ahead of print.

5. Campbell, W. M.; Jolley, K. W.; Wagner, P.; Wagner, K.; Walsh, P. J.; Gordon, K. C.; Schmidt-Mende, L.; Nazeeruddin, M. K.; Wang, Q.; Grätzel, M.; Officer, D. L., Highly Efficient Porphyrin Sensitizers for Dye-Sensitized Solar Cells. The Journal of Physical Chemistry C 2007, 111 (32), 11760-11762.

6. Gouterman, M., Optical Spectra and Electronic Structure of Porphyrins and Related Rings. In The Porphyrins, Dolphin, D., Ed. Academic Press: New York, 1978; 
Vol. III, pp 1-165.

7. Zakavi, S.; Najafi Ragheb, M.; Rafiee, M., Electrochemical study of the dication of porphyrins with carboxylic acids: Shift of the absorption bands compared to that of the redox potentials. Inorganic Chemistry Communications 2012, 22 (0), 48-53.

8. Vitasovic, M.; Gouterman, M.; Linschitz, H., Calculations on the origin of hyperporphyrin spectra in sequentially protonated meso-(dimethylaminophenyl) porphyrins. Journal of Porphyrins and Phthalocyanines 2001, 5 (3), 191-197.

9. Cheng, B.; Munro, O. Q.; Marques, H. M.; Scheidt, W. R., An Analysis of Porphyrin Molecular FlexibilityUse of Porphyrin Diacids. Journal of the American Chemical Society 1997, 119 (44), 10732-10742.

10. Hamor, M. J.; Hamor, T. A.; Hoard, J. L., The Structure of Crystalline Tetraphenylporphine. The Stereochemical Nature of the Porphine Skeleton. Journal of the American Chemical Society 1964, 86 (10), 1938-1942.

11. Stone, A.; Fleischer, E. B., The molecular and crystal structure of porphyrin diacids. Journal of the American Chemical Society 1968, 90 (11), 2735-2748.

12. Goldberg, P. K.; Pundsack, T. J.; Splan, K. E., Photophysical Investigation of Neutral and Diprotonated Free-Base Bis(Arylethynyl)porphyrins. J. Phys. Chem. A 2011, 115 (Copyright (C) 2013 American Chemical Society (ACS). All Rights Reserved.), 10452-10460.

13. Imahori, H.; Kurotobi, K.; Walter, M. G.; Rudine, A. B.; Wamser, C. C., Porphyrin- and Phthalocyanine-Based Solar Cells. Handbook of Porphyrin Science 2012, $18,58-123$. 
14. Diau, E. W.-G.; Li, L.-L., Porphyrin-Sensitized Solar Cells. Handbook of Porphyrin Science 2012, 28, 279-318.

15. Hasobe, T., Porphyrin-Based Supramolecular Nanoarchitectures for Solar Energy Conversion. J. Phys. Chem. Lett. 2013, 4 (Copyright (C) 2013 American Chemical Society (ACS). All Rights Reserved.), 1771-1780.

16. Shelnutt, J. A.; Tian, Y.; Martin, K. E.; Medforth, C. J., Binary Ionic Porphyrin Nanomaterials for Energy from Sunlight. Handbook of Porphyrin Science 2012, 28, $228-278$.

17. Denis, T. G. S.; Huang, Y.-Y.; Hamblin, M. R., Cyclic Tetrapyrroles in Photodynamic Therapy: The Chemistry of Porphyrins and Related Compounds in Medicine. Handbook of Porphyrin Science 2012, 27, 256-303.

18. Giuntini, F.; Boyle, R.; Sibrian-Vazquez, M.; Vicente, M. G. H., Porphyrin Conjugates for Cancer Therapy. Handbook of Porphyrin Science 2012, 27, 304-416.

19. Alonso, C.; Boyle, R. W., Bioconjugates of porphyrins and related molecules for photodynamic therapy. Handbook of Porphyrin Science 2010, 4, 121-190.

20. Fenwick, O.; Sprafke, J. K.; Binas, J.; Kondratuk, D. V.; Di Stasio, F.; Anderson, H. L.; Cacialli, F., Linear and Cyclic Porphyrin Hexamers as Near-Infrared Emitters in Organic Light-Emitting Diodes. Nano Lett. 2011, 11 (6), 2451-2456.

21. Graham, K. R.; Yang, Y.; Sommer, J. R.; Shelton, A. H.; Schanze, K. S.; Xue, J.; Reynolds, J. R., Extended Conjugation Platinum(II) Porphyrins for use in Near-Infrared Emitting Organic Light Emitting Diodes. Chem. Mater. 2011, 23 (Copyright (C) 2013 American Chemical Society (ACS). All Rights Reserved.), 
$5305-5312$.

22. Ryan, A.; Tuffy, B.; Horn, S.; Blau, W. J.; Senge, M. O., Carbazole-linked porphyrin dimers for organic light emitting diodes: synthesis and initial photophysical studies. Tetrahedron 2011, 67 (Copyright (C) 2013 American Chemical Society (ACS). All Rights Reserved.), 8248-8254.

23. Lei, J.; Ju, H., Porphyrin-Based Nanocomposites for Biosensing. Handbook of Porphyrin Science 2012, 18, 170-212.

24. Kemling, J. W.; Qavi, A. J.; Bailey, R. C.; Suslick, K. S., Nanostructured Substrates for Optical Sensing. J. Phys. Chem. Lett. 2011, 2 (22), 2934-2944.

25. Paolesse, R.; Monti, D.; Nardis, S.; Natale, C. D., Porphyrin-Based Chemical Sensors. Handbook of Porphyrin Science 2010, 12, 54.

26. Ruf, H. H.; Wende, P., Hyperporphyrin spectra of ferric dimercaptide-hemin complexes. Models for ferric cytochrome P450-thiol complexes. Journal of the American Chemical Society 1977, 99 (16), 5499-5500.

27. Ruf, H. H.; Wende, P.; Ullrich, V., Models for ferric cytochrome P450. Characterization of hemin mercaptide complexes by electronic and ESR spectra. Journal of Inorganic Biochemistry 1979, 11 (3), 189-204.

28. Sun, S.; Sono, M.; Dawson, J. H., Mono- and bis-phosphine-ligated H93G myoglobin: Spectral models for ferrous-phosphine and ferrous-CO cytochrome P450. Journal of Inorganic Biochemistry 2013, 127 (0), 238-245.

29. Sakurai, H.; Tsuchiya, K.; Sugasaki, N.; Shibuya, M., Unusual hyperporphyrin spectrum by bis(glutathione dimethyl ester)-hemin complex, a model of cytochrome 
P-450-thiolate complexes. Biochemical and Biophysical Research Communications 1990, $169(1), 22-29$.

30. Hanson, L. K.; Eaton, W. A.; Sligar, S. G.; Gunsalus, I. C.; Gouterman, M.; Connell, C. R., Origin of the anomalous Soret spectra of carboxycytochrome P-450. Journal of the American Chemical Society 1976, 98 (9), 2672-2674.

31. Wasbotten, I. H.; Conradie, J.; Ghosh, A., Electronic Absorption and Resonance Raman Signatures of Hyperporphyrins and Nonplanar Porphyrins. The Journal of Physical Chemistry B 2003, 107 (15), 3613-3623.

32. Rudine, A. B.; DelFatti, B. D.; Wamser, C. C., Spectroscopy of Protonated Tetraphenylporphyrins with Amino/Carbomethoxy Substituents: Hyperporphyrin Effects and Evidence for a Monoprotonated Porphyrin. The Journal of Organic Chemistry 2013, 78 (12), 6040-6049.

33. Wang, C.; Wamser, C. C., Hyperporphyrin Effects in the Spectroscopy of Protonated Porphyrins with 4-Aminophenyl and 4-Pyridyl Meso Substituents. The Journal of Physical Chemistry A 2014, 118 (20), 3605-3615.

34. Weinkauf, J. R.; Cooper, S. W.; Schweiger, A.; Wamser, C. C., Substituent and Solvent Effects on the Hyperporphyrin Spectra of Diprotonated Tetraphenylporphyrins. J. Phys. Chem. A 2003, 107 (Copyright (C) 2013 American Chemical Society (ACS). All Rights Reserved.), 3486-3496.

35. Antipas, A.; Buchler, J. W.; Gouterman, M.; Smith, P. D., Porphyrins. 36. Synthesis and optical and electronic properties of some ruthenium and osmium octaethylporphyrins. Journal of the American Chemical Society 1978, 100 (10), 
3015-3024.

36. Antipas, A.; Buchler, J. W.; Gouterman, M.; Smith, P. D., Porphyrins. 39. Ammine and nitridoosmium porphyrins. Ligand effects on the electronic structure of osmium octaethylporphyrins. Journal of the American Chemical Society 1980, 102 (1), 198-207.

37. Gouterman, M.; Hanson, L. K.; Khalil, G. E.; Leenstra, W. R.; Buchler, J. W., Porphyrins. XXXII. Absorptions and luminescence of Cr(III) complexes. The Journal of Chemical Physics 1975, 62 (6), 2343-2353.

38. Gouterman, M.; Schwarz, F. P.; Smith, P. D.; Dolphin, D., Porphyrins. XXVII. Spin - orbit coupling and luminescence of Group IV complexes. The Journal of Chemical Physics 1973, 59 (2), 676-690.

39. Sayer, P.; Gouterman, M.; Connell, C. R., Porphyrins. 34. Phosphorus complexes of octaethylporphyrin. Journal of the American Chemical Society 1977, 99 (4), 1082-1087.

40. De Luca, G.; Romeo, A.; Scolaro, L. M., Aggregation Properties of Hyperporphyrins with Hydroxyphenyl Substituents. The Journal of Physical Chemistry B 2006, 110 (29), 14135-14141.

41. Guo, H.; Jiang, J.; Shi, Y.; Wang, Y.; Liu, J.; Dong, S., UV-Vis Spectrophotometric Titrations and Vibrational Spectroscopic Characterization of meso-(p-Hydroxyphenyl)porphyrins. The Journal of Physical Chemistry B 2004, 108 (28), 10185-10191.

42. Guo, H.; Jiang, J.; Shi, Y.; Wang, Y.; Wang, Y.; Dong, S., Sequential 
Deprotonation of meso-(p-Hydroxyphenyl)porphyrins in DMF: From Hyperporphyrins to Sodium Porphyrin Complexes. The Journal of Physical Chemistry B 2005, 110 (1), 587-594.

43. Guo, H.; Jiang, J.; Shi, Y.; Wang, Y.; Dong, S., Solvent effects on spectrophotometric titrations and vibrational spectroscopy of 5,10,15-triphenyl-20-(4-hydroxyphenyl)porphyrin in aqueous DMF. Spectrochimica Acta Part A: Molecular and Biomolecular Spectroscopy 2007, 67 (1), 166-171.

44. Ojadi, E. C. A.; Linschitz, H.; Gouterman, M.; Walter, R. I.; Lindsey, J. S.; Wagner, R. W.; Droupadi, P. R.; Wang, W., Sequential protonation of meso-[p-(dimethylamino)phenyl]porphyrins: charge-transfer excited states producing hyperporphyrins. The Journal of Physical Chemistry 1993, 97 (50), 13192-13197.

45. Walter, R. I.; Ojadi, E. C. A.; Linschitz, H., A proton NMR study of the reactions with acid of meso-tetraphenylporphyrins with various numbers of 4-(dimethylamino) groups. The Journal of Physical Chemistry 1993, 97 (50), 13308-13312.

46. Van Caemelbecke, E.; Derbin, A.; Hambright, P.; Garcia, R.; Doukkali, A.; Saoiabi, A.; Ohkubo, K.; Fukuzumi, S.; Kadish, K. M., Electrochemistry of [(TMpyP)MII $] 4+(\mathrm{X}-) 4(\mathrm{X}-=\mathrm{Cl}-$ or $\mathrm{BPh} 4-)$ and $[(\mathrm{TMpyP}) \mathrm{MIIICl}] 4+(\mathrm{Cl}-) 4$ in N,N-Dimethylformamide Where M Is One of 15 Different Metal Ions. Inorganic Chemistry 2005, 44 (11), 3789-3798.

47. Lourenço, L. M. O.; Resende, J.; Iglesias, B. A.; Castro, K.; Nakagaki, S.; Lima, M. J.; da Cunha, A. F.; Neves, M. G. P. M. S.; Cavaleiro, J. A. S.; Tomé, J. P. C., Synthesis, characterization and electrochemical properties of 
meso-thiocarboxylate-substituted porphyrin derivatives. Journal of Porphyrins and Phthalocyanines 2014, 18 (10n11), 967-974.

48. Prasath, R.; Bhavana, P., An Improved Protocol for the Synthesis of 2-Nitro-7,8,17,18-tetrabromo-5,10,15,20-tetraphenylporphyrin and its Conformational Aspects by Electrochemistry and Spectroscopy. Journal of Heterocyclic Chemistry 2014, $51(6), 1735-1739$.

49. Clark, W. M., Oxidation-reduction potentials of organic systems. . The Williams \& Wilkins Co.: 1960; Vol. 49, p 1-740.

50. FALK, J. E., Porphyrins and Metalloporphyrins. . Elsevier Publ. Comp. : 1964; Vol. 4, p 1-398.

51. Kadish, K.; Van Caemelbecke, E., Electrochemistry of porphyrins and related macrocycles. Journal of Solid State Electrochemistry 2003, 7 (5), 254-258.

52. Clack, D. W.; Hush, N. S., Successive One-Electron Reduction Potentials of Porphins and Metal Prophins in Dimethylformamide. Journal of the American Chemical Society 1965, 87 (19), 4238-4242.

53. Furhop, J. H.; Kadish, K. M.; Davis, D. G., Redox behavior of metallo oxtaethylporhyrins. Journal of the American Chemical Society 1973, 95 (16), $5140-5147$.

54. Fang, Y.; Bhyrappa, P.; Ou, Z.; Kadish, K. M., Planar and Nonplanar Free-Base Tetraarylporphyrins: $\beta$-Pyrrole Substituents and Geometric Effects on Electrochemistry, Spectroelectrochemistry, and Protonation/Deprotonation Reactions in Nonaqueous Media. Chemistry - A European Journal 2014, 20 (2), 524-532. 
55. Wu, L.-Z.; Chen, B.; Li, Z.-J.; Tung, C.-H., Enhancement of the Efficiency of Photocatalytic Reduction of Protons to Hydrogen via Molecular Assembly. Accounts of Chemical Research 2014, 47 (7), 2177-2185.

56. Rodenberg, A.; Orazietti, M.; Probst, B.; Bachmann, C.; Alberto, R.; Baldridge, K. K.; Hamm, P., Mechanism of Photocatalytic Hydrogen Generation by a Polypyridyl-Based Cobalt Catalyst in Aqueous Solution. Inorganic Chemistry 2014.

57. Li, Q.; Schönleber, K.; Zeller, P.; Höhlein, I.; Rieger, B.; Wintterlin, J.; Krischer, K., Activation of silicon surfaces for $\mathrm{H} 2$ evolution by electrografting of pyridine molecules. Surface Science 2015, 631 (0), 185-189.

58. Seshadri, G.; Lin, C.; Bocarsly, A. B., A new homogeneous electrocatalyst for the reduction of carbon dioxide to methanol at low overpotential. Journal of Electroanalytical Chemistry 1994, 372 (1-2), 145-150.

59. Barton, E. E.; Rampulla, D. M.; Bocarsly, A. B., Selective Solar-Driven Reduction of CO2 to Methanol Using a Catalyzed p-GaP Based Photoelectrochemical Cell. Journal of the American Chemical Society 2008, 130 (20), 6342-6344.

60. Morris, A. J.; McGibbon, R. T.; Bocarsly, A. B., Electrocatalytic Carbon Dioxide Activation: The Rate-Determining Step of Pyridinium-Catalyzed CO2 Reduction. ChemSusChem 2011, 4 (2), 191-196.

61. Bocarsly, A. B.; Gibson, Q. D.; Morris, A. J.; L’Esperance, R. P.; Detweiler, Z. M.; Lakkaraju, P. S.; Zeitler, E. L.; Shaw, T. W., Comparative Study of Imidazole and Pyridine Catalyzed Reduction of Carbon Dioxide at Illuminated Iron Pyrite Electrodes. ACS Catalysis 2012, 2 (8), 1684-1692. 
62. Barton Cole, E.; Lakkaraju, P. S.; Rampulla, D. M.; Morris, A. J.; Abelev, E.; Bocarsly, A. B., Using a One-Electron Shuttle for the Multielectron Reduction of CO2 to Methanol: Kinetic, Mechanistic, and Structural Insights. Journal of the American Chemical Society 2010, 132 (33), 11539-11551.

63. Keith, J. A.; Carter, E. A., Theoretical Insights into Pyridinium-Based Photoelectrocatalytic Reduction of CO2. Journal of the American Chemical Society 2012, 134 (18), 7580-7583.

64. Lim, C.-H.; Holder, A. M.; Musgrave, C. B., Mechanism of Homogeneous Reduction of $\mathrm{CO} 2$ by Pyridine: Proton Relay in Aqueous Solvent and Aromatic Stabilization. Journal of the American Chemical Society 2012, 135 (1), 142-154.

65. Tossell, J. A., Calculation of the properties of molecules in the pyridine catalyst system for the photochemical conversion of $\mathrm{CO} 2$ to methanol. Computational and Theoretical Chemistry 2011, 977 (1-3), 123-127.

66. Ertem, M. Z.; Konezny, S. J.; Araujo, C. M.; Batista, V. S., Functional Role of Pyridinium during Aqueous Electrochemical Reduction of $\mathrm{CO} 2$ on $\mathrm{Pt}(111)$. The Journal of Physical Chemistry Letters 2013, 4 (5), 745-748.

67. Jeon, J. H.; Mareeswaran, P. M.; Choi, C. H.; Woo, S. I., Synergism between CdTe semiconductor and pyridine - photoenhanced electrocatalysis for $\mathrm{CO} 2$ reduction to formic acid. RSC Advances 2014, 4 (6), 3016-3019.

68. Parajuli, R.; Gerken, J.; Keyshar, K.; Sullivan, I.; Sivasankar, N.; Teamey, K.; Stahl, S.; Cole, E., Integration of Anodic and Cathodic Catalysts of Earth-Abundant Materials for Efficient, Scalable CO2 Reduction. Topics in Catalysis 2014, 1-10. 
69. Walter, M. G.; Wamser, C. C.; Ruwitch, J.; Zhao, Y.; Braden, D.; Stevens, M.; Denman, A.; Pi, R.; Rudine, A.; Pessiki, P. J., Syntheses and optoelectronic properties of amino/carboxyphenylporphyrins for potential use in dye-sensitized $\mathrm{TiO} 2$ solar cells. J. Porphyrins Phthalocyanines 2007, 11 (8), 601-612.

70. De Luca, G.; Romeo, A.; Scolaro, L. M., Role of Counteranions in Acid-Induced Aggregation of Isomeric Tetrapyridylporphyrins in Organic Solvents. J. Phys. Chem. $B$ 2005, 109 (15), 7149-7158.

71. Hill, J. P.; Ariga, K.; D'Souza, F., Structures and properties of hemiquinone-substituted oxoporphyrinogens. J. Porphyrins Phthalocyanines 2009, 13 (01), 60-69.

72. Gunter, M.; Robinson, B., Unusual Spectral Properties of $<\mathrm{I}>$ meso $</$ I $>$-(N,N-Dialkylaminophenyl)Porphyrins. Australian Journal of Chemistry 1989, 42 (11), 1897-1905.

73. Zakavi, S.; Omidyan, R.; Ebrahimi, L.; Heidarizadi, F., Substitution effects on the UV-vis and 1H NMR spectra of the dications of meso and/or $\beta$ substituted porphyrins with trifluoroacetic acid: Electron-deficient porphyrins compared to the electron-rich ones. Inorganic Chemistry Communications 2011, 14 (11), 1827-1832.

74. Smith, K. M.; Bobe, F. W.; Minnetian, O. M.; Abraham, R. J., The NMR spectra of porphyrins-25: Meso-substituent effects in neutral and protonated porphyrins. Tetrahedron 1984, 40 (17), 3263-3272.

75. Mohajer, D.; Zakavi, S.; Rayati, S.; Zahedi, M.; Safari, N.; Khavasi, H. R.; Shahbazian, S., Unique 1[ratio]2 adduct formation of meso-tetraarylporphyrins and 
meso-tetraalkylporphyrins with BF3: a spectroscopic and ab initio study. New Journal of Chemistry 2004, 28 (12), 1600-1607.

76. Ransdell, R. A. Solvent and Substituent Effects on the Redox Potentials of Several Substituted Tetraphenylporphyrins. Dissertations and Theses, Portland State University, 1991.

77. Wang, J., Analytical electrochemistry. Wiley, New York: 2000.

78. Roubelakis, M. M.; Bediako, D. K.; Dogutan, D. K.; Nocera, D. G., Proton-coupled electron transfer kinetics for the hydrogen evolution reaction of hangman porphyrins. Energy \& Environmental Science 2012, 5 (7), 7737-7740.

79. Samuel, A. P. S.; Co, D. T.; Stern, C. L.; Wasielewski, M. R., Ultrafast Photodriven Intramolecular Electron Transfer from a Zinc Porphyrin to a Readily Reduced Diiron Hydrogenase Model Complex. Journal of the American Chemical Society 2010, 132 (26), 8813-8815.

80. Song, L.-C.; Tang, M.-Y.; Su, F.-H.; Hu, Q.-M., A Biomimetic Model for the Active Site of Iron-Only Hydrogenases Covalently Bonded to a Porphyrin Photosensitizer. Angewandte Chemie 2006, 118 (7), 1148-1151.

81. Wang, S.; Tabata, I.; Hisada, K.; Hori, T., Hydrogen evolution sensitized by tin-porphyrin in microheterogeneous systems. Dyes and Pigments 2002, 55 (1), 27-33. 82. Walter, M. G.; Wamser, C. C., Synthesis and Characterization of Electropolymerized Nanostructured Aminophenylporphyrin Films. The Journal of Physical Chemistry C 2010, 114 (17), 7563-7574.

83. Hou, Y.; Abrams, B. L.; Vesborg, P. C. K.; Björketun, M. E.; Herbst, K.; Bech, L.; 
Setti, A. M.; Damsgaard, C. D.; Pedersen, T.; Hansen, O.; Rossmeisl, J.; Dahl, S.; Nørskov, J. K.; Chorkendorff, I., Bioinspired molecular co-catalysts bonded to a silicon photocathode for solar hydrogen evolution. Nat Mater 2011, 10 (6), 434-438. 